\author{
UNIVERSIDADE DE BRASÍLIA \\ FACULDADE DE TECNOLOGIA \\ DEPARTAMENTO DE ENGENHARIA MECÂNICA
}

\title{
ANÁLISE DE TENSÕES E DEFORMAÇÕES EM FIOS DE CABOS CONDUTORES DE LINHAS DE TRANSMISSÃO
}

EDUARDO LUIS SOUZA DE ATHAYDE NUNES FILHO

ORIENTADOR: EDGAR NOBUO MAMIYA

DISSERTAÇÃO DE MESTRADO EM CIÊNCIAS MECÂNICAS

BRASÍLIA, 03 DE AGOSTO DE 2016. 


\section{ANÁLISE DE TENSÕES E DEFORMAÇÕES EM FIOS DE CABOS CONDUTORES DE LINHAS DE TRANSMISSÃO}

EDUARDO LUIS SOUZA DE ATHAYDE NUNES FILHO

DISSERTAÇÃO DE MESTRADO SUBMETIDA AO DEPARTAMENTO DE ENGENHARIA MECÂNICA DA FACULDADE DE TECNOLOGIA DA UNIVERSIDADE DE BRASÍLIA, COMO PARTE DOS REQUISITOS NECESSÁRIOS PARA A OBTENÇÃO DO GRAU DE MESTRE EM CIÊNCIAS MECÂNICAS.

APROVADA POR:

Prof. Edgar Nobuo Mamiya, Dr. (ENM - UnB)

(Orientador)

Prof. José Alexander Araújo, Dr. (ENM - UnB)

(Examinador Interno)

Prof. Franscisco Evangelista Júnior, Ph. D. (ENC - UnB)

(Examinador Externo ao Programa)

BRASÍLIA/DF, 03 DE AGOSTO DE 2016. 


\section{RESUMO}

Este trabalho apresenta uma análise das tensões e deformações observadas nos fios do cabo condutor de linhas de transmissão de energia elétrica, na vizinhança de grampos de suspensão. O estudo considera um cabo IBIS submetido a condições de pré carga (EDS), carga de aperto no grampo e carregamento vibratório tipicamente associado a forças do vento. As simulações numéricas adotaram condições de carregamento consideradas em análises experimentais. O problema se mostra complexo em diversos aspectos, incluindo: (i) deformações plásticas de grande amplitude, (ii) centenas de regiões de contato, mesmo em pequenos trechos do cabo, (iii) necessidade de refinamento elevado da malha em cada região de contato, que levam a desafios como a solução de problemas envolvendo milhões de equações não lineares e estratégias de simulação numérica que evitem simultaneamente o travamento e os modos espúrios de deformação.

Palavras-chave: cabo IBIS, simulação numérica, interação cabo-grampo, modos espúrios, método dos elementos finitos. 


\section{Abstract}

This work aims to present an analysis of stresses and strains observed on the threads of electric transmission line conductors, in the neighborhood of suspension clamps. The study focuses on the IBIS cable submitted to conditions of Every Day Stress (EDS), clamp load and bending loads associated to aeolian forces. The numerical simulations adopted loading conditions typically considered in experimental analyses. The problem exhibits many complex features, including: (i) large plastic strains, (ii) hundreds of contact regions, even in small portions of cable, (iii) the need of highly refined mesh in the neighborhood of each contact region, which lead to challenges as the solution of problems involving millions of nonlinear equations as well as strategies of numerical simulations which tackle simultaneously the locking and hourglass modes often present when isochoric strains are involved.

Keywords: IBIS cable, numerical simulation, cable - clamp interaction, spurious modes, finite element method. 


\section{SUMÁRIO}

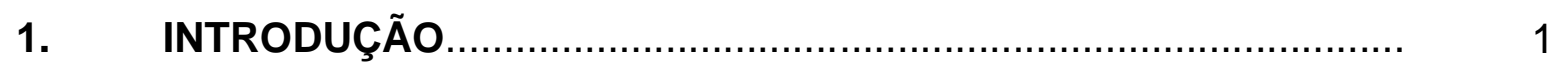

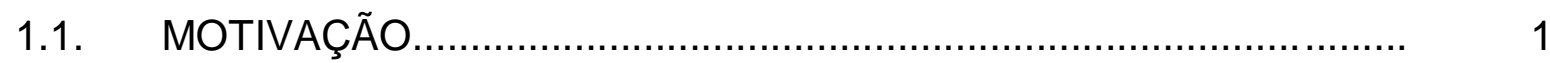

2. CONCEITOS BÁSICOS............................................................ 5

2.1. CONTATO UNILATERAL ENTRE CORPOS................................... 5

2.2. ATRITO DE COULOMB........................................... 8

2.3. FORMULAÇÃO VARIACIONAL DO PROBLEMA DE CONTATO E MULTIPLICADORES DE LAGRANGE .............................. 9

2.4. MÉTODO DA PENALIDADE PARA APROXIMAÇÃO DE RESTRIÇÃO......................................................... 14

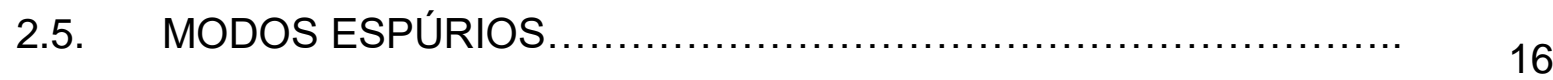

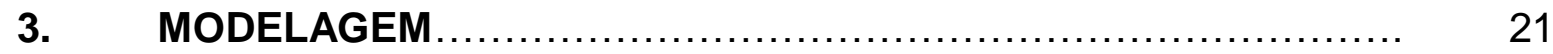

3.1. DESCRIÇÃO DO PROBLEMA...................................... 21

3.1.1. Geometria do cabo e carregamento aplicado.................. 21

3.1.2. Discussão sobre a complexidade do problema cabogrampo........................................................................ 25

3.2. CONTATO ENTRE DOIS FIOS ................................... 28

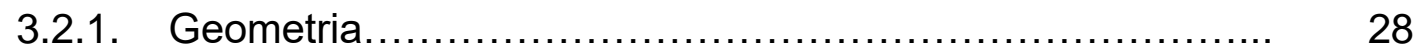

3.2.2. Material.................................................... 29

3.2.3. Condições de contorno.......................................... $\quad 30$

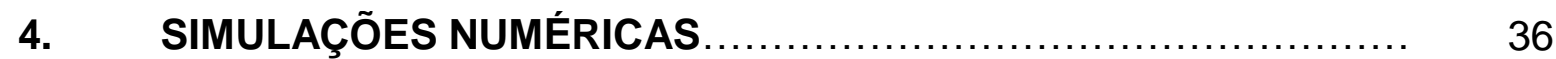

4.1. RECURSOS COMPUTACIONAIS .................................. 36

4.2. DISCRETIZAÇÃO ................................................ 37

4.3. CARGA DE APERTO ............................................. 38

4.4. SIMULAÇÃO DO APERTO ENTRE FIOS ............................... 40

4.5. SIMULAÇÃO DO CARREGAMENTO CÍCLICO......................... 50 
4.6. MODOS ESPÚRIOS DE DEFORMAÇÃO.............................. 55

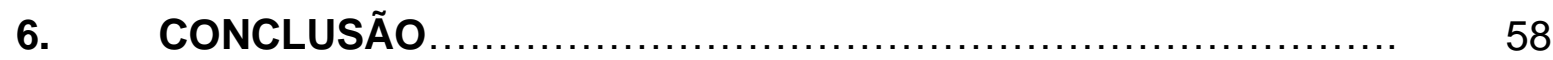

6.1. TRABALHOS FUTUROS ............................................ 59

REFERÊNCIAS BIBLIOGRÁFICAS ....................................... 60

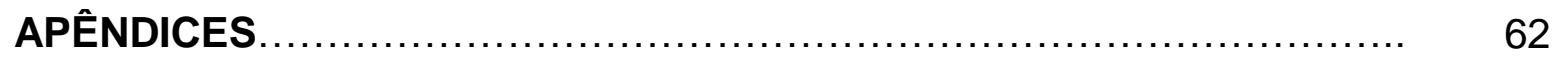




\section{LISTA DE TABELAS}

Tabela 4.1. Características do computador utilizado na análise numérica..... 36

Tabela 4.2. Dimensões da marca: experimental e simulada............... 40

Tabela 4.3. Dimensões medidas para marcas geradas por diferentes deslocamentos do bloco................................... 41 


\section{LISTA DE FIGURAS}

Figura 1.1. Foto do trecho de cabo condutor simulado experimentalmente no Laboratório de Ensaios Mecânicos (LABCABOS) da Universidade de Brasília na região próxima ao grampo de suspensão

Figura 2.1. Representação cinemática de movimento entre dois corpos quaisquer.

Figura 2.2. Representação gráfica das condições de complementariedade de KuhnTucker

Figura 2.3. Movimento relativo entre corpos em contato.

Figura 2.4. (a) potencial $\Pi$ e seu ponto de mínimo em problema sem restrição, e; (b) potencial $\Pi$ e seu ponto de mínimo quando se impõe restrição $u \geq u$

Figura 2.5. (a) sistema de dois corpos elásticos sem cargas aplicadas, e; (b) sistema submetido a força $F$ e sujeito a restrição de deslocamento nulo no nó 4 e de contato entre os nós 2 e 3

Figura 2.6. Representação esquemática do Lagrangeano e de seu ponto de sela, que fornece a solução do problema de equilíbrio.

Figura 2.7. Exemplo do "travamento" observado em malhas compostas por elementos triangulares lineares.

Figura 2.8. Elemento finito Q4. 
Figura 2.9. Modos espúrios 1 (a) e 2 (b) de deformação do elemento finito quadriateral de quatro nós com integração reduzida (um ponto de Gauss)

Figura 3.1. Desenho do conjunto cabo-grampo de suspensão.

Figura 3.2. Seção transversal do cabo IBIS ilustrando suas camadas

Figura 3.3. Carga de tração aplicada no condutor.

Figura 3.4. Carga distribuída aplicada pelo grampo sob trecho do cabo condutor.

Figura 3.5. Momento alternado de flexão aplicado ao condutor próximo a região do grampo

Figura 3.6. Cargas aplicadas sobre o cabo em operação

Figura 3.7. Trecho do cabo IBIS

Figura 3.8. Medida do ângulo de hélice em um trecho de cabo previamente submetido ao EDS

Figura 3.9. Partição da região de contato entre cilindros e malha de elementos necessária

Figura 3.10. Modelagem do problema de contato entre dois fios do cabo IBIS.

Figura 3.11. Vista superior de cada fio, com os cortes realizados em suas extremidades considerando os ângulos de hélice $\theta$ de sua respectiva camada.

Figura 3.12. Bloco representando a telha do grampo de suspensão 
Figura 3.13. Curva de encruamento do Al 1350-H19....................... 30

Figura 3.14. Condições de contorno do problema ............................... 31

Figura 3.15. Marca produzida pela pressão entre fios das camadas 1 e $2 \ldots \ldots .32$

Figura 3.16. Deslocamento transversal do cabo, medida a $89 \mathrm{~mm}$ do último ponto de contato com o grampo

Figura 3.17. Relação entre deformações dos fios da primeira e da segunda camada

Figura 3.18. Carregamento cíclico aplicado aos fios do cabo IBIS

Figura 4.1. Discretização dos fios das camadas 1 e 2

Figura 4.2. Discretização dos subdomínios dos fios

Figura 4.3. Marca analisada no Confocal

Figura 4.4. Relação entre o deslocamento aplicado ao bloco e a força equivalente aplicada aos fios em contato.

Figura 4.5. Campo de pressão na região de contato no fio mais externo do cabo condutor IBIS resultante: (a) da simulação do modelo global; (b) da simulação do submodelo.

Figura 4.6. Marcas geradas na região de contato entre os fios para as cargas de: (a) $1018 \mathrm{~N}$, (b) $1773 \mathrm{~N} \mathrm{e} \mathrm{(c)} 2810 \mathrm{~N}$

Figura 4.7. Relação entre a medida da marca no eixo maior e a força aplicada sobre os fios em contato. 
Figura 4.8. Relação entre a medida da marca no eixo menor e a força aplicada sobre os fios em contato

Figura 4.9. Cortes transversais dos fios na região de contato, ao longo do eixo $x$.

Figura 4.10. Distribuição da pressão de contato sobre o fio da camada 1 no modelo global

Figura 4.11. Distribuição da pressão de contato sobre o fio da camada 1 no submodelo.

Figura 4.12. Caminhos considerados para as descrições das distribuições da pressão de contato nas Figs. 4.12 e 4.13

Figura 4.13. Distribuição da pressão de contato sobre o fio da camada 1 ao longo do caminho AB da Fig.4.12

Figura 4.14. Distribuição da pressão de contato sobre o fio da camada 1 ao longo do caminho CD da Fig.4.12 .................................

Figura 4.15. Discretizações consideradas para a descrição bidimensional do problema de contato

Figura 4.16. Contato entre os fios resultante da aplicação da carga de aperto, exibindo nível elevado de deformações elastoplásticas e região de contato pronunciada

Figura 4.17. Distribuição de pressão entre fios descritos no contexto bidimensional. 
Figura 4.18. Distribuição das tensões tangenciais sobre a superfície do fio da camada 1 , devido a carga de aperto.

Figura 4.19. Distribuição de tensão tangencial sobre a superfície do fio da camada 1 ao longo do caminho $A B$.

Figura 4.20. Distribuição de tensão tangencial sobre a superfície do fio da camada 1 ao longo do caminho CD

Figura 4.21. Carregamento alternado aplicado ao fio da camada 1

Figura 4.22. Pressão de contato sob carregamento indicado no instante A da Fig.4.21

Figura 4.23. Pressão de contato sob carregamento indicado no instante B da Fig. 4.21

Figura 4.24. Pressão de contato sob carregamento indicado no instante $\mathrm{C}$ da Fig. 4.21

Figura 4.25. Distribuição da pressão ao longo da direção longitudinal da marca, para os instantes A, B e C do carregamento cíclico (Fig. 4.21)

Figura 4.26. Distribuição da pressão de contato ao longo da direção circunferencial do fio, para os instantes A, B e C do carregamento cíclico (Fig. 4.21).

Figura 4.27. Distribuição de tensão tangencial sobre a superfície do fio da camada 1 no instante A da história de carregamento.

Figura 4.28. Distribuição de tensão tangencial sobre a superfície do fio da camada 1 no instante B da história de carregamento. 
Figura 4.29. Distribuição de tensão tangencial sobre a superfície do fio da camada 1 no instante $C$ da história de carregamento

Figura 4.30. Distribuição da tensão tangencial ao longo da direção longitudinal do fio para os instantes A, B e C do gráfico da Fig.4.21......

Figura 4.31. Distribuição da tensão tangencial ao longo da direção circunferencial do fio para os instantes $A, B$ e $C$ do gráfico da Fig.4.21

Figura 4.32. Energia de deformação associada aos modos espúrios de deformação, sem e com controle via rigidez artificial.

Figura 4.33. Topografia da região de contato deformada, onde se observam oscilações espúrias da superfície. 


\section{LISTA DE SÍMBOLOS}

d distância inicial entre as superfícies dos corpos

$\mathbf{u}^{(1)}$

vetor deslocamento do corpo 1

$\mathbf{u}^{(2)} \quad$ vetor deslocamento do corpo 1

N vetor normal as superfícies

$\mathrm{F}_{\mathrm{N}} \quad$ força normal entre os corpos

$\mathrm{F}_{\mathrm{t}} \quad$ força tangencial

M coeficiente de atrito

$\Pi$ (a) função potencial

U variável de interesse

$\Delta \mathrm{u} \quad$ variação da variável de interesse

K constante de mínimo

W potencial da energia de deformação

F força externa

L Lagrangeano

$\lambda_{c}$ força de contato entre os nós 2 e 3

$\lambda_{4}$ força reativa associada ao deslocamento nulo do nó 4

A matriz dos coeficientes

$\varepsilon_{\mathrm{c}}, \varepsilon_{4} \quad$ parâmetros de penalidade

$\boldsymbol{\varepsilon}_{\mathbf{p}} \quad$ tensão de deformação plástica

$\mathbf{F}_{\mathbf{p}} \quad$ gradiente de deformações plásticas

$\mathrm{W}_{\mathrm{e}} \quad$ energia de deformação do elemento

D matriz de elasticidade

$\mathbf{B}_{\mathrm{e}} \quad$ matriz de relação entre deformações com deslocamentos nodais

N função de forma

$\mathrm{nf}_{\mathrm{i}} \quad$ número de fios em cada camada do cabo

$\mathrm{d}_{\mathrm{Al}} \quad$ diâmetro dos fios de alumínio

$\mathrm{d}_{\mathrm{aço}} \quad$ diâmetro dos fios de aço

$\Theta \quad$ ângulo de hélice da camada do cabo 
$\mathrm{n}_{\mathrm{rc}} \quad$ número de regiões de contato

$\mathrm{F}_{1}, \mathrm{~F}_{2}$ força de tração de um fio da primeira e segunda camada, respectivamente.

$\mathrm{n}_{\mathrm{Al}} \quad$ número de fios de alumínio do cabo

$\mathrm{n}_{\mathrm{aço}} \quad$ número de fios de aço do cabo

E módulo de elasticidade

x distância do último ponto de contato do cabo com o grampo

$\mathrm{y}_{\mathrm{B}} \quad$ amplitude de deslocamento transversal do cabo

$\varepsilon_{1 \mathrm{a}}, \varepsilon_{2 \mathrm{a}} \quad$ amplitudes de deformação nos fios das camadas 1 e 2 respectivamente $\sigma_{1 \mathrm{a}}, \sigma_{2 \mathrm{a}} \quad$ respectivamente.

$\mathrm{F}_{\text {EDS }} \quad$ força de tração de acordo com a EDS do cabo 


\section{INTRODUÇÃO}

\subsection{MOTIV AÇÃO}

Cabos condutores são elementos responsáveis pelo transporte da energia elétrica das usinas de geração até centros consumidores. Para isto, precisam ser fixados, ao longo de seu trajeto, por grampos de suspensão, amortecedores ou espaçadores junto às torres de fixação. Geralmente, é nestes pontos de fixação que ocorre a ruptura do cabo, levando a enormes prejuízos como o que ocorreu sobre o Rio Paraná no ano de 2002 (Azevedo, 2002).

Diversos estudos vêm sendo realizados nos últimos anos para compreender os fenômenos responsáveis pela quebra de fios até a ruptura total dos cabos condutores. Azevedo (2002) observou a existência de $\mathrm{Al}_{2} \mathrm{O}_{3}$ na camada externa do cabo condutor próximo à fratura dos fios, apresentando marcas típicas de deformação e fadiga provocada devido ao fretting entre os fios. Boniardi (2007) analisou a falha de uma linha de transmissão ocorrida após seis meses de operação na Argélia, sem espaçadores ou amortecedores montados na linha. Para a solução do problema, foi recomendada a utilização de amortecedores para amenizar os efeitos da vibração eólica sobre o cabo condutor. O efeito da geometria dos grampos foi estudado por Preston (1986), comparando experimentalmente a vida do condutor submetido a fadiga para diferentes modelos de grampos. O aumento das deformações estática e dinâmica sobre o cabo condutor foi observado nos grampos com menores raios de curvatura nas calhas dos grampos. Guérard (2011) estima a possibilidade de quebra dos fios do cabo condutor a partir da monitoração de sua vibração em pontos específicos. Poffenberger (1965) apresentou relação capaz de obter a carga alternada do fio da camada externa do cabo condutor próximo ao contato do grampo de suspensão. Para isto, pode-se utilizar como parâmetros a medida da amplitude de oscilação do cabo a $89 \mathrm{~mm}$ do último ponto de contato com o grampo e a força de tração aplicada ao cabo condutor.

Lévesque et al. (2011a) desenvolveram estudos numéricos sobre o contato entre um fio do cabo condutor e a calha do grampo de suspensão. As hipóteses adotadas incluem o alinhamento entre o fio e a calha, o que conduz a uma 
simplificação severa do problema, aumentado de maneira espúria a superfície de contato na direção longitudinal. Em outro estudo, Lévesque et al. (2011b) considera o problema de contato com atrito entre duas superfícies cilíndricas com ângulos de $30^{\circ}$, $60^{\circ}$ e $90^{\circ}$ entre seus eixos. Entretanto, as condições de contorno consideradas são bastante simples e distantes daquelas tipicamente encontradas em condições de operação dos cabos condutores. Em particular, os ângulos considerados não são observados nos cabos comerciais e a pré-carga (EDS: Every Day Stress) e aquelas alternadas causadas pela ação do vento não são consideradas.

O Grupo de Fadiga e Fratura dos Materiais (GFFM) da Universidade de Brasília vem desenvolvendo pesquisas científicas sobre a integridade de cabos condutores desde de 2001. O grupo possui laboratório de ensaios mecânicos para cabos condutores de energia (LABCABOS) capaz de ensaiar simultaneamente dois cabos. Os resultados obtidos experimentalmente, para os diversos cabos disponíveis comercialmente, têm permitido estimar suas durabilidades quando submetidos a vibrações por atuadores que simulam a ação do vento, conforme a foto ilustrativa da Fig. 1.1.

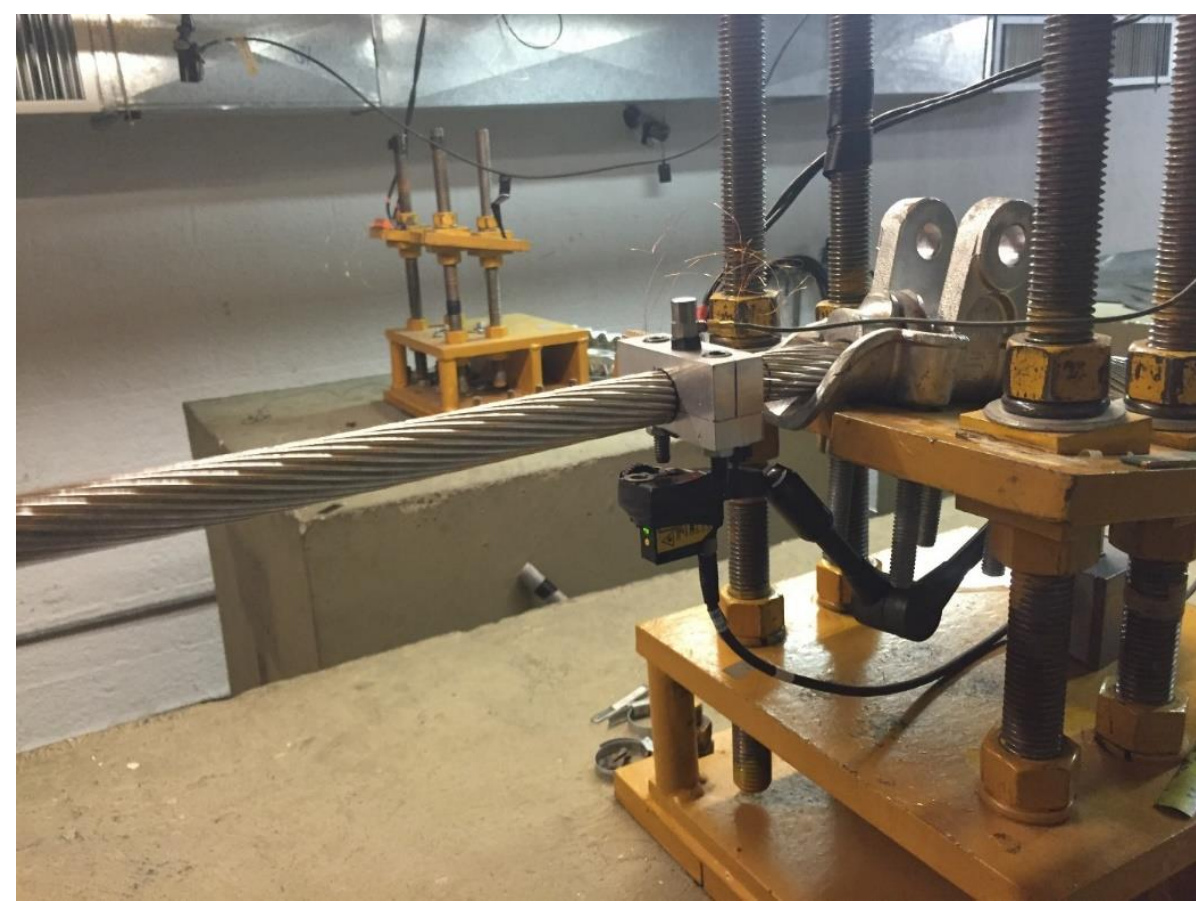

Fig. 1.1 - Foto do trecho de cabo condutor simulado experimentalmente no Laboratório de Ensaios Mecânicos (LABCABOS) da Universidade de Brasília na região próxima ao grampo de suspensão. 
Fadel (2010) apresenta estudo experimental sobre cabos IBIS, sob diversas condições de pré carga (EDS) e cargas dinâmicas, analisando a influência destes parâmetros sobre a vida à fadiga. Rolim et al. (2013) analisaram as deformações, provocadas pela vibração, próxima à região do grampo de suspensão, comparandoas com aquelas previstas pela fórmula de Poffenberger-Swart. Kalombo et al. (2015) apresentaram estudo sobre falhas ocorridas em sete linhas de transmissão na região Centro-Oeste do Brasil. O estudo concluiu que as falhas resultaram da escolha do cabo condutor, do uso de espaçadores rígidos sobre a linha e a da presença de ventos em regime laminar de alta frequência.

Falhas do cabo condutor têm sido associadas à fadiga por fretting nas regiões de contato entre os fios próximas ao grampo de suspensão. Entretanto, o problema exibe diversos níveis de complexidade, associados a: (i) um número elevado de regiões de contato entre fios e entre cabo e grampo, (ii) deformações elastoplásticas elevadas (e consequentes tensões residuais) nos fios na região do grampo, (iii) histórias complexas de carregamento de origem eólica, (iv) sensibilidade da vida à fadiga à qualidade da montagem do cabo condutor no grampo, etc.

Neste contexto, o objetivo deste trabalho é a análise das tensões observadas nos fios do cabo condutor, na vizinhança do grampo de suspensão. O estudo está focado no cabo IBIS submetido a condições de pré carga, aperto no grampo e de carregamento vibratório típicos considerados no estudo de Fadel (2012). A monografia discute em detalhes as simulações computacionais via método dos elementos finitos realizadas por meio do aplicativo Abaqus, abordando questões relativas a: (i) níveis de discretização necessárias para que se obtenha representações adequadas dos campos de tensão nas regiões de contato, (ii) adequação do elemento H8 com integração reduzida para a descrição das deformações plásticas de grande magnitude e, ao mesmo tempo, descrever as regiões em contato, (iii) estratégias disponíveis pelo aplicativo para a imposição do contato com atrito, entre outras. Ao longo do texto, são discutidas as diversas dificuldades enfrentadas no estudo, incluindo: (i) a necessidade de memória RAM e de processadores de alto desempenho para simulação do problema, (ii) o controle de modos espúrios de deformação associados a estratégias de representação de deformações plásticas isocóricas (a volume constante), (iii) imposição rigorosa da condição de contato unilateral via multiplicadores de Lagrange. 
A monografia está organizada da seguinte forma: o Capítulo 2 apresenta conceitos básicos de contato unilateral e atrito seco. As estratégias de imposição da restrição de contato via multiplicador de Lagrange e via penalidade são apresentadas. O problema das deformações espúrias associadas a estratégia de integração reduzida também apresentado neste capítulo. A descrição do problema de interesse - análise de tensões no cabo condutor, em região vizinha ao grampo de suspensão - e a definição do problema simplificado de dois fios são apresentadas no Capítulo 3. No Capítulo 4, são apresentados e discutidos os resultados numéricos obtidos com uso do aplicativo Abaqus. As conclusões e recomendações para estudos futuros são apresentadas no Capítulo 5. Esta monografia contém ainda quatro apêndices, nos quais são detalhados: (i) uma estimativa do número de regiões de contato entre fios em um determinado trecho de cabo, (ii) o cálculo das forças trativas sobre cada fio sob EDS, (iii) o cálculo das forças sobre os fios resultantes das cargas transversais de origem vibratória, (iv) um script típico, em linguagem Python, das simulações do contato entre dois fios realizadas no presente estudo. 


\section{CONCEITOS BÁSICOS}

A análise de tensões em cabos condutores constitui-se em problema de alta complexidade, envolvendo inúmeros conceitos da Mecânica dos Sólidos, de procedimentos computacionais associados ao Métodos dos Elementos Finitos e de procedimentos experimentais de determinação das propriedades materiais e das condições de carregamento a que o cabo é submetido. Uma exposição detalhada de todos os conceitos envolvidos na análise do problema transcende em muito os objetivos desta dissertação de Mestrado. Neste contexto, este capítulo se restringe à apresentação introdutória dos tópicos cujas abordagens representaram os maiores desafios: (i) contato unilateral, (ii) atrito e (iii) descrição aproximada de deformações a volume constante - associadas a deformações plásticas.

\subsection{CONTATO UNILATERAL ENTRE CORPOS}

O contato unilateral entre dois corpos quaisquer pode ser representado conforme a Fig.2.1.

Corpo 2

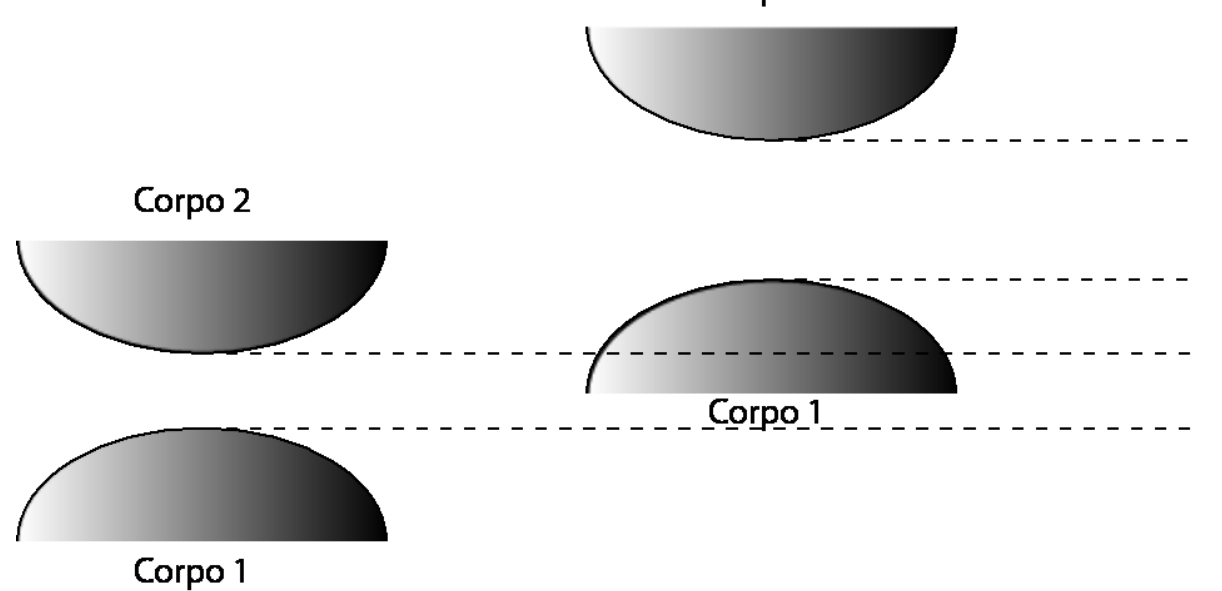

(B)

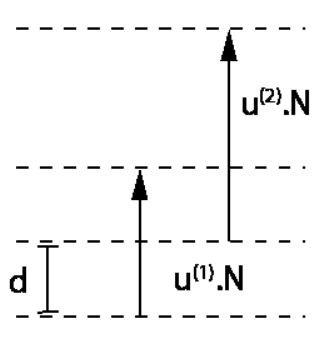

(A)

(C)

Fig. 2.1 - Representação cinemática de movimento entre dois corpos quaisquer.

Quando dois corpos estão na situação inicial da Fig. 2.1..A a uma distância $d$ e se deslocam para uma situação posterior representada na Fig. 2.1.B, o vetor $\mathbf{u}^{(1)}$ representa o deslocamento do corpo 1 , o vetor $\mathbf{u}^{(2)}$ o deslocamento do corpo 2 e $\mathbf{N}$ o 
vetor normal às superfícies. Caso os corpos estejam em contato, a seguinte condição é satisfeita:

$$
\mathbf{u}^{(2)} \cdot \mathbf{N}+\mathrm{d}=\mathbf{u}^{(1)} \cdot \mathbf{N}
$$

Para o caso de não ocorrer contato entre os corpos, obtém-se a seguinte igualdade:

$$
\mathbf{u}^{(2)} \cdot \mathbf{N}+\mathrm{d}>\mathbf{u}^{(1)} \cdot \mathbf{N},
$$

significando que, por mais que o corpo 1 se desloque, este será sempre menor que a soma do deslocamento do corpo 2 mais a distância $d$ de separação entre as superfícies na posição inicial da fig. 2.1.A. A desigualdade expressa por

$$
p\left(\mathbf{u}^{(1)}, \mathbf{u}^{(2)}, \mathbf{N}\right)=\left(\underline{\mathbf{u}}^{(2)}-\underline{\mathbf{u}}^{(1)}\right) . \mathbf{N}+\mathrm{d} \geq 0
$$

condensa as Eqs. 2.1 e 2.2 e representa uma restrição cinemática de contato, afirmando que duas superfícies contínuas só podem estar separadas ou em contato.

Para o contato unilateral, deve-se observar que os deslocamentos representados são pequenos, podendo-se desprezar as variações da normal $\mathbf{N}$ às superfícies.

No caso de contato, haverá uma força normal $\mathrm{F}_{\mathrm{N}}$ de sinal negativo entre os corpos

$$
\mathrm{F}_{\mathrm{N}}<0
$$

pois se trata de uma força compressiva. Caso não haja contato, não ocorrerá força normal, sendo esta então nula.

Para relacionar a força e a ocorrência de contato, estabelecem-se as seguintes relações, denominadas de relações de complementariedade de Kuhn-Tucker-Karush:

$$
p\left(\mathbf{u}^{(1)}, \mathbf{u}^{(2)}, \mathbf{N}\right) \geq 0, \quad \mathrm{~F}_{\mathrm{N}} \leq 0, \quad p\left(\mathbf{u}^{(1)}, \mathbf{u}^{(2)}, \mathbf{N}\right) \mathrm{F}_{\mathrm{N}}=0 .
$$

Observe-se que a igualdade na Eq. 2.5 impõe as seguintes situações:

$$
\left\{\begin{array}{l}
\operatorname{Se}\left(\underline{\mathbf{u}}^{(2)}-\underline{\mathbf{u}}^{(1)}\right) \cdot \mathbf{N}+\mathrm{d}>0, \text { então } \quad \mathrm{F}_{\mathrm{N}}=0 \\
\operatorname{Se}\left(\underline{\mathbf{u}}^{(2)}-\underline{\mathbf{u}}^{(1)}\right) \cdot \mathbf{N}+\mathrm{d}=0, \text { então } \quad \mathrm{F}_{\mathrm{N}} \leq 0
\end{array}\right.
$$




$$
\left\{\begin{array}{c}
\text { Se } \mathrm{F}_{\mathrm{N}}=0, \quad \text { então } \quad\left(\underline{\mathbf{u}}^{(2)}-\underline{\mathbf{u}}^{(1)}\right) \cdot \mathbf{N}+\mathrm{d} \geq 0 \\
\text { Se F } \mathrm{F}_{\mathrm{N}}<0, \quad \text { então }\left(\underline{\mathbf{u}}^{(2)}-\underline{\mathbf{u}}^{(1)}\right) \cdot \mathbf{N}+\mathrm{d}=0
\end{array}\right.
$$

As relações da Eq. 2.6 afirmam que, caso a diferença dos deslocamentos dos corpos mais a distância inicial $d$ seja maior que zero, não existirá força de compressão normal nas superfícies, mas se a diferença dos deslocamentos entre os corpos mais a distância inicial $d$ for nula, pode ser que hajam forças compressivas. $E$ as relações da Eq. 2.7 afirmam que, se não houver força de contato entre as superfícies, então os deslocamentos relativos devem ser menores ou iguais à distância inicial entre as superfícies e, se houver força de contato, então os deslocamentos relativos serão iguais à distância $d$. Tratam-se, portanto, de relações de complementariedade, pois uma desigualdade estrita na codnição de força de contato/deslocamentos relativos impõe igualdade na condição complementar deslocamentos relativos/força de contato.

Estas condições de complementariedade podem ser resumidas graficamente conforme mostrado na Fig.2.2.

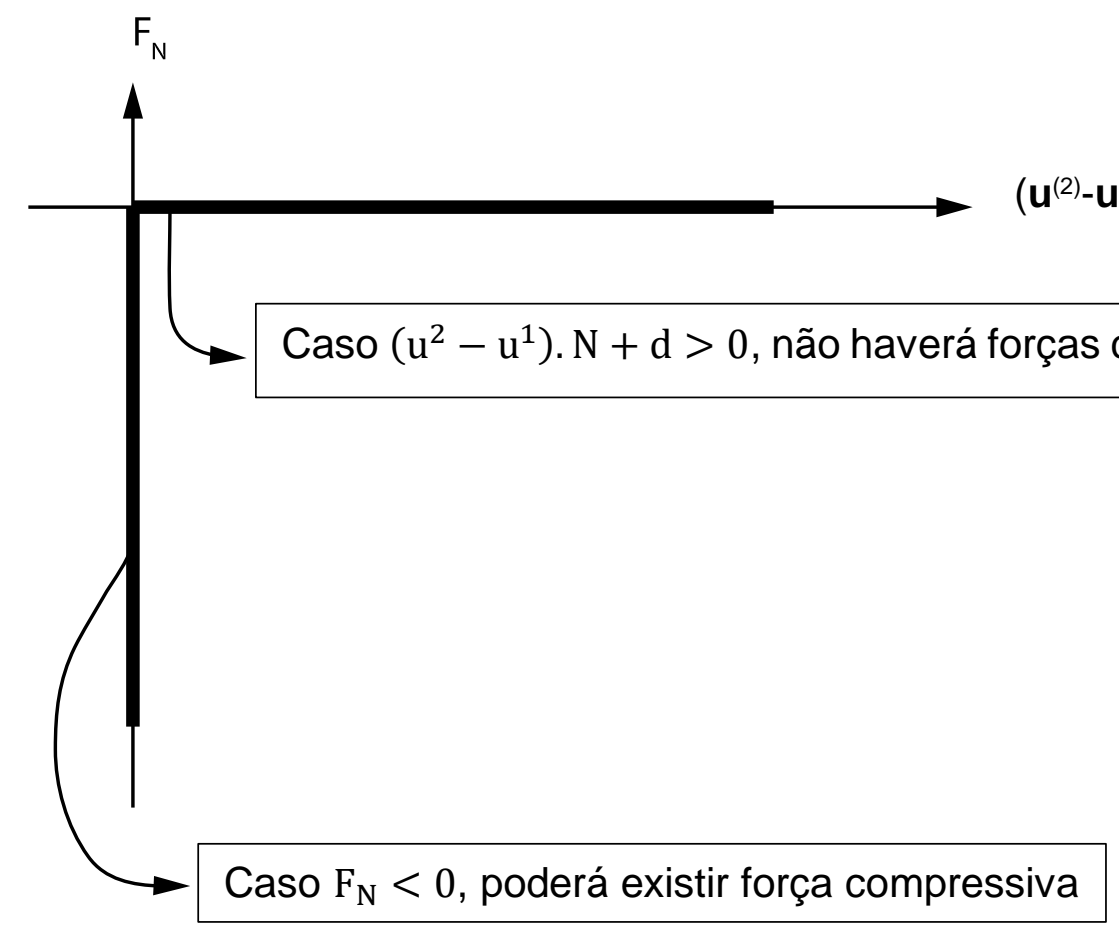

Fig.2.2 - Representação gráfica das condições de complementariedade de KuhnTucker-Kurash. 


\subsection{ATRITO DE COULOMB}

Considerando-se dois corpos em contato com velocidades $\underline{\dot{\mathbf{u}}}^{(1)}$ e $\underline{\dot{\mathbf{u}}}^{(2)}$, o movimento relativo entre eles ocorrerá caso a força tangencial $\mathrm{F}_{\mathrm{t}}$ seja maior que $\mathrm{o}$ coeficiente $\mu$ multiplicado pela força normal $\mathrm{F}_{\mathrm{N}}$. Esta situação é representada na Fig.2.3.

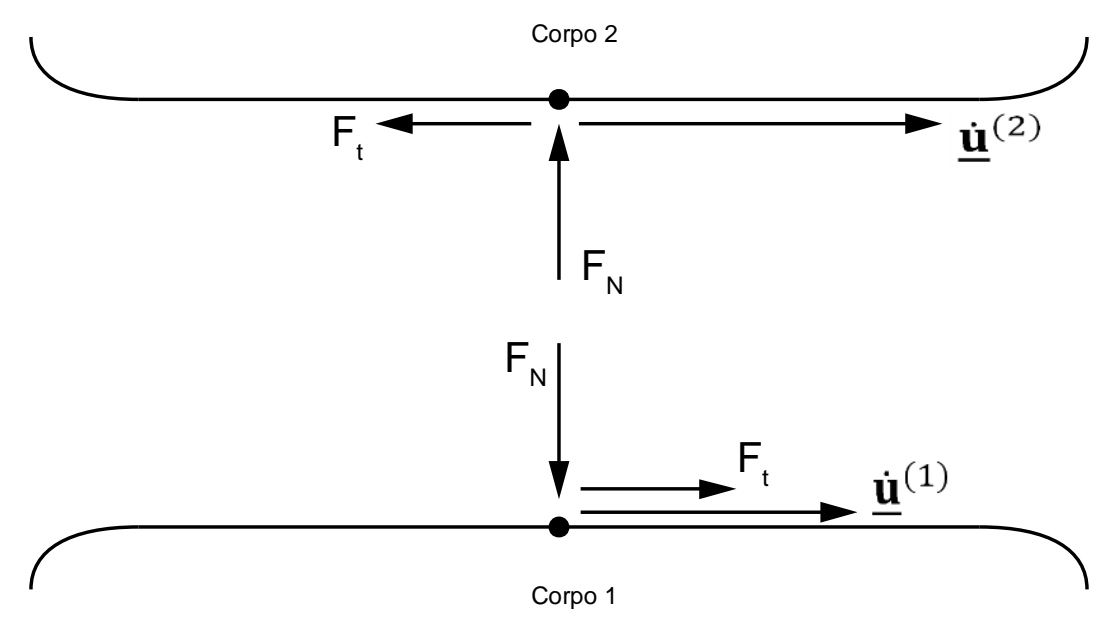

Fig.2.3 - Movimento relativo entre corpos em contato.

Não ocorrerá escorregamento entre os corpos, i.e., a velocidade tangencial relativa é nula (situação de atrito estático), quando:

$$
\left|F_{t}\right|<\mu\left|F_{N}\right| .
$$

onde $\mu$ representa o coeficiente de atrito.

Se a força tangente $F_{t}$ for igual a $\mu\left|F_{N}\right|$, pode haver escorregamento e, neste caso, a situação é representada como:

$$
\left|\mathrm{F}_{\mathrm{t}}\right|=\mu\left|\mathrm{F}_{\mathrm{N}}\right| \Rightarrow\left|\left(\dot{\mathbf{u}}^{(2)}-\dot{\mathbf{u}}^{(1)}\right) \cdot \mathbf{T}\right| \geq 0 .
$$

As condições de escorregamento podem ainda ser escritas da seguinte forma:

- Sem escorregamento:

$$
\left|F_{\mathrm{t}}\right|-\mu\left|\mathrm{F}_{\mathrm{N}}\right|<0 \Rightarrow\left\|\left(\dot{\mathbf{u}}^{(2)}-\dot{\mathbf{u}}^{(1)}\right) \cdot \mathbf{T}\right\|=0
$$

- Com escorregamento:

$$
\left|\mathrm{F}_{\mathrm{t}}\right|-\mu\left|\mathrm{F}_{\mathrm{N}}\right|=0 \Rightarrow\left\|\left(\dot{\mathbf{u}}^{(2)}-\dot{\mathbf{u}}^{(1)}\right) . \mathbf{T}\right\| \geq 0
$$


As relações expressas nas Eqs. 2.10 e 2.11 podem ser reescritas na forma de condições de complementaridade de Kuhn-Tucket-Kurash. De fato, definindo:

$$
f_{t}\left(\mathrm{~F}_{\mathrm{t}}, \mathrm{F}_{\mathrm{N}}\right)=\left|\mathrm{F}_{\mathrm{t}}\right|-\mu\left|\mathrm{F}_{\mathrm{N}}\right| \leq 0
$$

e

$$
g_{t}\left(\dot{\mathbf{u}}^{(1)}, \dot{\mathbf{u}}^{(2)}, \mathbf{T}\right)=\left\|\left(\dot{\mathbf{u}}^{(2)}-\dot{\mathbf{u}}^{(1)}\right) . \mathbf{T}\right\| \geq 0,
$$

a condição de complementaridade associada ao atrito seco de Coulomb pode ser expressa escrita como:

$$
f_{t}\left(\mathrm{~F}_{\mathrm{t}}, \mathrm{F}_{\mathrm{N}}\right) \leq 0, \quad g_{t} \geq 0, \quad f_{t} g_{t}=0 \text {. }
$$

\subsection{FORMULAÇÃO VARIACIONAL DO PROBLEMA DE CONTATO E MULTIPLICADORES DE LAGRANGE}

Esta seção ilustra, em um contexto simples, os conceitos de formulação variacional e de multiplicadores de Lagrange. A formulação variacional constitui a base teórica do Método dos Elementos Finitos, enquanto os multiplicadores de Lagrange permitem incorporar restrições à formulação variacional.

Pode-se interpretar a descrição variacional como um problema de ponto de mínimo (ou, de maneira mais geral, ponto estacionário) de uma função potencial.

A Fig. 2.4.a representa um potencial $\Pi(a)$ e seu ponto de mínimo, caracterizado como

$$
\delta \Pi=\frac{\mathrm{d} \Pi}{\mathrm{du}} \delta \mathrm{u}=0, \forall \delta \mathrm{u}
$$

onde u é a variável de interesse e $\delta$ u é sua variação. 


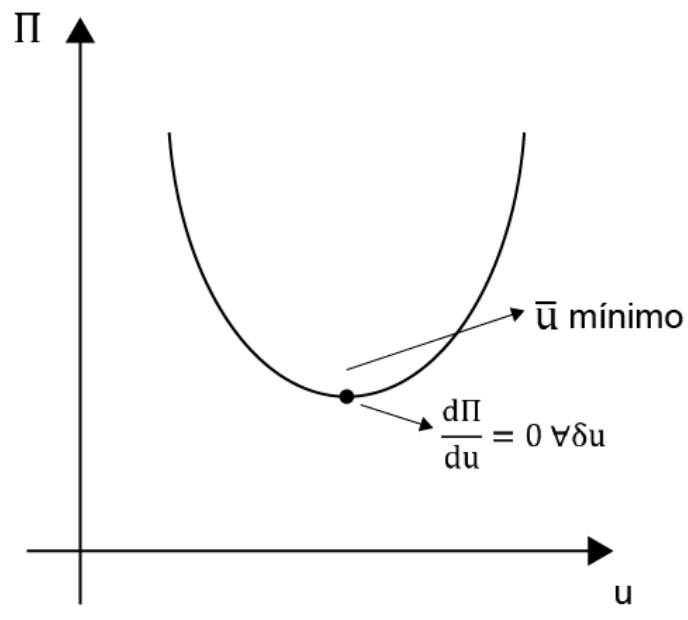

(a)

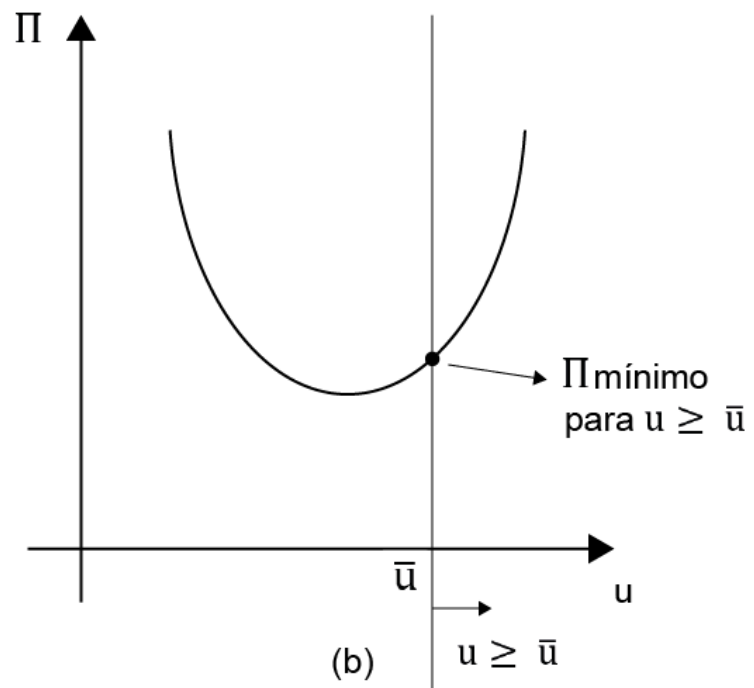

(b)

Fig. 2.4 - (a) potencial $\Pi$ e seu ponto de mínimo em problema sem restrição, e; (b) potencial $\Pi$ e seu ponto de mínimo quando se impõe restrição $u \geq \bar{u}$.

Por outro lado, impondo-se uma restrição sobre a variável $\mathrm{u}$ - no caso, $\mathrm{u} \geq \overline{\mathrm{u}}$ - a Fig. 2.4.b ilustra o fato de que o mínimo do potencial deixa de estar associado a um ponto estacionário de $\Pi$.

Neste cenário, os multiplicadores de Lagrange surgem como uma ferramenta poderosa, pois transformam um problema sem mínimo regular (deformável) em um problema com ponto estacionário regular.

Nesta seção, introduz-se os multiplicadores de Lagrange no contexto de um problema simples de contato (sem atrito) entre dois sólidos elásticos. Por simplicidade, os sólidos são representados como duas molas de constante k: a primeira com nós 1 e 2 e a segunda com nós 3 e 4, conforme é ilustrado na Fig.2.5.a. 


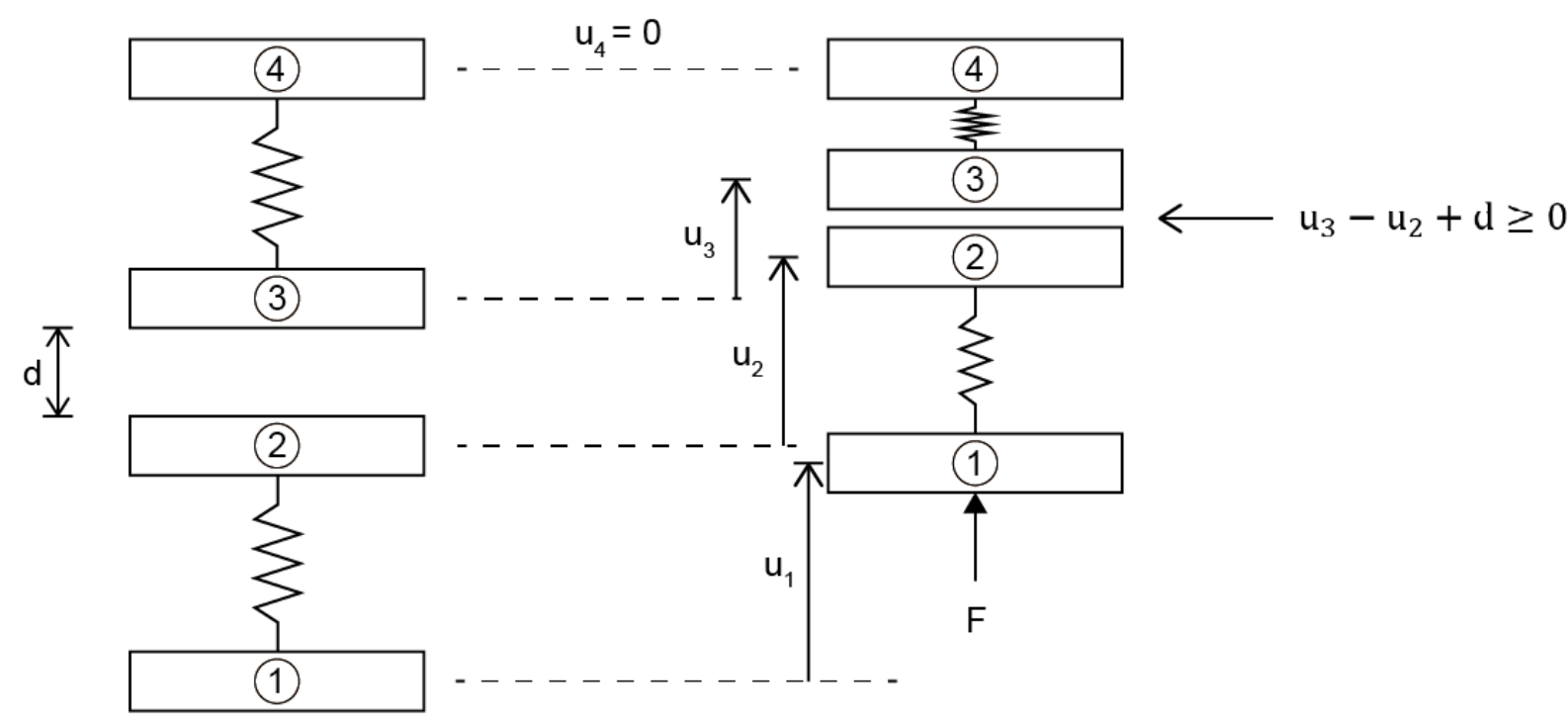

(a)

(b)

Fig. 2.5 - (a) sistema de dois corpos elásticos sem cargas aplicadas, e; (b) sistema submetido a força $\mathrm{F}$ e sujeito a restrição de deslocamento nulo no nó 4 e de contato entre os nós 2 e 3.

A Fig. 2.5.b ilustra o sistema submetido:

(a) a uma força externa F aplicada ao nó 1;

(b) restrição de deslocamento nulo no nó 4;

$$
\mathrm{u}_{4}=0
$$

(c) restrição de contato entre os nós 2 e 3;

$$
\mathrm{p}\left(\mathrm{u}_{2}, \mathrm{u}_{3}\right)=\mathrm{u}_{3}-\mathrm{u}_{2}+\mathrm{d} \geq 0
$$

Pode-se associar a cada uma das molas os potenciais de energia de deformação:

$$
\mathrm{W}_{1}\left(\mathrm{u}_{1}, \mathrm{u}_{2}\right)=\frac{\mathrm{k}}{2}\left(\mathrm{u}_{2}-\mathrm{u}_{1}\right)^{2}, \mathrm{~W}_{2}=\left(\mathrm{u}_{3}, \mathrm{u}_{4}\right)=\frac{\mathrm{k}}{2}\left(\mathrm{u}_{4}-\mathrm{u}_{3}\right)^{2}
$$

de modo que o potencial de energia de deformação total do sistema é dado por:

$$
\mathrm{W}\left(\mathrm{u}_{1}, \mathrm{u}_{2}, \mathrm{u}_{3}, \mathrm{u}_{4}\right)=\frac{\mathrm{k}}{2}\left(\mathrm{u}_{2}-\mathrm{u}_{1}\right)^{2}+\frac{\mathrm{k}}{2}\left(\mathrm{u}_{4}-\mathrm{u}_{3}\right)^{2} .
$$

O sistema carregado deve incorporar ainda o potencial da força externa $\mathrm{F}$ aplicada sobre o nó 1 :

$$
\mathrm{W}_{\mathrm{F}}=-\mathrm{Fu}_{1}
$$


e as restrições expressas pelas Eqs. 2.16 e 2.17. Tais restrições são incorporadas ao potencial de energia total $\mathrm{W}+\mathrm{W}_{\mathrm{F}}$, multiplicadas pelos respectivos multiplicadores de Lagrange, definindo-se assim o Lagrangeano:

$$
\begin{aligned}
& \mathrm{L}\left(\mathrm{u}_{1}, \mathrm{u}_{2}, \mathrm{u}_{3}, \mathrm{u}_{4}, \lambda_{\mathrm{c}}, \lambda_{4}\right)= \\
& \frac{\mathrm{k}}{2}\left(\mathrm{u}_{2}-\mathrm{u}_{1}\right)^{2}+\frac{\mathrm{k}}{2}\left(\mathrm{u}_{4}-\mathrm{u}_{3}\right)^{2}-\mathrm{Fu}_{1}+\lambda_{\mathrm{c}}\left(\mathrm{u}_{3}-\mathrm{u}_{2}+\mathrm{d}\right)+\lambda_{4} \mathrm{u}_{4}
\end{aligned}
$$

onde $\lambda_{c}$ é o multiplicador de Lagrange associado à restrição de contato unilateral, enquanto $\lambda_{4}$ é o multiplicador associado à restrição de deslocamento nulo do nó 4 .

A imposição da estacionariedade do Lagrangeano em relação as variações $\delta u_{1}, \delta u_{2}, \delta u_{3}, \delta u_{4}, \delta u_{c}$ e $\delta \lambda_{4}$ fornece as equações:

$$
\begin{gathered}
\frac{\partial \mathrm{L}}{\partial \mathrm{u}_{1}} \delta \mathrm{u}_{1}=0 \forall \delta \mathrm{u}_{1} \Rightarrow \frac{\partial \mathrm{L}}{\partial \mathrm{u}_{1}}=0 \\
\vdots \\
\frac{\partial \mathrm{L}}{\partial \mathrm{u}_{4}} \delta \mathrm{u}_{4}=0 \forall \delta \mathrm{u}_{4} \Rightarrow \frac{\partial \mathrm{L}}{\partial \mathrm{u}_{4}}=0 \\
\frac{\partial \mathrm{L}}{\partial \mathrm{u}_{\mathrm{c}}} \delta \mathrm{u}_{\mathrm{c}}=0 \forall \delta \mathrm{u}_{\mathrm{c}} \Rightarrow \frac{\partial \mathrm{L}}{\partial \mathrm{u}_{\mathrm{c}}}=0 \\
\frac{\partial \mathrm{L}}{\partial \lambda_{4}} \delta \lambda_{4}=0 \forall \delta \lambda_{4} \Rightarrow \frac{\partial \mathrm{L}}{\partial \lambda_{4}}=0
\end{gathered}
$$

$$
\begin{gathered}
\frac{\partial \mathrm{L}}{\partial \mathrm{u}_{1}}=-\mathrm{k}\left(\mathrm{u}_{2}-\mathrm{u}_{1}\right)-\mathrm{F}=0 \\
\frac{\partial \mathrm{L}}{\partial \mathrm{u}_{2}}=\mathrm{k}\left(\mathrm{u}_{2}-\mathrm{u}_{1}\right)-\lambda_{\mathrm{c}}=0 \\
\frac{\partial \mathrm{L}}{\partial \mathrm{u}_{3}}=-\mathrm{k}\left(\mathrm{u}_{4}-\mathrm{u}_{3}\right)+\lambda_{\mathrm{c}}=0 \\
\frac{\partial \mathrm{L}}{\partial \mathrm{u}_{4}}=\mathrm{k}\left(\mathrm{u}_{4}-\mathrm{u}_{3}\right)+\lambda_{4}=0 \\
\frac{\partial \mathrm{L}}{\partial \mathrm{u}_{\mathrm{c}}}=\mathrm{u}_{3}-\mathrm{u}_{2}+\mathrm{d}=0 \\
\frac{\partial \mathrm{L}}{\partial \lambda_{4}}=\mathrm{u}_{4}=0
\end{gathered}
$$


As Eqs. 2.23. a a 2.23.d constituem as equações de equilíbrio dos nós 1 a 4 , respectivamente, enquanto as Eqs. (2.23.e) e (2.23.f) representam as restrições geométricas. $\lambda_{c}$ é a força de contato entre os nós 2 e 3 , enquanto $\lambda_{4}$ é a força reativa associada ao deslocamento nulo do nó 4 .

Em representação matricial as Eqs. 2.23 podem ser reescritas como:

$$
\left(\begin{array}{rrrrrr}
\mathrm{k} & -\mathrm{k} & 0 & 0 & 0 & 0 \\
-\mathrm{k} & \mathrm{k} & 0 & 0 & -1 & 0 \\
0 & 0 & \mathrm{k} & -\mathrm{k} & 1 & 0 \\
0 & 0 & -\mathrm{k} & \mathrm{k} & 0 & 1 \\
0 & -1 & 1 & 0 & 0 & 0 \\
0 & 0 & 0 & 1 & 0 & 0
\end{array}\right)\left(\begin{array}{c}
\mathrm{u}_{1} \\
\mathrm{u}_{2} \\
\mathrm{u}_{3} \\
\mathrm{u}_{4} \\
\lambda_{\mathrm{c}} \\
\lambda_{4}
\end{array}\right)=\left(\begin{array}{r}
\mathrm{F} \\
0 \\
0 \\
0 \\
-\mathrm{d} \\
0
\end{array}\right)
$$

ou

$$
\mathbf{A u}=\mathbf{f}
$$

A solução do sistema de equações lineares fornece:

$$
\begin{gathered}
\mathrm{u}_{1}=\mathrm{d}+2 \frac{\mathrm{F}}{\mathrm{k}} \\
\mathrm{u}_{2}=\mathrm{d}+\frac{\mathrm{F}}{\mathrm{k}} \\
\mathrm{u}_{3}=\frac{\mathrm{F}}{\mathrm{k}} \\
\mathrm{u}_{4}=0 \\
\lambda_{\mathrm{c}}=-\mathrm{F} \\
\lambda_{4}=\mathrm{F}
\end{gathered}
$$

Apesar de simétrica, a matriz A da Eq. (2.25) não é positiva definida, de modo que o problema de ponto estacionário não é problema de mínimo. De fato, a solução para o sistema Eq. (2.24) representa um ponto de sela do Lagrangeano expresso pela Eq. (2.21), conforme a ilustração esquemática da Fig. 2.6. 


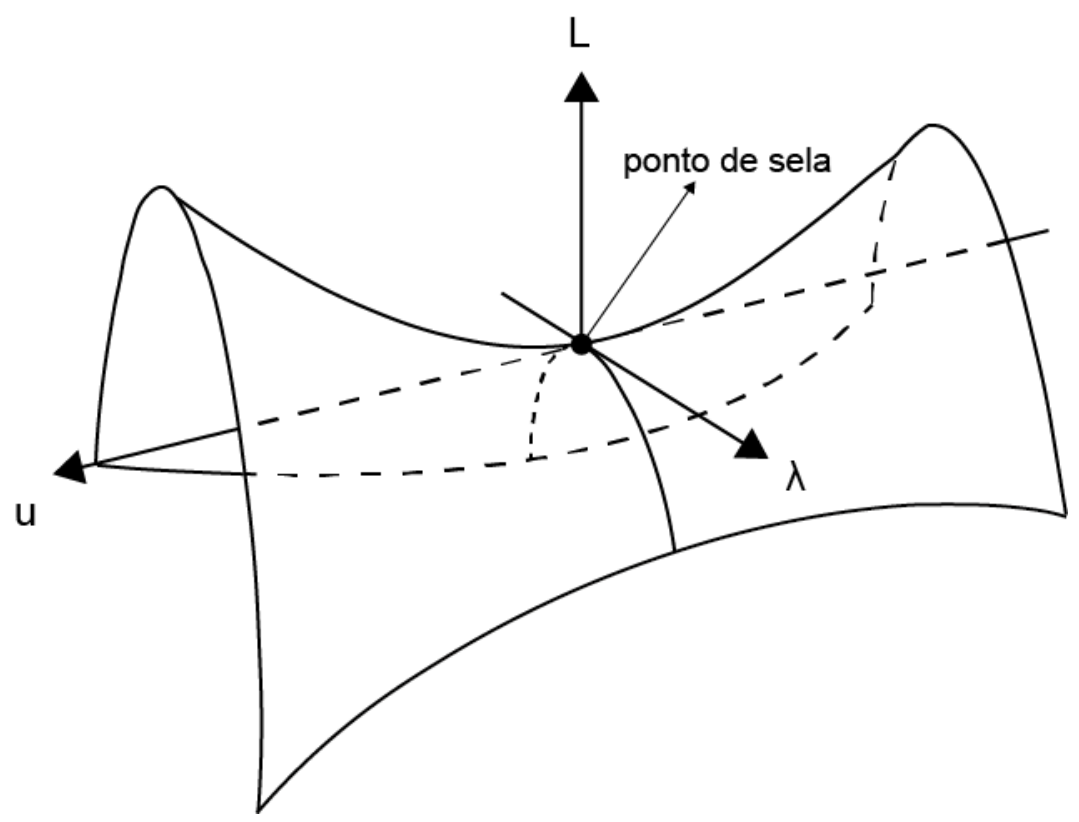

Fig. 2.6 - Representação esquemática do Lagrangeano e de seu ponto de sela, que fornece a solução do problema de equilíbrio.

A formulação do problema de equilíbrio utilizando multiplicadores de Lagrange permite a imposição exata das restrições de contato, mas por outro lado aumenta a dimensão do problema e o sistema linear resultante não é associado a um problema de mínimo de um potencial de energia total, mas sim um problema de sela do Lagrangeano.

\subsection{MÉTODO DA PENALIDADE PARA APROXIMAÇÃO DE RESTRIÇÃO}

Uma alternativa ao uso dos multiplicadores de Lagrange para impor restrição à solução de um problema de equilíbrio consiste na adição de termo de penalização ao potencial de energia total.

$$
\begin{aligned}
\Pi_{\mathrm{p}}\left(\mathrm{u}_{1}, \mathrm{u}_{2}, \mathrm{u}_{3}, \mathrm{u}_{4}\right)=W\left(\mathrm{u}_{1}, \mathrm{u}_{2}, \mathrm{u}_{3}, \mathrm{u}_{4}\right)-\mathrm{Fu}_{1}+\frac{\varepsilon_{\mathrm{c}}}{2} \mathrm{p}^{2}\left(\mathrm{u}_{2}, \mathrm{u}_{3}\right)+\frac{\varepsilon_{4}}{2} \mathrm{u}_{4}^{2} \\
=\frac{\mathrm{k}}{2}\left(\mathrm{u}_{2}-\mathrm{u}_{1}\right)^{2}+\frac{\mathrm{k}}{2}\left(\mathrm{u}_{4}-\mathrm{u}_{3}\right)^{2}-\mathrm{Fu}_{1}+\frac{\varepsilon_{\mathrm{c}}}{2}\left(\mathrm{u}_{3}-\mathrm{u}_{2}+\mathrm{d}\right)^{2}+\frac{\varepsilon_{4}}{2} \mathrm{u}_{4}^{2}
\end{aligned}
$$

onde $\varepsilon_{c}$ e $\varepsilon_{4}$ são parâmetros de penalidade de pontos arbitrariamente escolhidos. Neste formato, apenas os valores dos deslocamentos nodais $u_{1}, \ldots, u_{4}$ são incógnitas do problema. O problema de mínimo com restrição é assim substituído por um problema de mínimo sem restrição. 
Entretanto, as restrições geométricas do problema são apenas satisfeitas de forma aproximada. Quanto maiores forem os valores adotados para os parâmetros de penalização, melhores são as aproximações para as restrições. De fato, a condição de mínimo imposta ao potencial $\Pi_{p}$ fornece:

$$
\begin{aligned}
& \frac{\partial \Pi_{\mathrm{p}}}{\partial \mathrm{u}_{1}}=-\mathrm{k}\left(\mathrm{u}_{2}-\mathrm{u}_{1}\right)-\mathrm{F}=0 \\
& \frac{\partial \Pi_{\mathrm{p}}}{\partial \mathrm{u}_{2}}=\mathrm{k}\left(\mathrm{u}_{2}-\mathrm{u}_{1}\right)-\varepsilon_{\mathrm{c}}\left(\mathrm{u}_{3}-\mathrm{u}_{2}+\mathrm{d}\right)=0 \\
& \frac{\partial \Pi_{\mathrm{p}}}{\partial \mathrm{u}_{3}}=-\mathrm{k}\left(\mathrm{u}_{4}-\mathrm{u}_{3}\right)+\varepsilon_{\mathrm{c}}\left(\mathrm{u}_{3}-\mathrm{u}_{2}+\mathrm{d}\right)=0 \\
& \frac{\partial \Pi_{\mathrm{p}}}{\partial \mathrm{u}_{4}}=\mathrm{k}\left(\mathrm{u}_{4}-\mathrm{u}_{3}\right)+\varepsilon_{4} \mathrm{u}_{4}=0
\end{aligned}
$$

ou, na forma matricial:

$$
\left(\begin{array}{cccc}
\mathrm{k} & -\mathrm{k} & 0 & 0 \\
-\mathrm{k} & \mathrm{k}+\varepsilon_{\mathrm{c}} & -\varepsilon_{\mathrm{c}} & 0 \\
0 & -\varepsilon_{\mathrm{c}} & \mathrm{k}+\varepsilon_{\mathrm{c}} & -\mathrm{k} \\
0 & 0 & -\mathrm{k} & \mathrm{k}+\varepsilon_{4}
\end{array}\right)\left(\begin{array}{l}
\mathrm{u}_{1} \\
\mathrm{u}_{2} \\
\mathrm{u}_{3} \\
\mathrm{u}_{4}
\end{array}\right)=\left(\begin{array}{c}
\mathrm{F} \\
\varepsilon_{\mathrm{c}} \mathrm{d} \\
-\varepsilon_{\mathrm{c}} \mathrm{d} \\
0
\end{array}\right)
$$

A solução do sistema de equações fornece

$$
\begin{gathered}
\mathrm{u}_{1}=\mathrm{d}+2 \frac{\mathrm{F}}{\mathrm{k}}+\frac{\mathrm{F}}{\varepsilon_{\mathrm{c}} \varepsilon_{4}}\left(\varepsilon_{4}+1\right) \\
\mathrm{u}_{2}=\mathrm{d}+\frac{\mathrm{F}}{\mathrm{k}}+\frac{\mathrm{F}}{\varepsilon_{\mathrm{c}} \varepsilon_{4}}\left(\varepsilon_{4}+1\right) \\
\mathrm{u}_{3}=\frac{\mathrm{F}}{\mathrm{k}}+\frac{\mathrm{F}}{\varepsilon_{4}} \\
\mathrm{u}_{4}=\frac{\mathrm{F}}{\varepsilon_{4}}
\end{gathered}
$$

Observa-se que a solução do problema com restrição aproximadas pelo método da penalização converge para a solução obtida com os multiplicadores de Lagrange à medida que os valores de $\varepsilon_{\mathrm{c}}$ e $\varepsilon_{4}$ aumentam.

Em geral, a escolha entre o uso dos multiplicadores de Lagrange e o método da penalidade é feita de acordo com as dificuldades na convergência dos resultados numéricos para problemas de contato. Sendo o método da penalidade o mais recomendado para simulações com dificuldades de convergência numérica. 


\subsection{MODOS ESPÚRIOS}

Tipicamente, deformações plásticas evoluem, nos metais, a volume constante. Esta restrição é descrita matematicamente como:

$$
\operatorname{tr} \boldsymbol{\varepsilon}_{\mathbf{p}}=0
$$

onde $\varepsilon_{\mathbf{p}}$ é a tensão de deformação plástica, no caso de pequenas deformações ou como:

$$
\operatorname{det} \mathbf{F}_{\mathbf{p}}=0
$$

onde $\mathbf{F}_{\mathbf{p}}$ é o gradiente de deformações plásticas, no caso de grandes deformações.

A satisfação à restrição de volume constante pode produzir resultado espúrio, usualmente denominado "travamento", quando elementos finitos não apropriados são empregados na simulação.

Para ilustrar o "travamento", considere-se o elemento triangular linear apresentado na Fig. 2.7.a (Hughes, 1987).

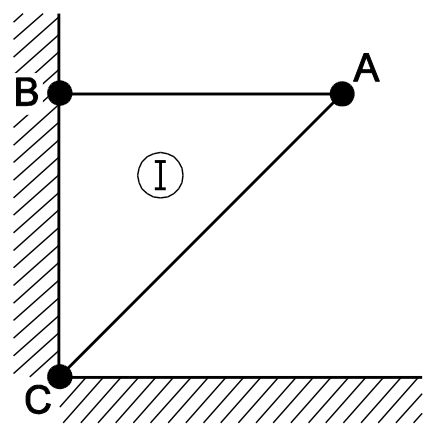

(a)

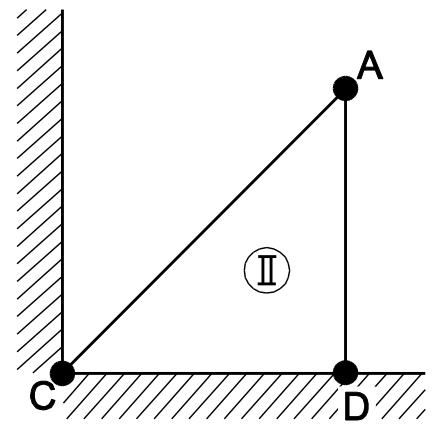

(b)

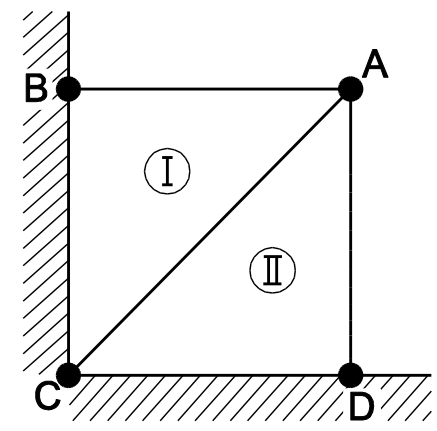

(c)

Fig. 2.7 - Exemplo do "travamento" observado em malhas compostas por elementos triangulares lineares.

O elemento em questão tem deslocamentos impedidos nos nós B e C. Assim, o elemento triangular só pode se deformar, preservando a área, pelo deslocamento vertical do nó $A$. Por sua vez, o elemento da Fig. 2.7.b só pode se deformar com área constante se o nó A se deslocar horizontalmente. Assim, considerando-se a malha da Fig. 2.7.c, o nó A fica impedido de se deslocar, caracterizando-se o "travamento".

O "travamento" pode ser observado em muitos elementos finitos, entre os quais o quadrilateral de quatro nós - em problemas de deformação plana - e o hexaédrico 
de oito nós, no caso tridimensional. Uma opção para se evitar o "travamento" numérico consiste em considerar elementos finitos de ordem superior, mas, por outro lado, isto pode levar a outras dificuldades, quando o contato unilateral for parte do problema, por exemplo.

Uma estratégia simples frequentemente empregada, mesmo em aplicativos comerciais como o Abaqus ou Ansys, para evitar o "travamento" numérico consiste na adoção de um esquema de integração reduzida. No caso do elemento hexaédrico de oito nós, por exemplo, a integração plena exige oito pontos de Gauss enquanto a integração reduzida envolve o cálculo dos integrandos da fórmula variacional em apenas um ponto (central) em cada elemento.

Embora esta estratégia seja, em geral, eficaz para se evitar "travamento" numérico, por outro lado, pode produzir um efeito colateral de exibição de modos espúrios de deformação conhecido como hourglass.

A Fig.2.8 apresenta um elemento finito quadrilateral com quatro nós.

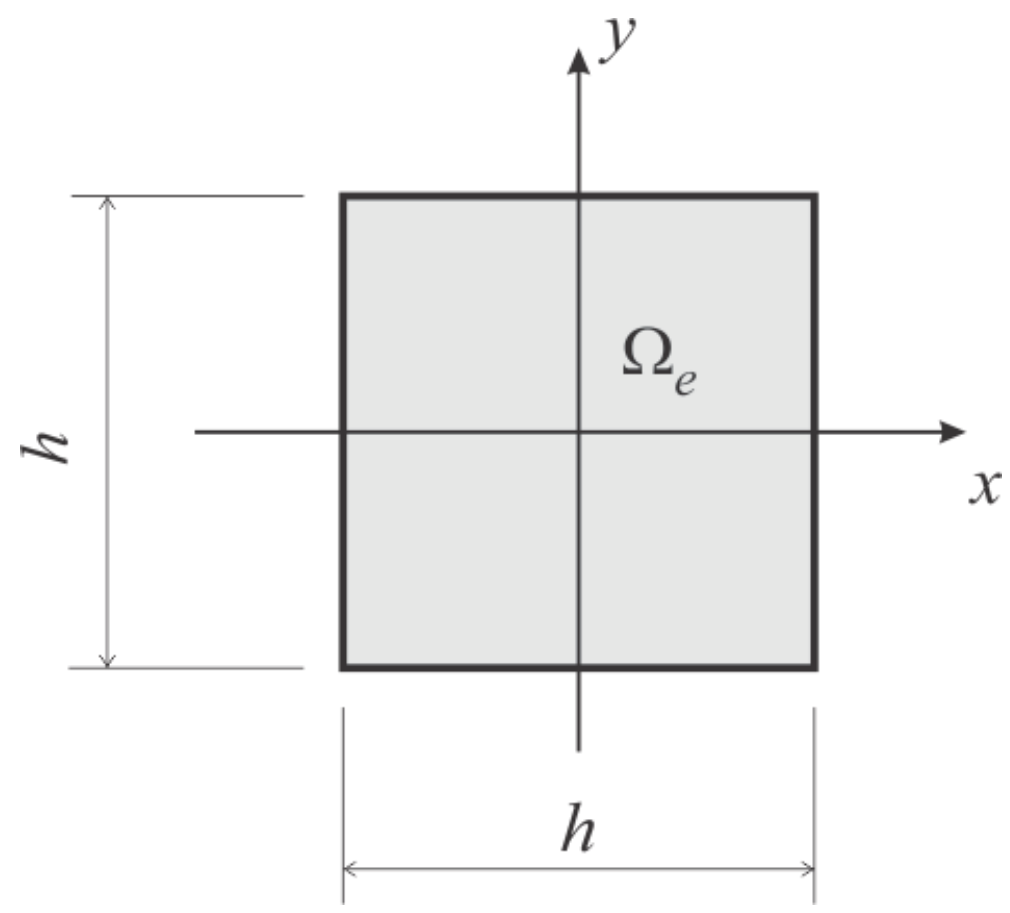

Fig. 2.8 - Elemento finito Q4.

O uso de integração reduzida permite, eventualmente, que os campos de deslocamentos estejam contaminados com modos espúrios de deformação, conforme pode ser ilustrado por meio de um exemplo simples. De fato, os cálculos que se 
seguem mostram que modos espúrios de deformação do elemento finito quadrilateral de quatro nós ilustrado na Fig. 2.8 estão associados a energia de deformação

$$
\begin{aligned}
\mathrm{W}_{\mathrm{e}} & =\frac{1}{2} \mathbf{u}_{\mathrm{e}}^{\mathrm{T}} \int_{\Omega_{\mathrm{e}}} \mathbf{B}_{\mathrm{e}}^{\mathrm{T}} \mathbf{D} \mathbf{B}_{\mathrm{e}} \mathrm{d} \Omega \mathbf{u}_{\mathrm{e}} \\
& \cong \frac{\mathrm{h}^{2}}{2} \mathbf{u}_{\mathrm{e}}^{\mathrm{T}}\left(\mathbf{B}_{\mathrm{e}}^{\mathrm{T}} \mathbf{D} \mathbf{B}_{\mathrm{e}}\right) \mathbf{u}_{\mathrm{e}}
\end{aligned}
$$

nula ao se empregar integração aproximada em um único ponto de Gauss. Na expressão da energia de deformação $\mathrm{W}_{\mathrm{e}}$ do elemento, a matriz de elasticidade $\mathbf{D}$ é expressa, sob estados planos de deformação, como:

$$
\mathbf{D}=\left(\begin{array}{ccc}
\lambda+2 \mu & \lambda & 0 \\
\lambda & \lambda+2 \mu & 0 \\
0 & 0 & \mu
\end{array}\right)
$$

e a matriz $\boldsymbol{B}_{e}$, que relaciona deformações com deslocamentos nodais, é dada por:

$$
\mathbf{B}_{\mathrm{e}}=\left(\begin{array}{cccccccc}
\frac{\partial \mathrm{N}_{1}}{\partial \mathrm{x}} & 0 & \frac{\partial \mathrm{N}_{2}}{\partial \mathrm{x}} & 0 & \frac{\partial \mathrm{N}_{3}}{\partial \mathrm{x}} & 0 & \frac{\partial \mathrm{N}_{4}}{\partial \mathrm{x}} & 0 \\
0 & \frac{\partial \mathrm{N}_{1}}{\partial \mathrm{y}} & 0 & \frac{\partial \mathrm{N}_{2}}{\partial \mathrm{y}} & 0 & \frac{\partial \mathrm{N}_{3}}{\partial \mathrm{y}} & 0 & \frac{\partial \mathrm{N}_{4}}{\partial \mathrm{y}} \\
\frac{\partial \mathrm{N}_{1}}{\partial \mathrm{y}} & \frac{\partial \mathrm{N}_{1}}{\partial \mathrm{x}} & \frac{\partial \mathrm{N}_{2}}{\partial \mathrm{y}} & \frac{\partial \mathrm{N}_{2}}{\partial \mathrm{x}} & \frac{\partial \mathrm{N}_{3}}{\partial \mathrm{y}} & \frac{\partial \mathrm{N}_{3}}{\partial \mathrm{x}} & \frac{\partial \mathrm{N}_{4}}{\partial \mathrm{y}} & \frac{\partial \mathrm{N}_{4}}{\partial \mathrm{x}}
\end{array}\right)
$$

No caso específico do elemento finito ilustrado a Fig. 2.5, as funções de forma $N_{i}(x, y), i=1, \ldots, 4$ da Eq. (2.35) são descritas pelas expressões:

$$
\begin{aligned}
& \mathrm{N}_{1}(\mathrm{x}, \mathrm{y})=\left(\frac{1}{2}+\frac{\mathrm{x}}{\mathrm{h}}\right)\left(\frac{1}{2}+\frac{\mathrm{y}}{\mathrm{h}}\right), \\
& \mathrm{N}_{2}(\mathrm{x}, \mathrm{y})=\left(\frac{1}{2}-\frac{\mathrm{x}}{\mathrm{h}}\right)\left(\frac{1}{2}+\frac{\mathrm{y}}{\mathrm{h}}\right), \\
& \mathrm{N}_{3}(\mathrm{x}, \mathrm{y})=\left(\frac{1}{2}-\frac{\mathrm{x}}{\mathrm{h}}\right)\left(\frac{1}{2}-\frac{\mathrm{y}}{\mathrm{h}}\right), \\
& \mathrm{N}_{4}(\mathrm{x}, \mathrm{y})=\left(\frac{1}{2}+\frac{\mathrm{x}}{\mathrm{h}}\right)\left(\frac{1}{2}-\frac{\mathrm{y}}{\mathrm{h}}\right),
\end{aligned}
$$


com derivadas parciais em $(x, y)=(0,0)$ - ponto de integração reduzida - iguais a:

$$
\begin{array}{ll}
\frac{\partial \mathrm{N}_{1}}{\partial \mathrm{x}}(0,0)=\frac{1}{2 \mathrm{~h}}, & \frac{\partial \mathrm{N}_{1}}{\partial \mathrm{y}}(0,0)=\frac{1}{2 \mathrm{~h}}, \\
\frac{\partial \mathrm{N}_{2}}{\partial \mathrm{x}}(0,0)=-\frac{1}{2 \mathrm{~h}}, & \frac{\partial \mathrm{N}_{2}}{\partial \mathrm{y}}(0,0)=\frac{1}{2 \mathrm{~h}} \\
\frac{\partial \mathrm{N}_{3}}{\partial \mathrm{x}}(0,0)=-\frac{1}{2 \mathrm{~h}}, & \frac{\partial \mathrm{N}_{3}}{\partial \mathrm{y}}(0,0)=-\frac{1}{2 \mathrm{~h}}, \\
\frac{\partial \mathrm{N}_{4}}{\partial \mathrm{x}}(0,0)=\frac{1}{2 \mathrm{~h}}, & \frac{\partial \mathrm{N}_{4}}{\partial \mathrm{y}}(0,0)=-\frac{1}{2 \mathrm{~h}} .
\end{array}
$$

A substituição das derivadas da Eq. (2.37) na matriz $\mathbf{B}_{\mathrm{e}}$ da Eq. (2.35) fornece:

$$
\mathbf{B}_{\mathrm{e}}=\frac{1}{2 \mathrm{~h}}\left(\begin{array}{rrrrrrrr}
1 & 0 & -1 & 0 & -1 & 0 & 1 & 0 \\
0 & 1 & 0 & 1 & 0 & -1 & 0 & -1 \\
1 & 1 & 1 & -1 & -1 & -1 & -1 & 1
\end{array}\right)
$$

O produto $\mathbf{D} \mathbf{B}_{\mathrm{e}}$ fornece a matriz:

$$
\mathbf{D B}_{\mathrm{e}}=\left(\begin{array}{cccccccc}
\lambda+2 \mu & \lambda & -\lambda-2 \mu & \lambda & -\lambda-2 \mu & -\lambda & \lambda+2 \mu & -\lambda \\
\lambda & \lambda+2 \mu & -\lambda & \lambda+2 \mu & -\lambda & -\lambda-2 \mu & \lambda & -\lambda-2 \mu \\
\mu & \mu & \mu & -\mu & -\mu & -\mu & -\mu & \mu
\end{array}\right) .
$$

Em seguida, o produto $\frac{\mathrm{h}^{2}}{2} \mathbf{B}_{\mathrm{e}}^{\mathrm{T}}\left(\mathbf{D} \mathbf{B}_{\mathrm{e}}\right)$ fornece:

$$
\begin{aligned}
& \frac{\mathrm{h}^{2}}{2} \mathbf{B}_{\mathrm{e}}^{\mathrm{T}}\left(\mathbf{D} \mathbf{B}_{\mathrm{e}}\right)= \\
& \left.\qquad \begin{array}{cccccccc}
\lambda+3 \mu & \lambda+\mu & -\lambda-\mu & \lambda-\mu & -\lambda-3 \mu & -\lambda-\mu & \lambda+\mu & -\lambda+\mu \\
\lambda+\mu & \lambda+3 \mu & -\lambda+\mu & \lambda+\mu & -\lambda-\mu & -\lambda-3 \mu & \lambda-\mu & -\lambda-\mu \\
-\lambda-\mu & -\lambda+\mu & \lambda+3 \mu & -\lambda-\mu & \lambda+\mu & \lambda-\mu & -\lambda-3 \mu & \lambda+\mu \\
\frac{1}{8}-\mu & \lambda+\mu & -\lambda-\mu & \lambda+3 \mu & -\lambda+\mu & -\lambda-\mu & \lambda+\mu & -\lambda-3 \mu \\
-\lambda-3 \mu & -\lambda-\mu & \lambda+\mu & -\lambda+\mu & \lambda+3 \mu & \lambda+\mu & -\lambda-\mu & \lambda-\mu \\
-\lambda-\mu & -\lambda-3 \mu & \lambda-\mu & -\lambda-\mu & \lambda+\mu & \lambda+3 \mu & -\lambda+\mu & \lambda+\mu \\
\lambda+\mu & \lambda-\mu & -\lambda-3 \mu & \lambda+\mu & -\lambda-\mu & -\lambda+\mu & \lambda+3 \mu & -\lambda-\mu \\
-\lambda+\mu & -\lambda-\mu & \lambda+\mu & -\lambda-3 \mu & \lambda-\mu & \lambda+\mu & -\lambda-\mu & \lambda+3 \mu
\end{array}\right)
\end{aligned}
$$




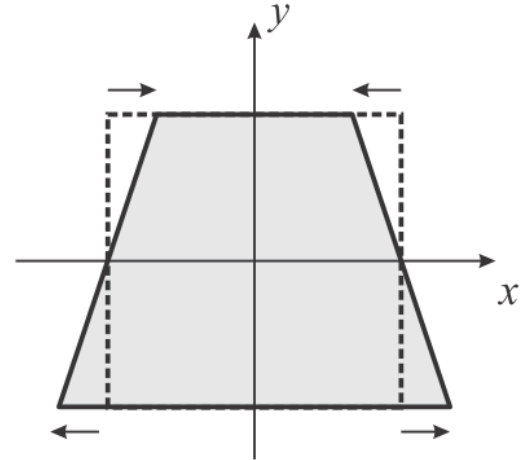

(a)

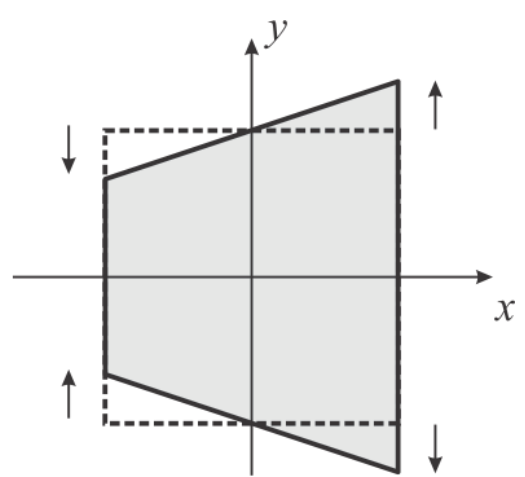

(b)

Fig. 2.9 - Modos espúrios 1 (a) e 2 (b) de deformação do elemento finito quadriateral de quatro nós com integração reduzida (um ponto de Gauss).

A substituição de qualquer dos modos espúrios de deformação deste elemento finito expressos pelos vetores:

$$
\begin{aligned}
& \mathbf{u}_{\mathrm{e}(1)}^{\mathrm{T}}=\left(\begin{array}{llllllll}
-\alpha & 0 & \alpha & 0 & -\alpha & 0 & \alpha & 0
\end{array}\right), \\
& \mathbf{u}_{\mathrm{e}(2)}^{\mathrm{T}}=\left(\begin{array}{llllllll}
0 & -\alpha & 0 & \alpha & 0 & -\alpha & 0 & \alpha
\end{array}\right),
\end{aligned}
$$

e ilustrados respectivamente nas Figs. 2.9.a e 2.9.b, na expressão da energia de deformação $\mathrm{W}_{\mathrm{e}}$ da Eq. (2.33), produz, considerando a Eq. (2.40) obtida por integração reduzida,

$$
\mathrm{W}_{\mathrm{e}}=\mathbf{u}_{\mathrm{e}(\mathrm{i})}^{\mathrm{T}}\left[\frac{\mathrm{h}^{2}}{2} \mathbf{B}_{\mathrm{e}}^{\mathrm{T}}\left(\mathbf{D} \mathbf{B}_{\mathrm{e}}\right)\right] \mathrm{u}_{\mathrm{e}(\mathrm{i})}=0, \quad \mathrm{i}=1,2,
$$

i.e., energia de deformação nula.

Problemas de modo espúrios por deformação são solucionados através da adição de rigidez artificial para modos de deformação por hourglass (método utilizado em problemas estáticos e quasi-estáticos), por adição de viscosidade artificial (problemas dinâmicos e de impacto) ou com refino da malha de elementos. 


\section{MODELAGEM}

Neste capítulo, a modelagem do contato entre fios do cabo condutor IBIS é apresentada. Como o problema é complexo e envolve altos custos computacionais, optou-se pela modelagem do contato entre dois fios apenas. A geometria, o material, as condições de contorno, as forças aplicadas e a malha de elementos finitos são descritas.

\subsection{DESCRIÇÃO DO PROBLEMA}

\subsubsection{Geometria do cabo e carregamento aplicado}

As análises numéricas apresentadas neste trabalho são relativas às tensões e deformações a que os fios do cabo condutor IBIS são submetidos na região interior ao grampo de suspensão, conforme é ilustrado na Fig. 3.1.

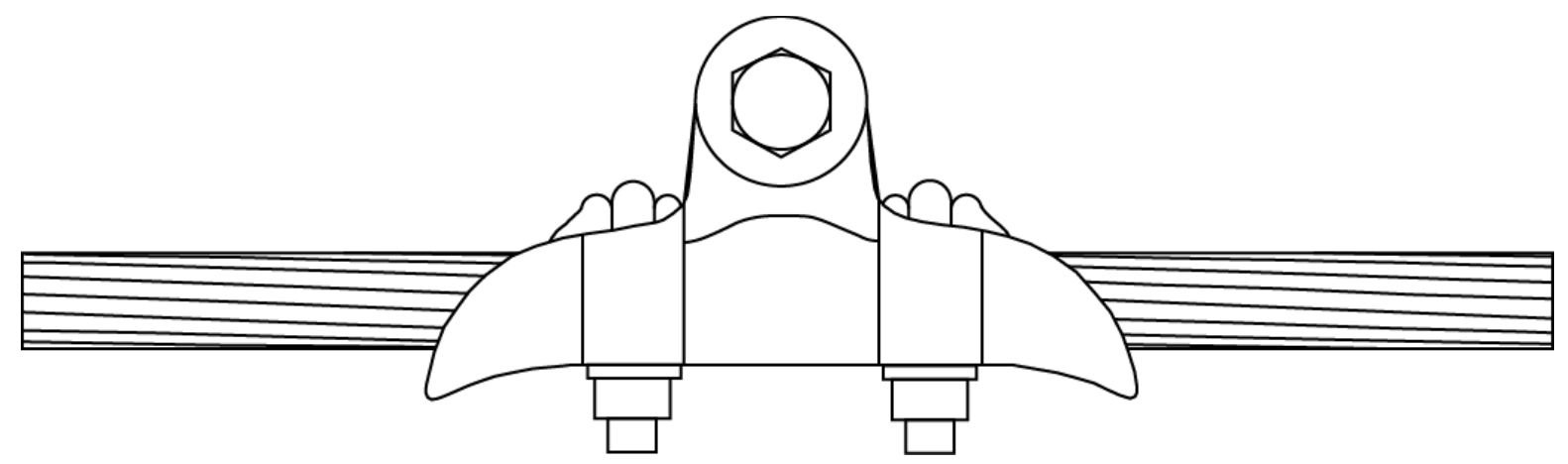

Fig. 3.1 - Desenho do conjunto cabo-grampo de suspensão.

A seção transversal do cabo condutor IBIS é composta por duas camadas de fios de alumínio recobrindo a alma de aço, conforme ilustrado na Fig. 3.2. 


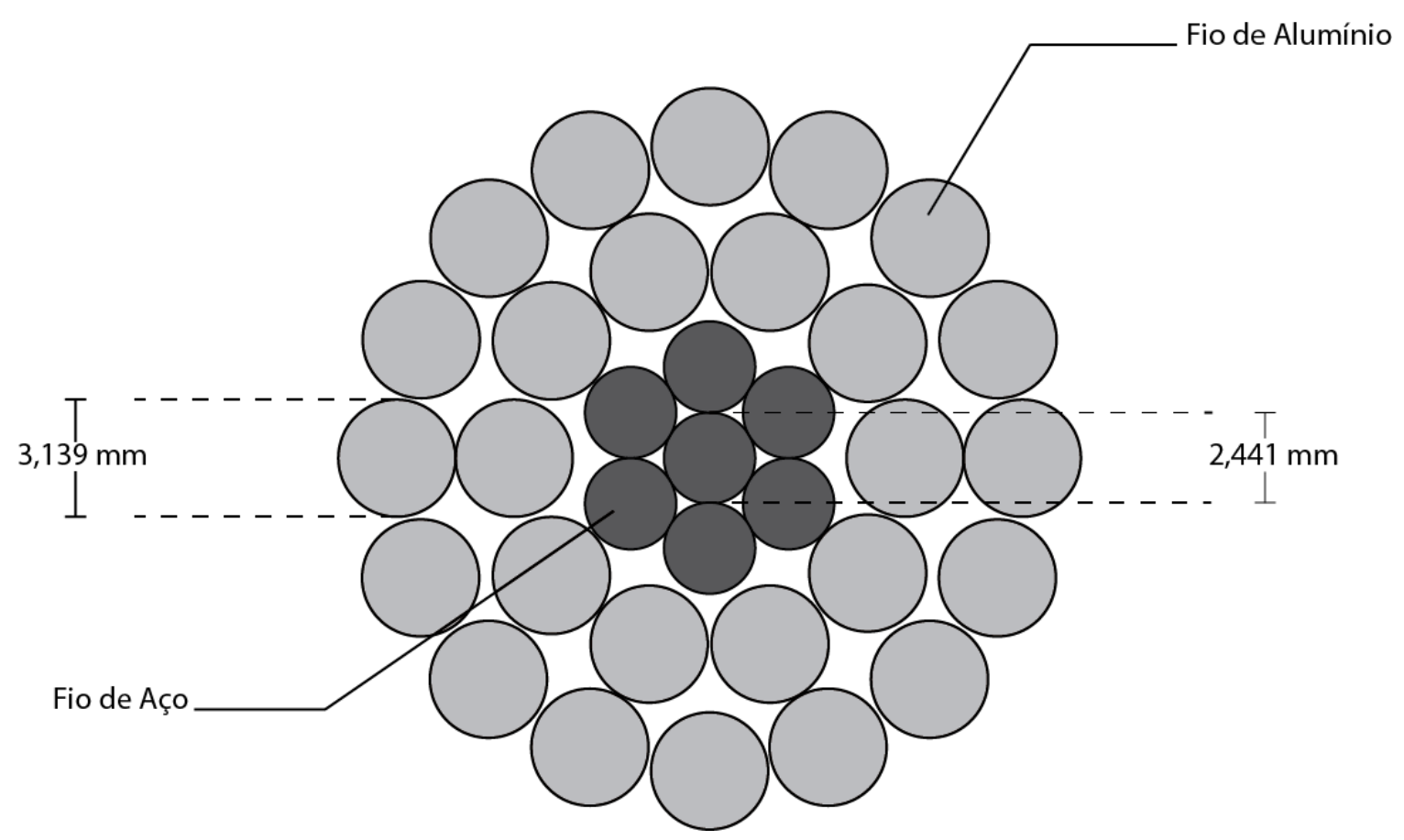

Fig. 3.2 - Seção transversal do cabo IBIS ilustrando suas camadas.

As duas camadas mais externas do cabo são compostas respectivamente por dezesseis e dez fios de alumínio com diâmetro de 3,139 $\mathrm{mm}$. Os sete fios de aço que constituem a alma do cabo têm diâmetro de 2,441 mm.

A história de carregamentos considerada no presente estudo obedece a uma condição específica considerada por Fadel (2010). O carregamento mecânico sobre o cabo condutor foi aplicado em três etapas:

(i) pré carga de tração do cabo conforme o valor da EDS (20\% da carga de ruptura);

(ii) carga de aperto aplicada pelo grampo de suspensão ao cabo e

(iii) carregamento alternado devido à vibração do cabo.

\section{$\underline{\text { Tração }}$}

$\mathrm{Na}$ etapa de pré carga, o cabo é tracionado com a força $\mathrm{F}_{\mathrm{EDS}}=14,7 \mathrm{kN}$, o que representa $20 \%$ da carga de ruptura, conforme é ilustrado na Fig. 3.3. 


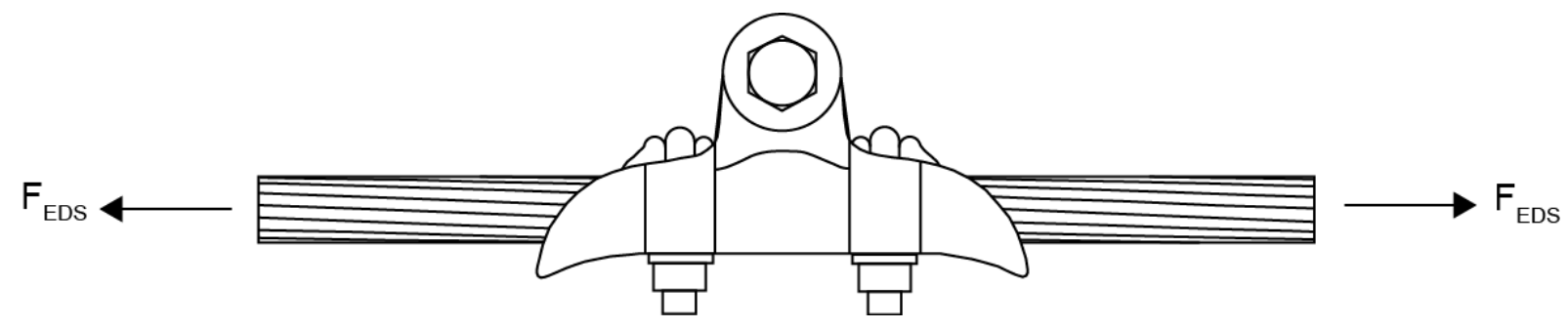

Fig. 3.3 - Carga de tração aplicada no condutor.

\section{Aperto do grampo de suspensão}

Os parafusos do grampo de suspensão, para o cabo IBIS, devem ser apertados conforme recomendação dada pelo fabricante do grampo. Nos trabalhos realizados por Fadel (2010), o torque sobre as porcas foi de $50 \mathrm{Nm}$.

A Fig. 3.4 ilustra a carga distribuída sobre o trecho de cabo em consequência do aperto dos parafusos de fixação.

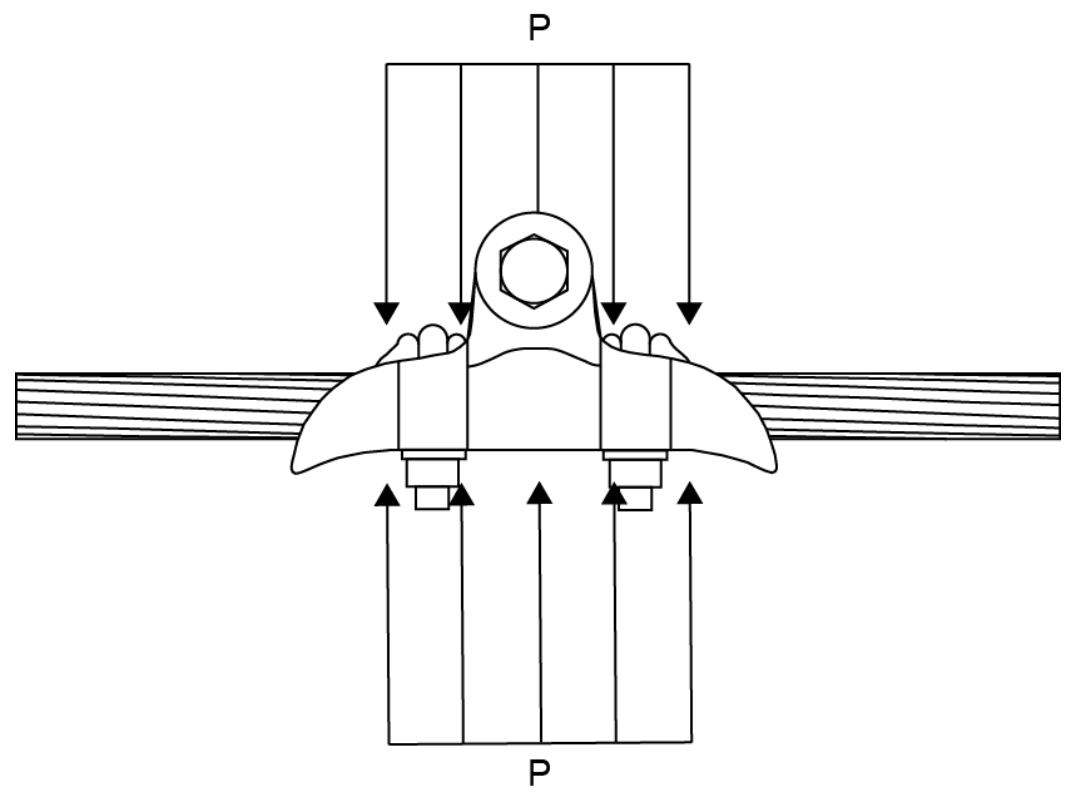

Fig. 3.4 - Carga distribuída aplicada pelo grampo sob trecho do cabo condutor. 


\section{Carregamento alternado}

A carga de flexão ilustrada na Fig. 3.5 é resultante da vibração do cabo condutor.

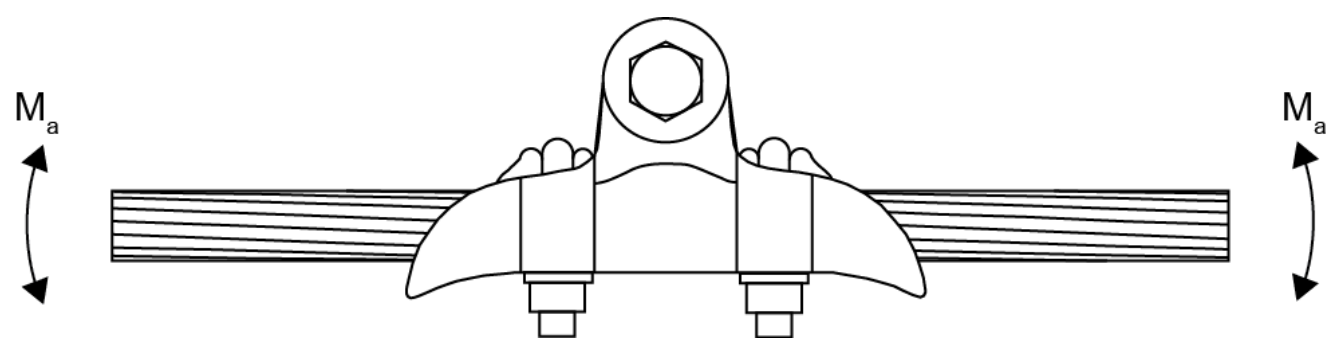

Fig. 3.5 - Momento alternado de flexão aplicado ao condutor próximo a região do grampo.

A amplitude de tensão sofrida pelos fios do cabo, devido ao carregamento alternado da Fig.3.5, pode ser estimada utilizando a equação de Poffenberger-Swart. Detalhes do cálculo desta amplitude estão descritos no Apêndice C.

O cabo condutor é, portanto, submetido à composição dos esforços aplicados conforme ilustrado na Fig. 3.6.

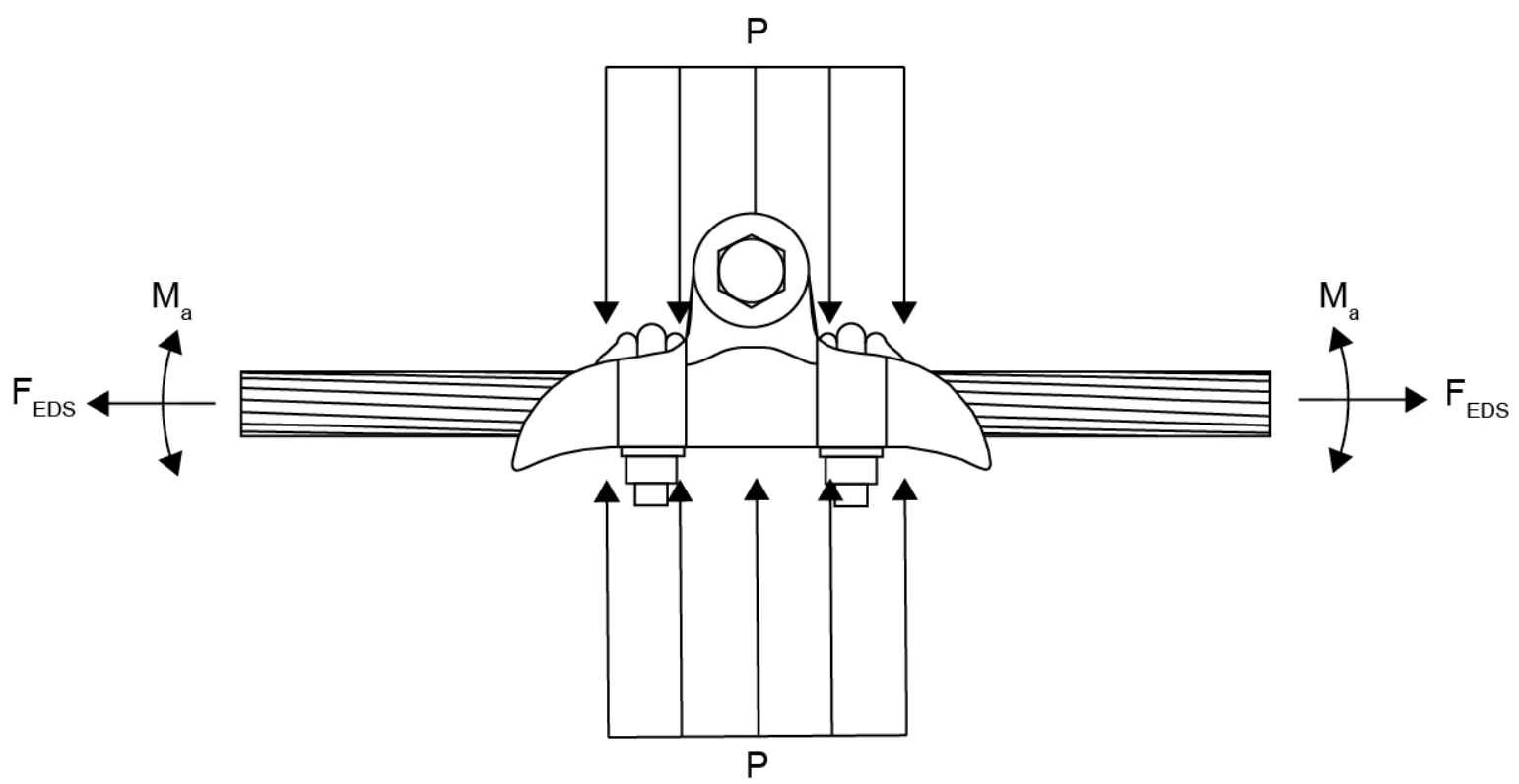

Fig. 3.6 - Cargas aplicadas sobre o cabo em operação. 


\subsubsection{Discussão sobre a complexidade do problema cabo- grampo}

Esta seção discute como a geometria do cabo condutor e o contato entre fios no regime elastoplástico contribuem para o elevado nível de complexidade do problema.

Conforme apresentado na seção anterior, o cabo condutor IBIS, com trecho ilustrado na Fig. 3.7, é formado por um total de trinta e três fios. Cada fio deste cabo pode apresentar inúmeras regiões de contato ao longo de seu comprimento. Hills (1994) observa que para se obter as tensões produzidas pelo contato entre corpos é necessário uso de métodos numéricos, como o dos elementos finitos, com malha refinada nestas regiões.

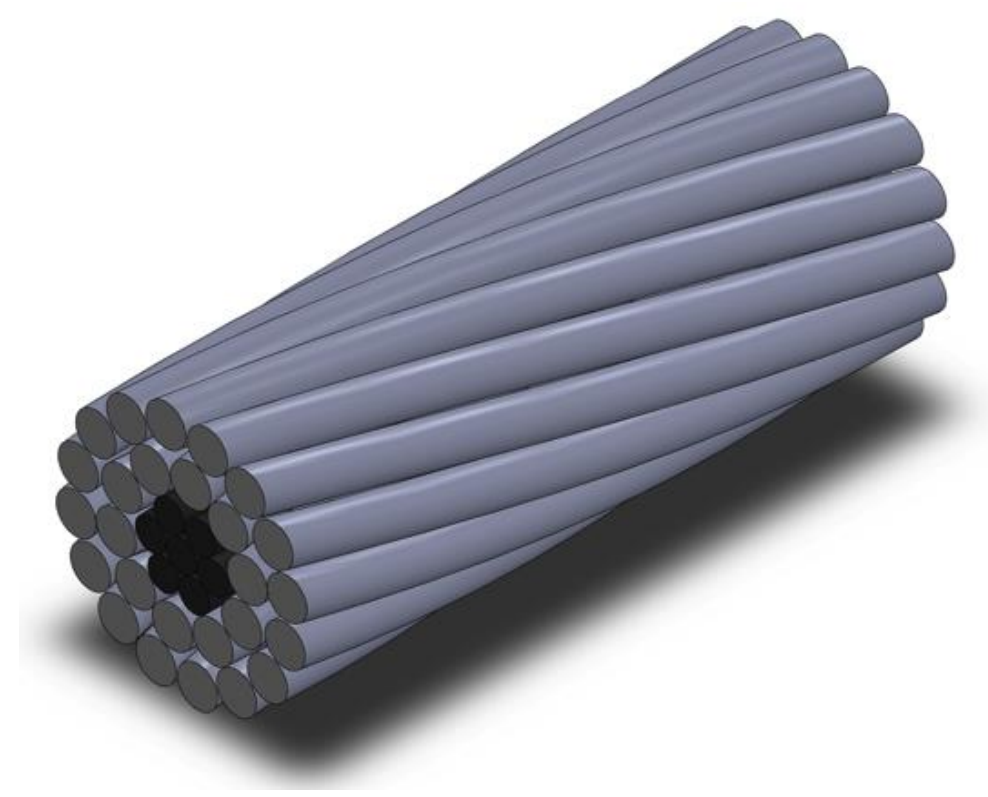

Fig. 3.7 - Trecho do cabo IBIS.

Para realizar a estimativa do número de regiões de contato ao longo de um trecho de cabo IBIS, é necessário conhecer os ângulos de hélice em cada camada do cabo. Estes ângulos foram obtidos a partir de três amostras de cabo tracionadas e apertadas pelo grampo de suspensão. A Fig. 3.8 apresenta um dos trechos fixados em uma morsa. 


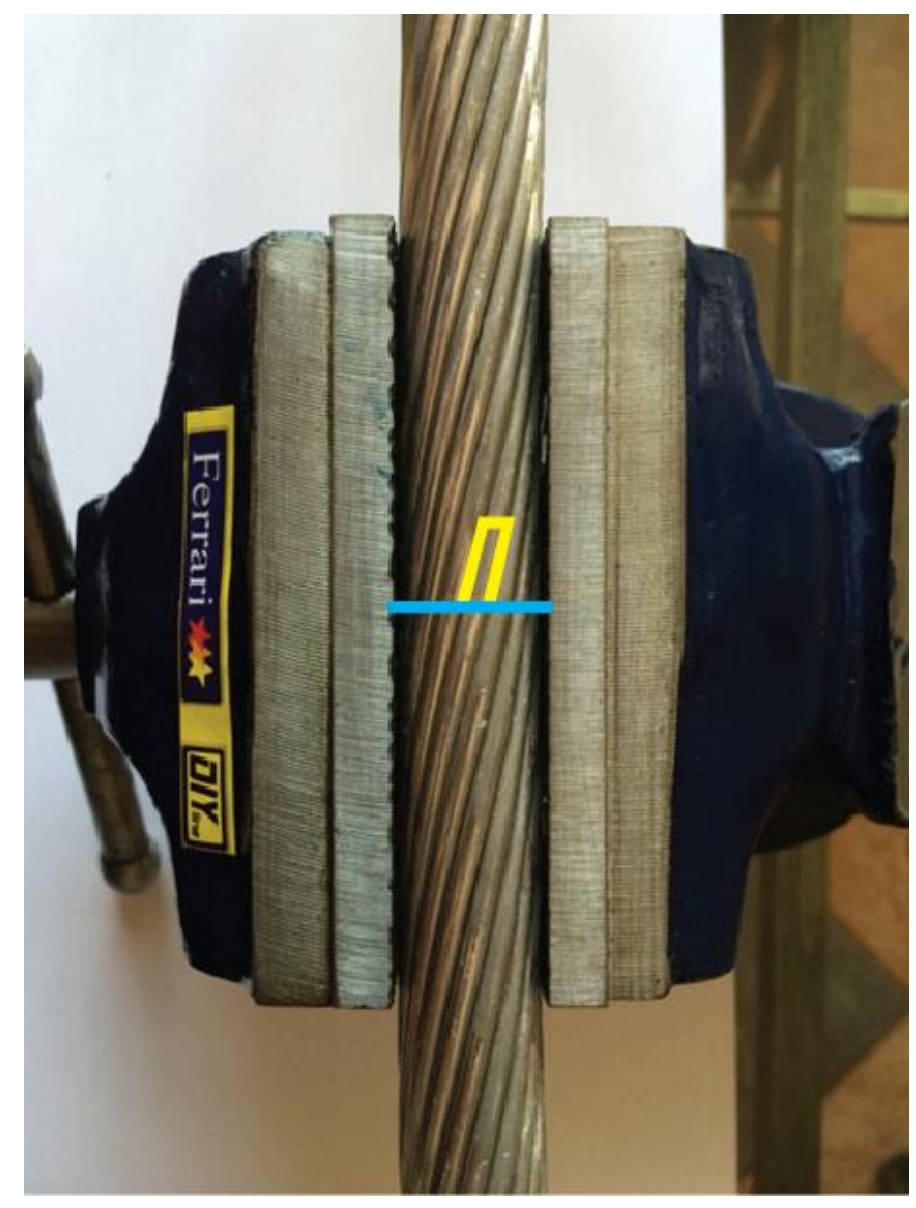

Fig. 3.8 - Medida do ângulo de hélice em um trecho de cabo previamente submetido ao EDS.

$\mathrm{Na}$ Fig. 3.8, o ângulo de hélice do fio destacado em amarelo foi medido utilizando, como referência, a reta horizontal em azul. A média dos ângulos encontrados para as camadas 1,2 e 3 foi respectivamente igual a $13,9^{\circ}, 10,1^{\circ}$ e $6,2^{\circ}$.

A estimativa do número total de regiões de contato entre os fios do cabo IBIS pode ser calculada por meio da expressão

$$
\mathrm{n}_{\mathrm{rc}}=\text { trecho }\left(\mathrm{nf}_{1} \frac{\cos \left(90^{\circ}-\left(\theta_{1}+\theta_{2}\right)\right)}{\mathrm{d}_{\mathrm{Al}} \cos \left(\theta_{1}\right)}+\mathrm{nf}_{2} \frac{\cos \left(90^{\circ}-\left(\theta_{2}+\theta_{3}\right)\right)}{\mathrm{d}_{\mathrm{aço}} \cos \left(\theta_{2}\right)}\right)
$$

demonstrada no Apêndice A. A Eq. 3.1 é função do número de fios $\mathrm{nf}_{\mathrm{i}}$ em cada camada do cabo, do diâmetro $\mathrm{d}_{\mathrm{Al}}$ dos fios de alumínio, do diâmetro $\mathrm{d}_{\mathrm{acco}}$ dos fios de aço e do comprimento do trecho do cabo considerado. Substituindo os valores, para o cabo IBIS, na Eq. 3.1, estima-se que, para um trecho de cabo com $100 \mathrm{~mm}$ de comprimento, haja aproximadamente 300 regiões de contato entre os fios. Por sua 
vez, cada uma destas regiões de contato exige um elevado nível de discretização. Neste contexto, esta análise tem como ponto de partida a descrição bidimensional do problema de contato entre dois cilindros sujeitos a grandes deformações elastoplásticas. A Fig. 3.9.a ilustra a malha de elementos finitos necessária para obtenção de uma descrição detalhada das tensões na região de contato para o caso do contato entre dois cilindros. Devido as grandes deformações, a superfície de contato é definida sobre uma parcela significativa do perímetro de cada um dos cilindros. Assim, cada uma destas superfícies de contato exige uma discretização de pelo menos 160 elementos. Isto implica que cada uma das regiões vizinhas às superfícies de contato é discretizada em aproximadamente $160 \times 160=25.600$ elementos quadrilaterais. Nestas condições, cada seção do cilindro seria discretizado em aproximadamente 40.000 elementos.

Extrapolando esta análise para problemas tridimensionais, se forem considerados cerca de 160 elementos na direção longitudinal, somente na região de contato, a malha resultará em $25.600 \times 160=4.096 .000$ elementos. Portanto, para trezentas regiões de contato ao longo de um trecho de cabo de $100 \mathrm{~mm}$, serão necessários mais de $2 \times 300 \times 4.096 .000=2,5$ bilhões de elementos finitos!!!

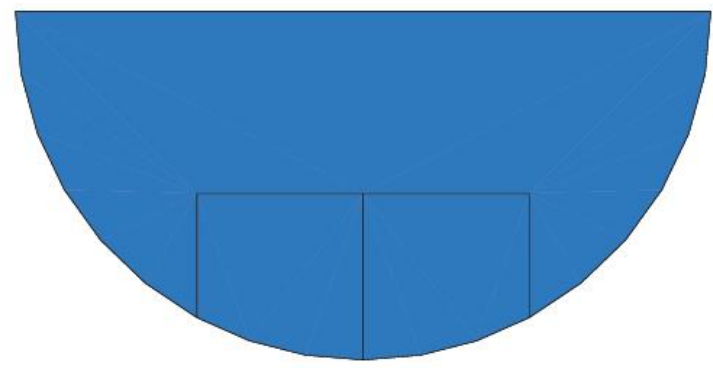

(a)

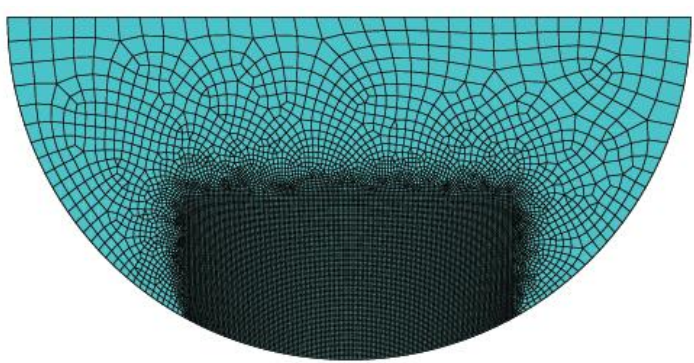

(b)

Fig. 3.9 - Partição da região de contato entre cilindros e malha de elementos necessária.

Esta análise motiva o estudo, numa primeira etapa, do contato de apenas um par de fios, em região vizinha ao grampo de suspensão. A modelagem deste problema é detalhada na próxima seção. 


\subsection{CONTATO ENTRE DOIS FIOS}

\subsubsection{Geometria}

A Fig. 3.10 ilustra o problema de contato entre dois fios objeto do presente estudo. São considerados os fios de alumínio das duas camadas externas em região interna ao grampo de suspensão. Um bloco é responsável pela aplicação da carga de pressão sobre os fios, enquanto as camadas internas de fios de aço são representadas simplificadamente por um cilindro.
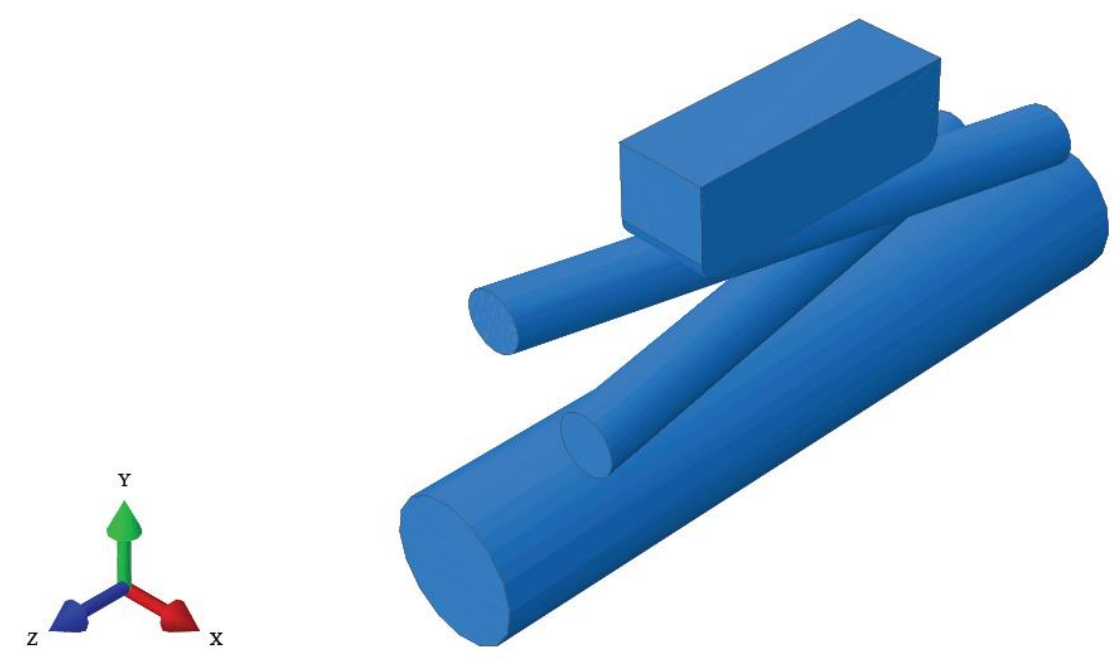

Fig. 3.10 - Modelagem do problema de contato entre dois fios do cabo IBIS.

Os fios de alumínio foram modelados como cilindros com diâmetros iguais a $3,139 \mathrm{~mm}$ e comprimento de $40 \mathrm{~mm}$. As extremidades de cada fio foram cortadas de acordo com o ângulo de hélice da sua camada com objetivo de que suas seções transversais sejam paralelas ao plano xy. A Fig.3.11 ilustra os cortes sobre os fios de alumínio. Os fios de aço do cabo IBIS foram representados como um único cilindro rígido com diâmetro igual a três vezes o dos fios de aço $(7,323 \mathrm{~mm})$.

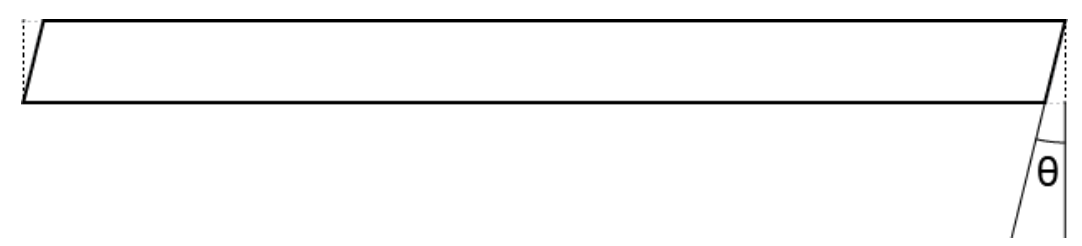

Fig. 3.11 - Vista superior de cada fio, com os cortes realizados em suas extremidades considerando os ângulos de hélice $\theta$ de sua respectiva camada. 
O bloco responsável pela aplicação da carga de pressão foi modelado como corpo rígido com dimensões da sua seção apresentadas na Fig.3.12 e largura igual a $5 \mathrm{~mm}$. Um filete de raio igual a $1 \mathrm{~mm}$ foi criado nas quinas da superfície de contato do bloco com o fio de alumínio da camada mais externa com objetivo de evitar singularidade na região de contato.

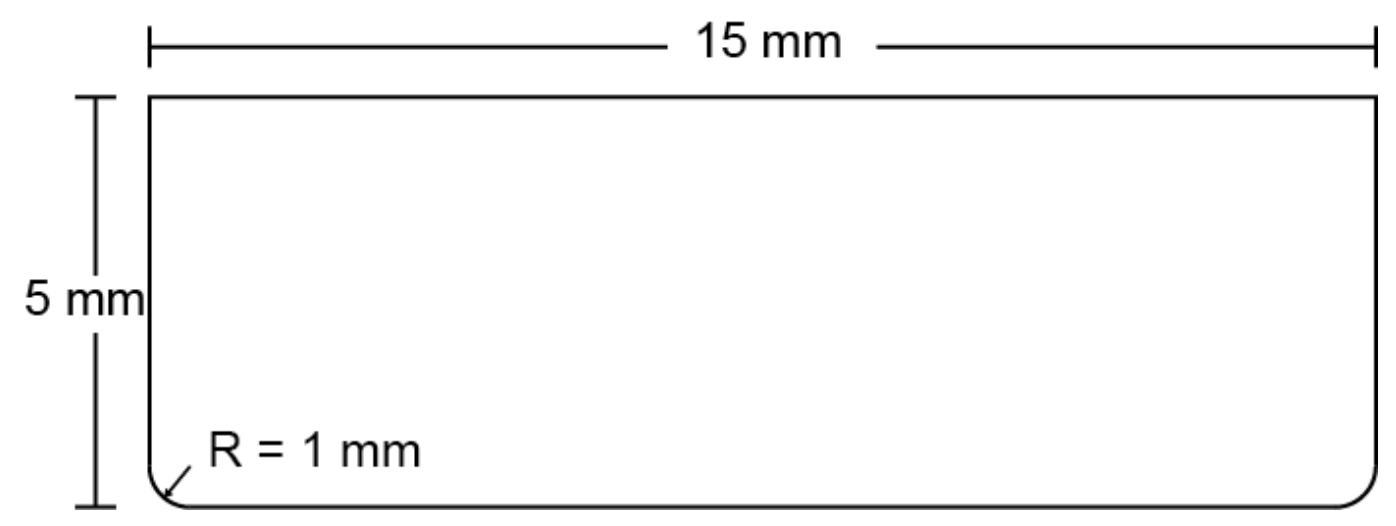

Fig.3.12 - Bloco representando a telha do grampo de suspensão.

\subsubsection{Material}

As propriedades mecânicas do Al 1350-H19 que constitui as camadas externas do cabo IBIS são: módulo de elasticidade $E=69.900 \mathrm{MPa}$ e coeficiente de Poisson $v=0,33$. Tais parâmetros foram recuperados do catálogo da Nexans. A curva de encruamento deste material (Wang et al., 2008) está representada na Fig. 3.13. 


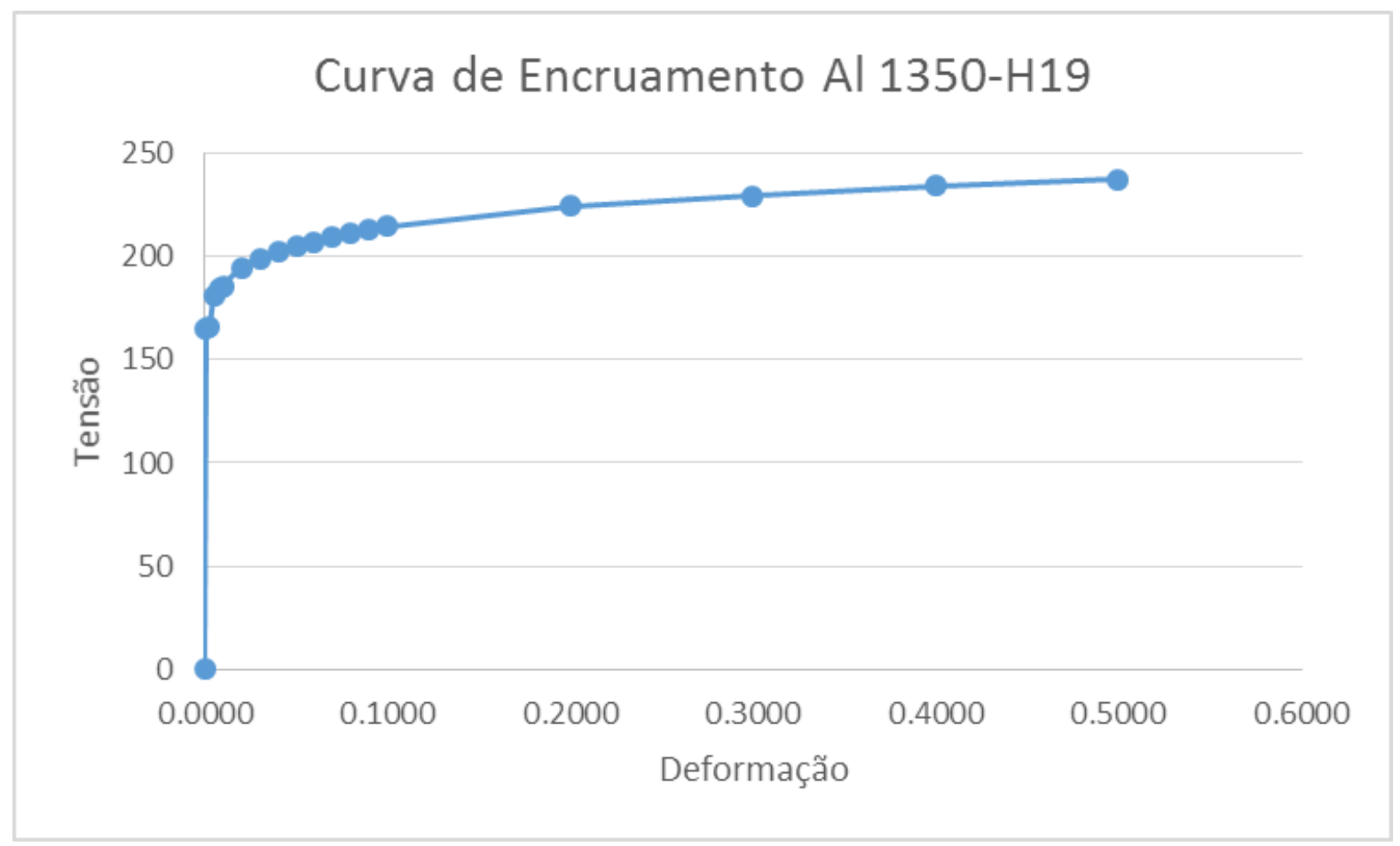

Fig. 3.13 - Curva de encruamento do Al 1350-H19.

Para 0 aço, foram considerados módulo de elasticidade $E_{\text {aço }}=210 \mathrm{GPa}$ e coeficiente de Poisson $v_{\text {aço }}=0,3$.

\subsubsection{Condições de contorno}

\section{Vinculações:}

Os dois fios de alumínio têm seus deslocamentos impedidos em uma das extremidades, enquanto na outra apenas o deslocamento na direção longitudinal do cabo é admitido. O cilindro central, que representa a alma de aço, tem todos os seus deslocamentos impedidos. O bloco, que pressiona os fios contra a alma do cabo, pode se deslocar apenas na direção radial do cabo. 


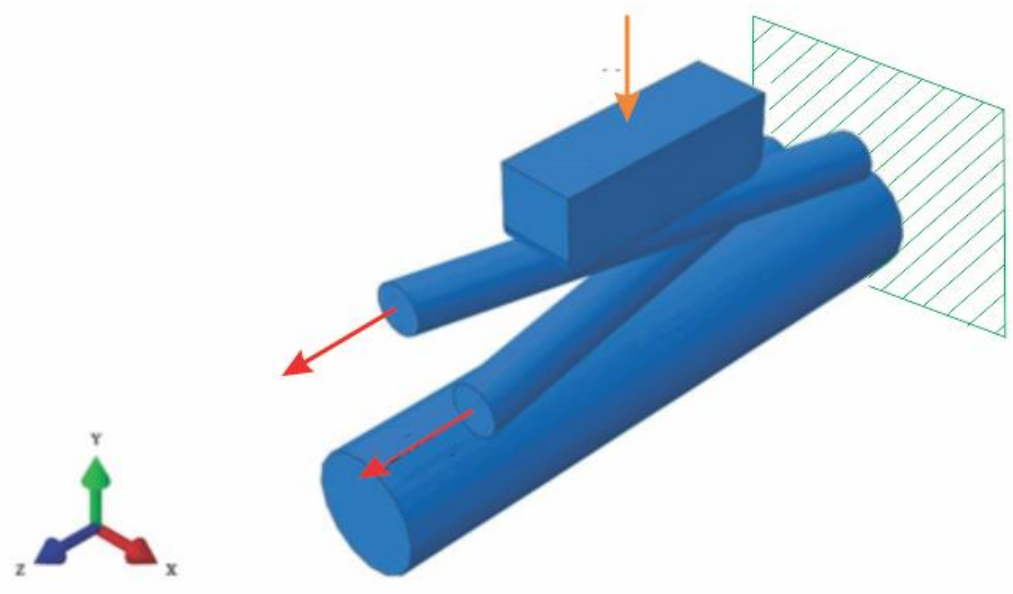

Fig. 3.14 - Condições de contorno do problema.

\section{Pré carga:}

A pré carga no cabo condutor considerada no presente estudo é igual a $\mathrm{F}_{\mathrm{EDS}}=$ $14,7 \mathrm{kN}$. A distribuição desta força nos diversos fios que constituem o cabo pode ser obtida admitindo-se a hipótese de Bernoulli, i.e., que as seções transversais do cabo permanecem planas após a deformação. Como o cabo é constituído de fios de diâmetros distintos e de materiais de composições diferentes, a força sobre o cabo não se distribui uniformemente entre seus fios. Além disso, deve-se considerar o fato de que cada camada de fios está enrolada no cabo segundo um ângulo de hélice distinto. Assim, as forças de pré carga observadas nos fios das camadas 1 e 2 - cujos cálculos são detalhados no Apêndice $B$ - são função dos módulos de elasticidade $\mathrm{E}_{\mathrm{Al}}$, $\mathrm{E}_{\mathrm{aço}}$, dos diâmetros dos fios $\mathrm{d}_{\mathrm{Al}}, \mathrm{d}_{\mathrm{aço}}$, dos números de fios de alumínio e de aço, $\mathrm{n}_{\mathrm{Al}}$, $\mathrm{n}_{\text {aço }}$ e dos ângulos de hélice das camadas 1 e $2, \theta_{1}, \theta_{2}$ podem ser expressas como:

$$
\begin{gathered}
\mathrm{F}_{1}=\frac{\mathrm{F}_{\mathrm{EDS}} \cos \theta_{1}}{\mathrm{n}_{\mathrm{Al}}+\mathrm{n}_{\mathrm{aço}} \frac{\mathrm{E}_{\mathrm{aço}}}{\mathrm{E}_{\mathrm{Al}}}\left(\frac{\mathrm{d}_{\mathrm{aço}}}{\mathrm{d}_{\mathrm{Al}}}\right)^{2}}, \\
\mathrm{~F}_{2}=\frac{\mathrm{F}_{\mathrm{EDS}} \cos \theta_{2}}{\mathrm{n}_{\mathrm{Al}}+\mathrm{n}_{\mathrm{aço}} \frac{\mathrm{E}_{\mathrm{aço}}}{\mathrm{E}_{\mathrm{Al}}}\left(\frac{\mathrm{d}_{\mathrm{aço}}}{\mathrm{d}_{\mathrm{Al}}}\right)^{2}} .
\end{gathered}
$$


As Eqs. 3.2 e 3.3 fornecem, para $\mathrm{F}_{\mathrm{EDS}}=14,7 \mathrm{kN}$, os valores $\mathrm{F}_{1}=367 \mathrm{~N}$ para 0 fio da primeira camada e $\mathrm{F}_{2}=372 \mathrm{~N}$ para o fio da segunda camada.

\section{Carga de aperto:}

A carga de aperto foi definida, no presente estudo, de tal forma que a marca de contato resultante fosse dimensionalmente similar à marca observada experimentalmente.

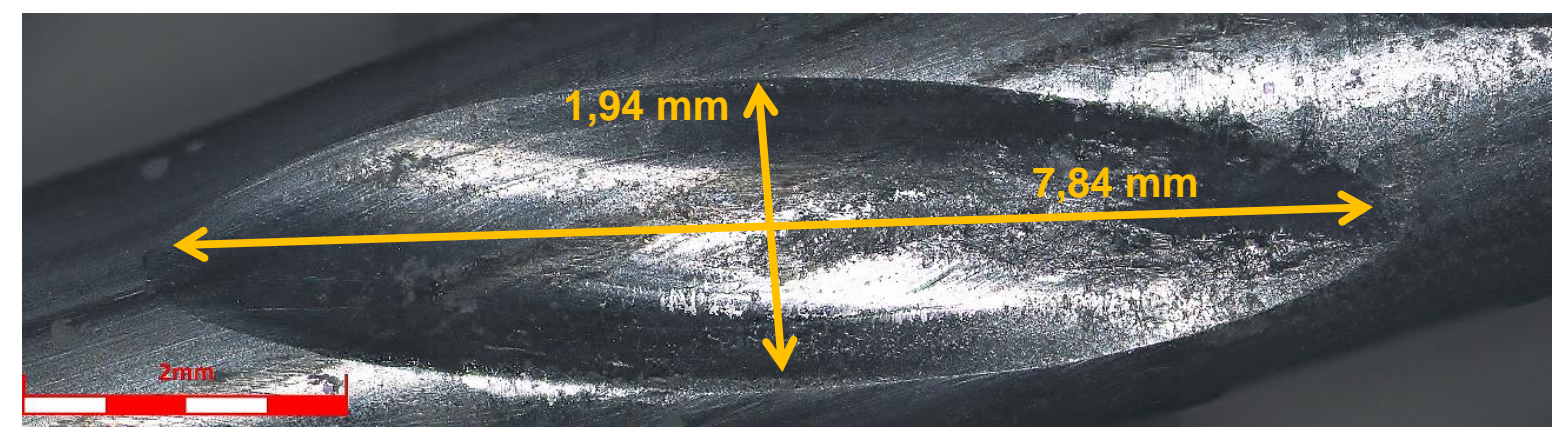

Fig. 3.15 - Marca produzida pela pressão entre fios das camadas 1 e 2 .

No presente estudo, a marca de contato considerada tem forma aproximadamente elíptica e mede, de acordo com observação no microscópio Confocal, 7,84 mm em seu maior eixo e 1,94 mm em seu eixo menor.

\section{Carregamento cíclico:}

O presente estudo considera que o cabo oscila transversalmente com magnitude $\mathrm{y}_{\mathrm{B}}=1,39 \mathrm{~mm}$ (pico a pico), quando medido a uma distância de $\mathrm{x}=89 \mathrm{~mm}$ do último ponto de contato entre o cabo e o grampo, conforme é ilustrado na Fig. 3.16. 


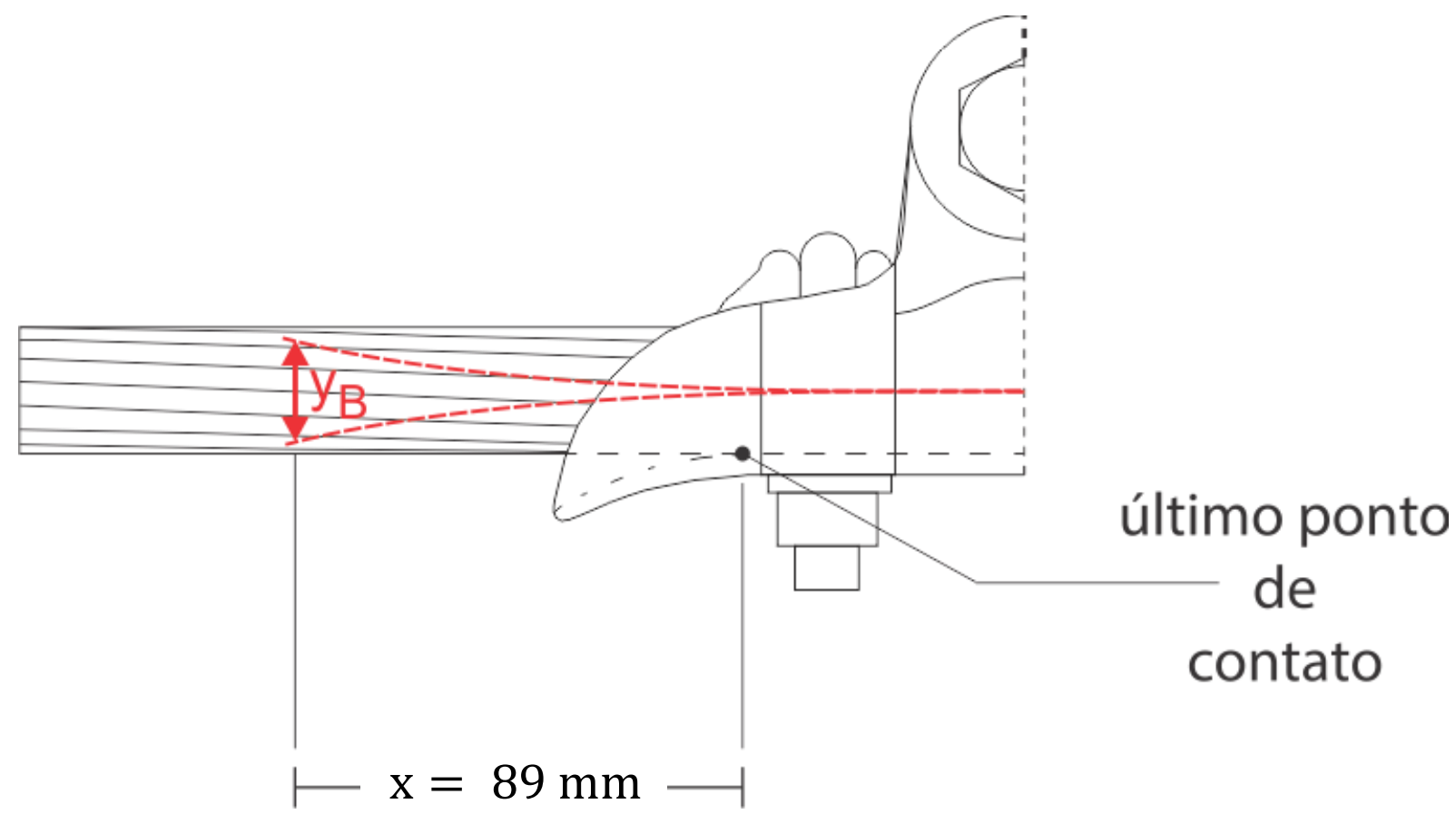

Fig. 3.16 - Deslocamento transversal do cabo, medida a $89 \mathrm{~mm}$ do último ponto de contato com o grampo.

A medida do deslocamento transversal especificamente nesta posição é necessária para que se possa calcular a amplitude de tensão (de zero a pico) observada nos fios da camada externa empregando a fórmula de Poffenberger-Swartz (1965):

$$
\sigma_{1 \mathrm{a}}=\mathrm{Ky}_{\mathrm{B}}
$$

onde:

$$
\begin{gathered}
\mathrm{K}=\frac{\mathrm{E}_{\mathrm{Al}} \mathrm{d}_{\mathrm{Al}} \mathrm{p}^{2}}{4\left(\mathrm{e}^{-\mathrm{px}}-1+\mathrm{px}\right)^{\prime}} \\
\mathrm{p}=\sqrt{\frac{\mathrm{F}_{\mathrm{EDS}}}{\mathrm{EI}}}
\end{gathered}
$$

e,

$$
\mathrm{EI}=\mathrm{n}_{\mathrm{Al}} \mathrm{E}_{\mathrm{Al}}\left(\frac{\pi \mathrm{d}_{\mathrm{Al}}^{4}}{64}\right)+\mathrm{n}_{\mathrm{aço}} \mathrm{E}_{\mathrm{aço}}\left(\frac{\pi \mathrm{d}_{\text {aço }}^{4}}{64}\right)
$$




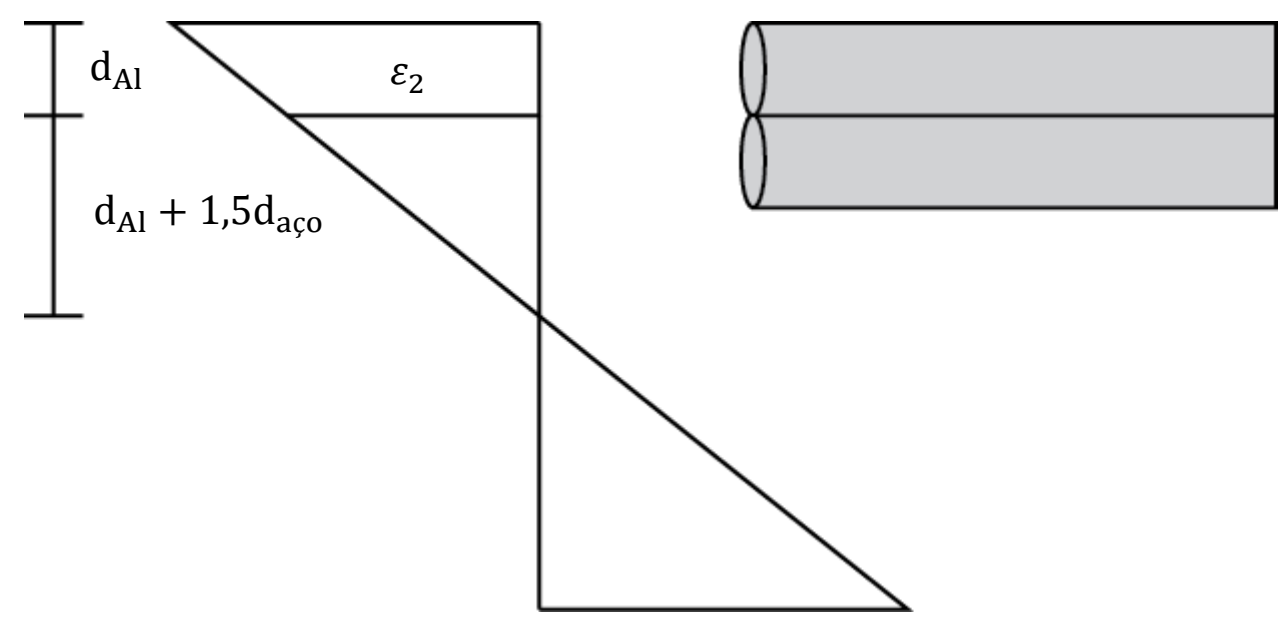

Fig. 3.17 - Relação entre deformações dos fios da primeira e da segunda camada.

A amplitude de tensão $\sigma_{2 \mathrm{a}}$ nos fios da segunda camada pode ser calculada considerando-se a hipótese de Bernoulli. Conforme se observa na Fig. 3.17, as amplitudes de deformação $\varepsilon_{1 \mathrm{a}}$ e $\varepsilon_{2 \mathrm{a}}$, respectivamente nos fios das camadas 1 e 2 , obedecem à relação:

$$
\frac{\varepsilon_{2 \mathrm{a}}}{\varepsilon_{1 \mathrm{a}}}=\frac{\mathrm{d}_{\mathrm{Al}}+\frac{3}{2} \mathrm{~d}_{\mathrm{aço}}}{2 \mathrm{~d}_{\mathrm{Al}}+\frac{3}{2} \mathrm{~d}_{\mathrm{aço}}} .
$$

As Eqs. 3.4 e 3.8 permitem, então, expressar a amplitude de tensão na segunda camada como,

$$
\sigma_{2 \mathrm{a}}=\left(\frac{\mathrm{d}_{\mathrm{Al}}+\frac{3}{2} \mathrm{~d}_{\mathrm{aço}}}{2 \mathrm{~d}_{\mathrm{Al}}+\frac{3}{2} \mathrm{~d}_{\mathrm{aço}}}\right) \sigma_{1 \mathrm{a}}
$$

Assim, com uso das Eqs. 3.4 e 3.9, as forças resultantes $F_{1 a}$ e $F_{2 a}$ aplicadas sobre os fios na primeira e segunda camadas são calculadas por meio das expressões:

$$
\mathrm{F}_{1 \mathrm{a}}=\mathrm{Ky}_{\mathrm{B}}\left(\frac{\pi \mathrm{d}_{\mathrm{Al}}^{2}}{4}\right)
$$

e

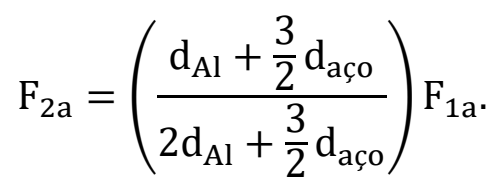


As Eqs. 3.10 e 3.11 fornecem os valores de $F_{1 a}=337 \mathrm{~N}$ para o fio da camada externa e $\mathrm{F}_{2 \mathrm{a}}=210 \mathrm{~N}$ para o fio da segunda camada.

Assim, a história de carregamento dos fios, representando a vibração do cabo, ilustrada na Fig. 3.18, pode ser expressa como:

$$
\begin{aligned}
& F_{1}(t)=367+337 \operatorname{sen}(\omega t) \quad[N] \\
& F_{2}(t)=372+210 \operatorname{sen}(\omega t)[N]
\end{aligned}
$$

Carregamento Cíclico Aplicado no Modelo Numérico

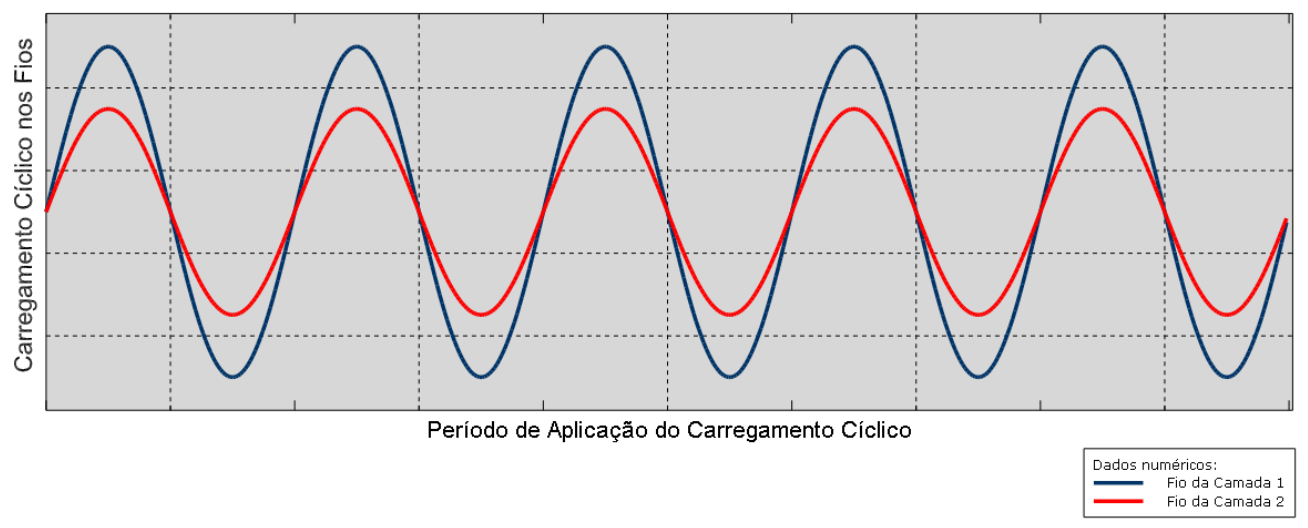

Fig. 3.18 - Carregamento cíclico aplicado aos fios do cabo IBIS. 


\section{SIMULAÇÕES NUMÉRICAS}

Neste capítulo, os resultados numéricos são apresentados e discutidos para o modelo simplificado de contato entre dois fios do cabo condutor IBIS. Todas as simulações foram realizadas no aplicativo Abaqus, baseado no método dos elementos finitos. As seguintes hipóteses foram consideradas:

- Cinemática das grandes deformações;

- Comportamento elastoplástico;

- Lei de atrito seco de Coulomb;

- Carregamentos quase-estáticos.

Ao longo do presente estudo, não se logrou convergência ao se considerar multiplicadores de Lagrange na imposição da condição de contato. Assim, o método da penalidade foi empregado para representar esta restrição.

A definição da geometria do sistema fios-grampo, do material e da história de carregamentos utilizou-se extensivamente dos scripts em linguagem Python que servem de interface de comunicação com o aplicativo Abaqus. $O$ Apêndice $D$ lista um script típico das simulações numéricas conduzidas no presente estudo.

\subsection{RECURSOS COMPUTACIONAIS}

Do ponto de vista computacional, os problemas simulados através do método dos elementos finitos são dependentes da quantidade de memória RAM disponível e da capacidade de processamento do computador utilizado nas simulações. Por causa desta limitação, somente foi possível utilizar malhas nas simulações com pouco menos de 400.000 elementos com o computador apresentado na Tabela 4.1.

Tabela 4.1 - Características do computador utilizado na análise numérica.

\begin{tabular}{ll}
\hline Componente & Descrição \\
\hline Processador & Intel i7 4770k - 4 Cores - 3,4 GHz \\
\hline Placa Gráfica & Nvidia Quadro k2200 - 4 GB GDDR5 \\
\hline GPU & Nvidia Tesla -6 GB GDDR5 \\
\hline Memória & 32 GB DDR 3 $-1333 \mathrm{MHz}$ \\
\hline Disco Rígido & SSD Kingston $-240 \mathrm{~GB}$ \\
\hline
\end{tabular}




\subsection{DISCRETIZAÇÃO}

A discretização dos fios, ilustrada na Fig. 4.1, define 156.352 elementos hexaédricos de oito nós no fio da camada 1 e 146.511 elementos no fio da camada 2. O sistema resultante é composto por cerca de 900 mil equações não lineares.

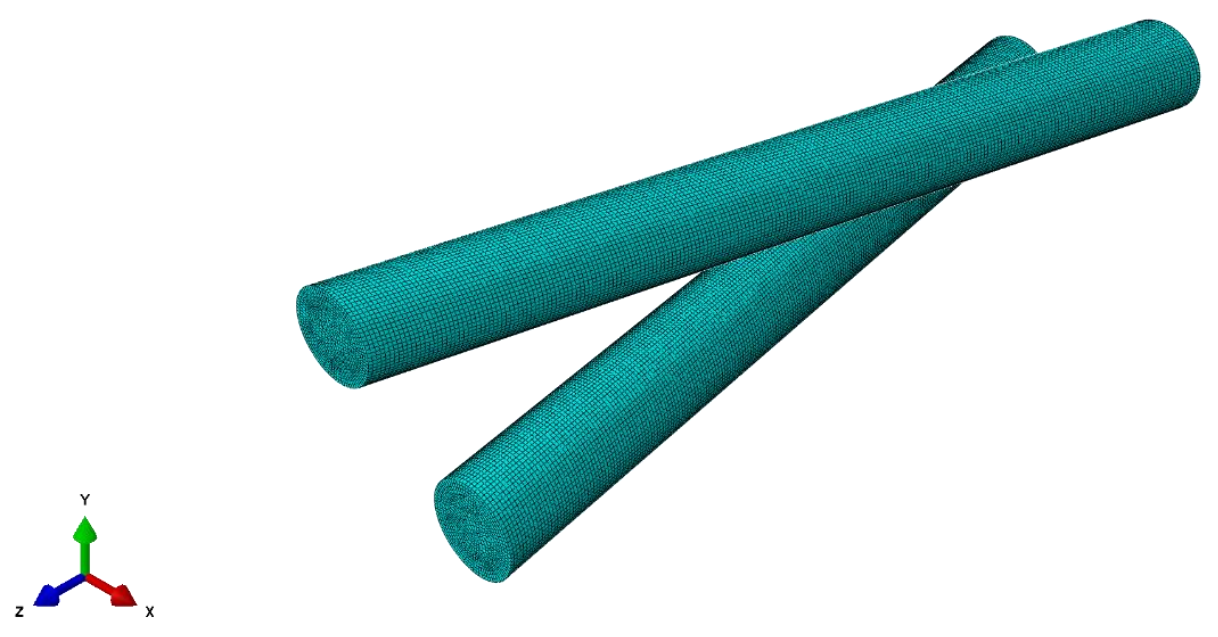

Fig. 4.1 - Discretização dos fios das camadas 1 e 2.

A integração reduzida foi adotada de modo a evitar o travamento espúrio associado às deformações plásticas (que evoluem a volume constante). Elementos finitos de maior ordem de aproximação não foram considerados porque estes estão associados a dificuldades na simulação da condição de contato entre superfícies. Por outro lado, a estratégia de integração reduzida resultou no surgimento de modos espúrios de deformação, parcialmente controlado por meio da adição de rigidez artificial - disponível no aplicativo Abaqus.

Para se obter um refinamento maior na região de contato, considerou-se também a submodelagem localizada do domínio em região próxima às superfícies de contato, ilustrada na Fig. 4.2: os campos de deslocamentos na interface entre o domínio original e o submodelo são impostos como condições de contorno para o problema local. A discretização do subdomínio definiu 210.489 elementos. Deve-se observar que tal estratégia permite a representação das superfícies de contato com um maior número de elementos a um custo computacional significativamente menor. 


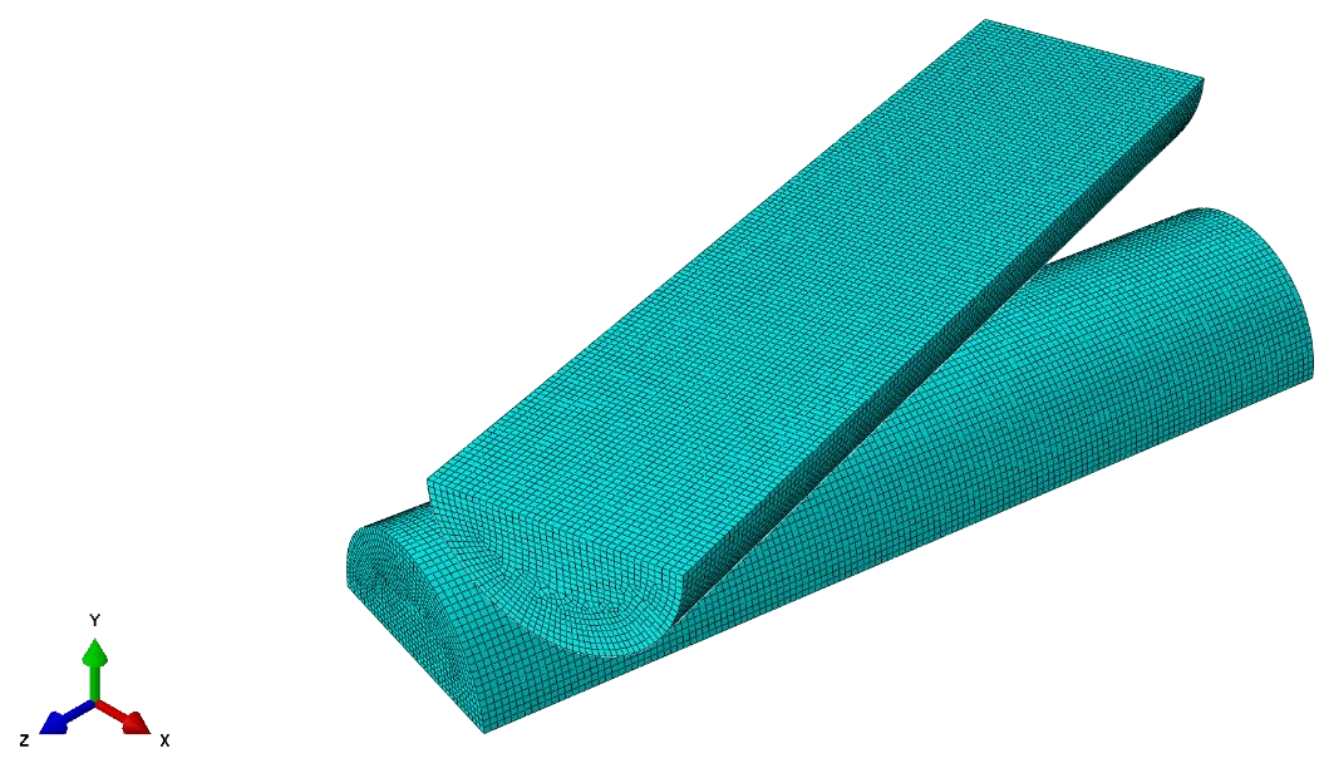

Fig. 4.2 - Discretização dos subdomínios dos fios.

\subsection{CARGA DE APERTO}

Esta seção apresenta os resultados da simulação numérica conduzida com objetivo de definir a carga de aperto entre os fios. Conforme descrito no capítulo anterior, tal carga deve produzir uma marca de contato dimensionalmente próxima à observada experimentalmente.

O tamanho da marca escolhida foi a gerada em laboratório para um cabo IBIS tracionado com $20 \%$ da EDS e apertado junto ao grampo de suspensão com carga sobre as porcas dos parafusos de $50 \mathrm{Nm}$. Após o carregamento descrito anteriormente, o cabo foi desmontado e o trecho pertencente a região do grampo foi cortado. Descascou-se a última camada de fios do condutor, apresentando as marcas de contato entre os fios conforme ilustrado na Fig. 4.3 medida com microscópio Confocal. Esta marca foi retirada próxima a saída do grampo, sendo uma das mais severas encontradas nesta região. 


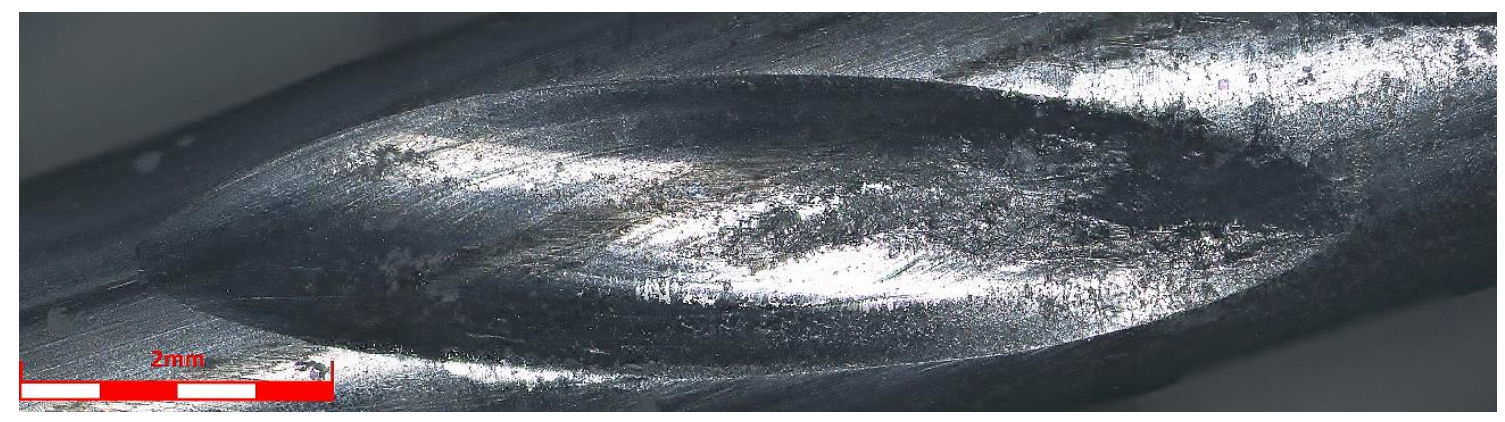

Fig. 4.3 - Marca analisada no Confocal.

As dimensões das marcas medidas para o formato elíptico observado na Fig. 4.3 foram de 7,84 mm para o eixo maior e 1,943 mm para o eixo menor. O critério de parada para a simulação realizada pelo script foi encerrar a simulação numérica quando uma das medidas obtidas estivesse próxima da observada com o Confocal com erro inferior a $5 \%$. O Abaqus obteve as dimensões de 7,62 mm para o eixo maior com erro próximo dos $4 \%$ e $1,515 \mathrm{~mm}$ para o eixo menor com erro superior a $20 \%$. Esta marca foi gerada por um deslocamento do bloco rígido de $0,602 \mathrm{~mm}$ e a relação entre o deslocamento prescrito no bloco e a força resultante aplicada é ilustrada na Fig. 4.4.

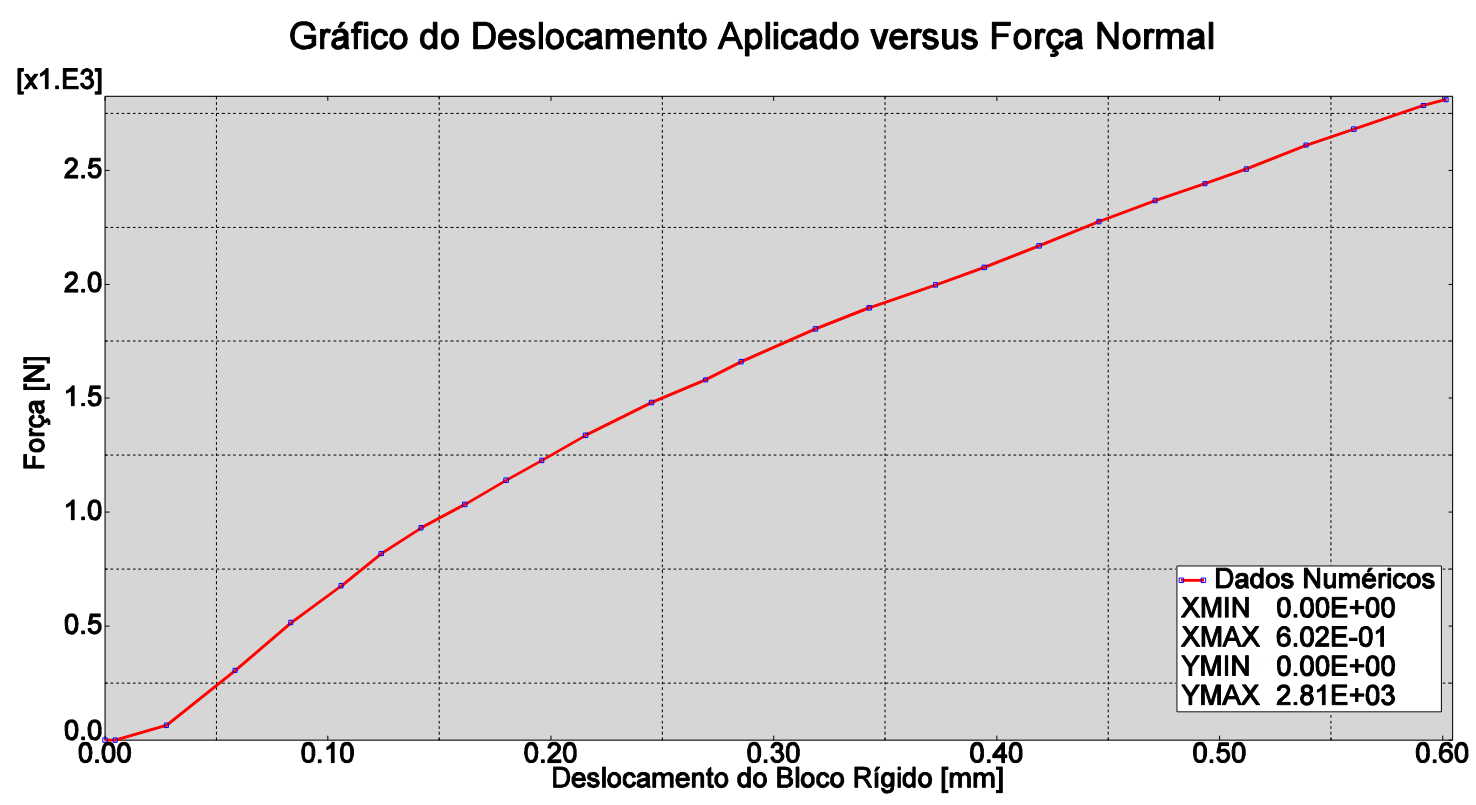

Fig. 4.4 - Relação entre o deslocamento aplicado ao bloco e a força equivalente aplicada aos fios em contato. 


\subsection{SIMULAÇÃO DO APERTO ENTRE FIOS}

A Fig. 4.5 apresenta a região de contato resultante da aplicação de $2810 \mathrm{~N}$ sobre o par de fios. A simulação numérica produziu uma marca de contato com medidas $\mathrm{b}=7,62 \mathrm{~mm}$ para o maior eixo e $\mathrm{c}=1,52 \mathrm{~mm}$ para o eixo menor. A Tabela 4.2 compara estas medidas com aquelas observadas experimentalmente.

Tabela 4.2 - Dimensões da marca: experimental e simulada.

\begin{tabular}{lccc}
\hline & Experimental & Simulação & Erro (\%) \\
\hline eixo maior b $[\mathrm{mm}]$ & 7,84 & 7,62 & 2,81 \\
\hline eixo menor c $[\mathrm{mm}]$ & 1,94 & 1,51 & 22,2 \\
\hline
\end{tabular}

Na figura, é possível notar o formato elíptico da marca obtida em ambos os modelos apresentados. No caso do submodelo apresentado na Fig. 4.5.b, a marca e a distribuição de pressão apresentam mais detalhes do que no caso do modelo global da Fig. 4.5.a.

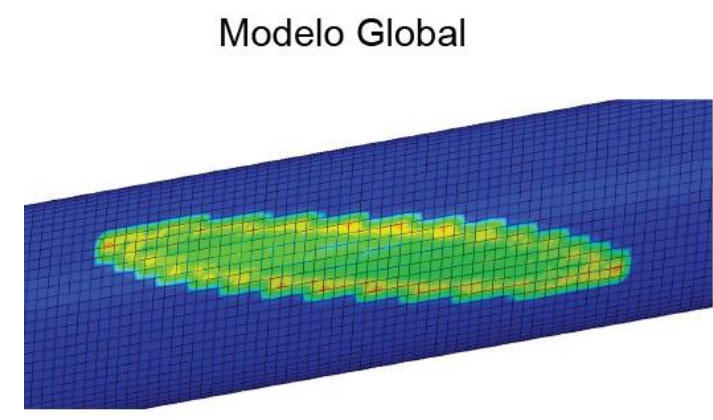

(a)

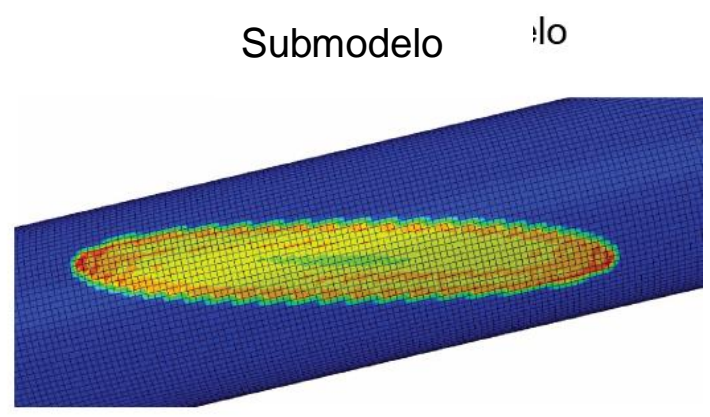

(b)

Fig. 4.5 - Campo de pressão na região de contato no fio mais externo do cabo condutor IBIS resultante: (a) da simulação do modelo global; (b) da simulação do submodelo.

Realizaram-se mais duas simulações, aplicando-se cargas de aperto iguais a $25 \%$ e $50 \%$ do valor originalmente considerado. Este procedimento foi realizado com objetivo de obter três marcas com tamanhos diferentes conforme os resultados apresentados na Tab.4.3. 
Tabela 4.3 - Dimensões medidas para marcas geradas por diferentes deslocamentos do bloco

\begin{tabular}{ccccc}
\hline $\begin{array}{c}\text { Deslocamento do } \\
\text { bloco }[\mathrm{mm}]\end{array}$ & $\begin{array}{c}\text { Força } \\
\text { aplicada }[\mathrm{N}]\end{array}$ & $b[\mathrm{~mm}]$ & $c[\mathrm{~mm}]$ & $c / b$ \\
\hline $0,1505=0,25 d$ & 1018 & 3,86 & 0,861 & 0,223 \\
\hline $0,301=0,5 d$ & 1773 & 5,47 & 1,07 & 0,195 \\
\hline $0,602=d$ & 2810 & 7,62 & 1,52 & 0,199 \\
\hline
\end{tabular}

A Fig. 4.6 ilustra a evolução da marca de contato em função da carga de aperto.

(a)

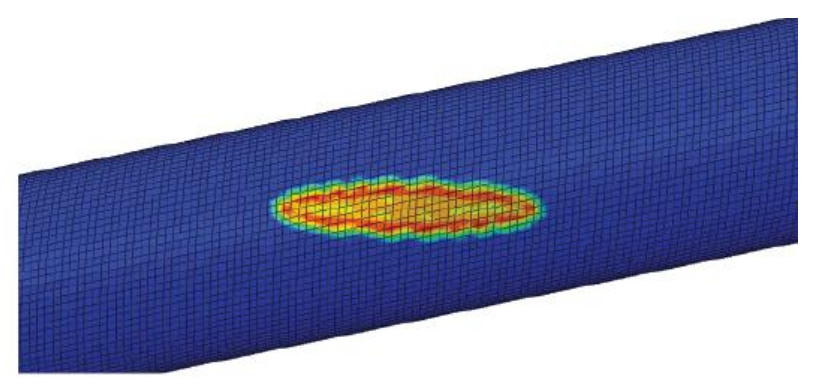

(b)

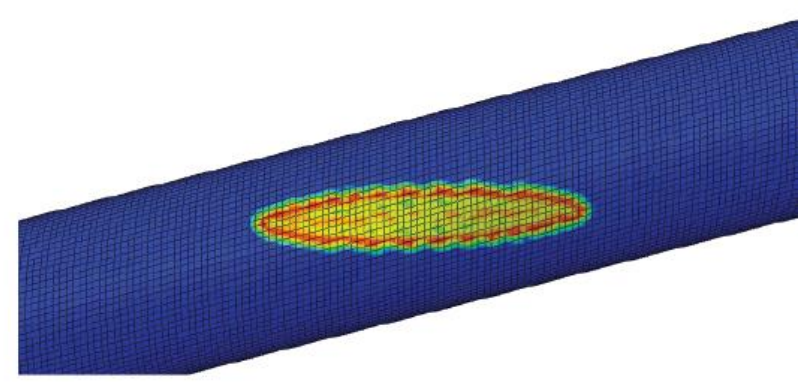

(c)

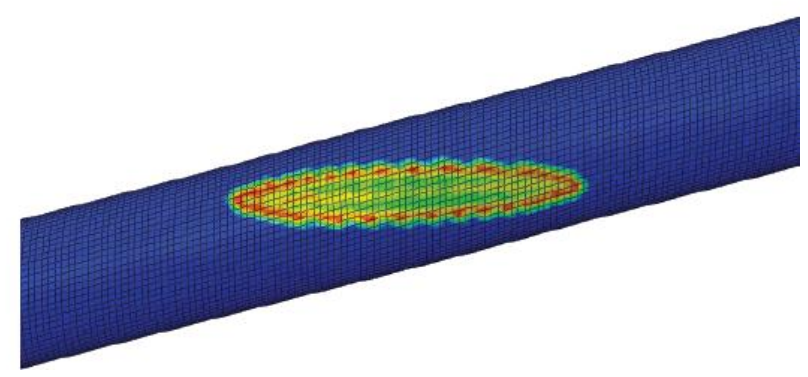

Fig. 4.6 - Marcas geradas na região de contato entre os fios para as cargas de: (a) $1018 \mathrm{~N},(\mathrm{~b}) 1773 \mathrm{~N}$ e (c) $2810 \mathrm{~N}$.

Os gráficos ilustrados em Figs. 4.7 e 4.8 relacionam o tamanho dos eixos da marca elíptica observada nos fios com a força aplicada pelo bloco rígido. 


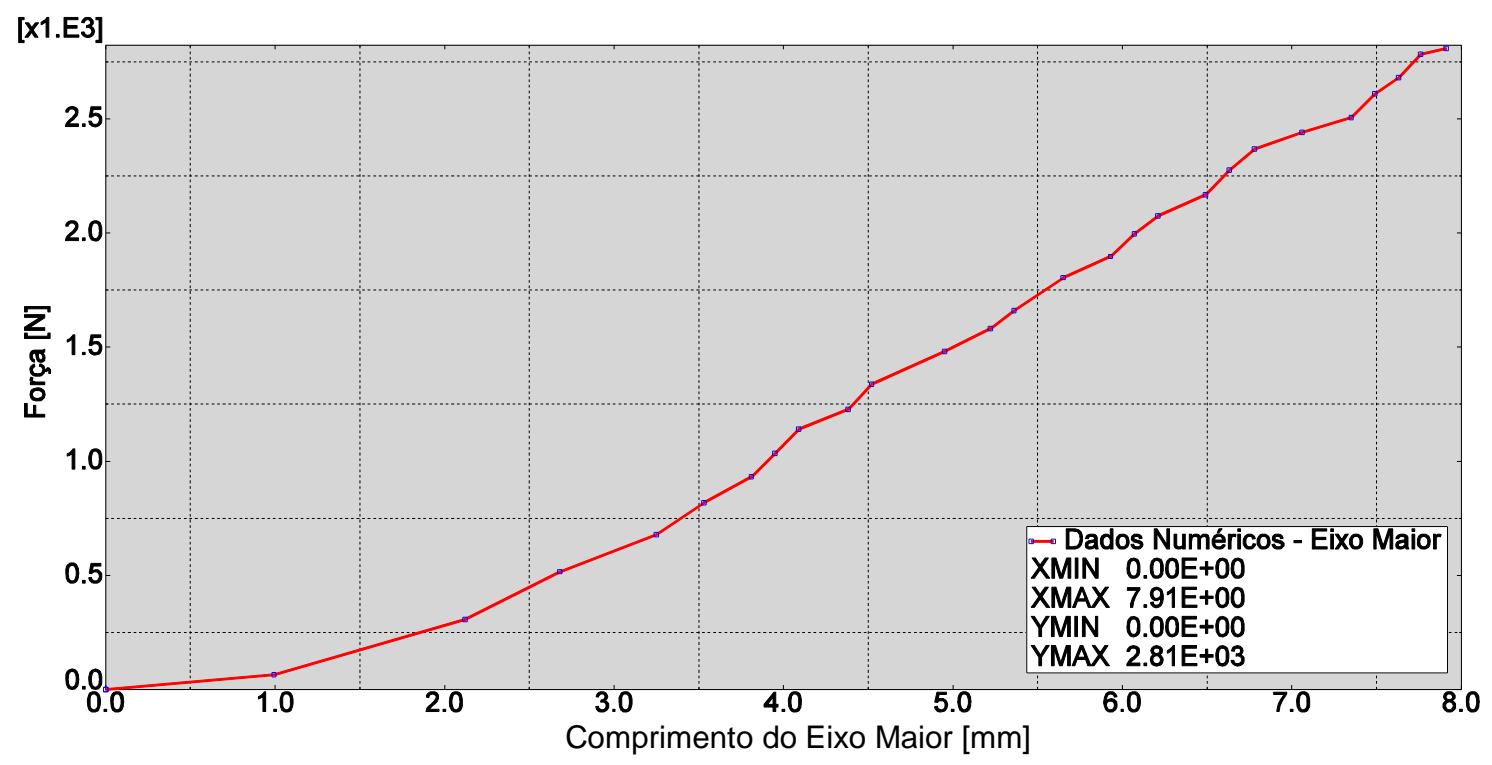

Fig. 4.7 - Relação entre a medida da marca no eixo maior e a força aplicada sobre os fios em contato.

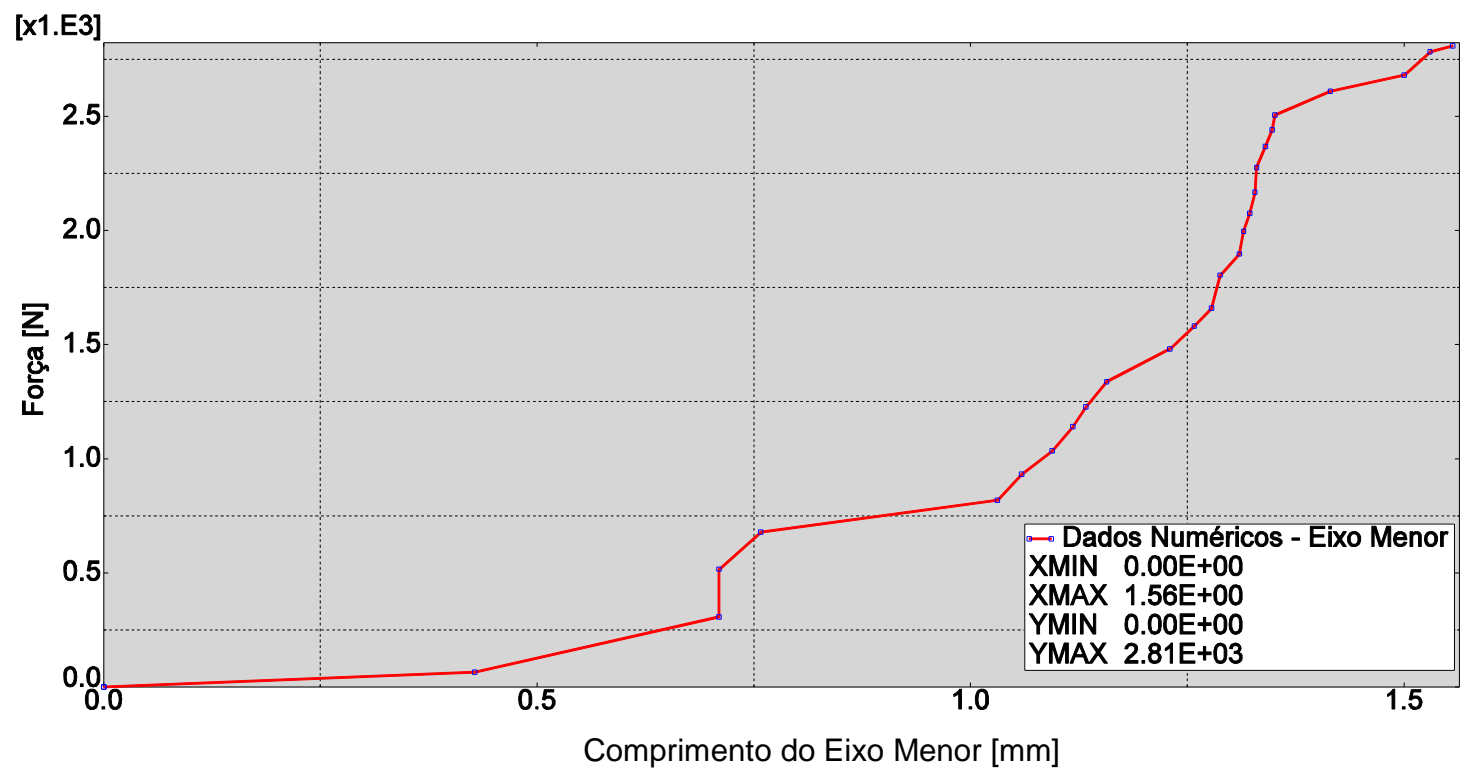

Fig.4.8 - Relação entre a medida da marca no eixo menor e a força aplicada sobre os fios em contato.

$\mathrm{Na}$ Fig. 4.8, a evolução tamanho do eixo menor com aumento da força de aperto mostra-se irregular devido ao baixo nível de discretização da malha na direção circunferencial do fio. 
Outra consideração a ser feita sobre a região de contato é como duas marcas de contato côncavas entram em contato. Na Fig. 4.9, a marca do contato entre os dois fios é apresentada em cortes da sua seção transversal ilustrada pelas linhas amarelas pontilhadas sobre a foto do Confocal. Pode-se notar que à medida em que se desloca na direção longitudinal do fio (eixo $x$ indicado na figura), a região de contato é representada por uma linha reta cuja a inclinação muda em função da coordenada $x$. Portanto, a marca define uma superfície regrada em que os fios sempre permanecem em contato.
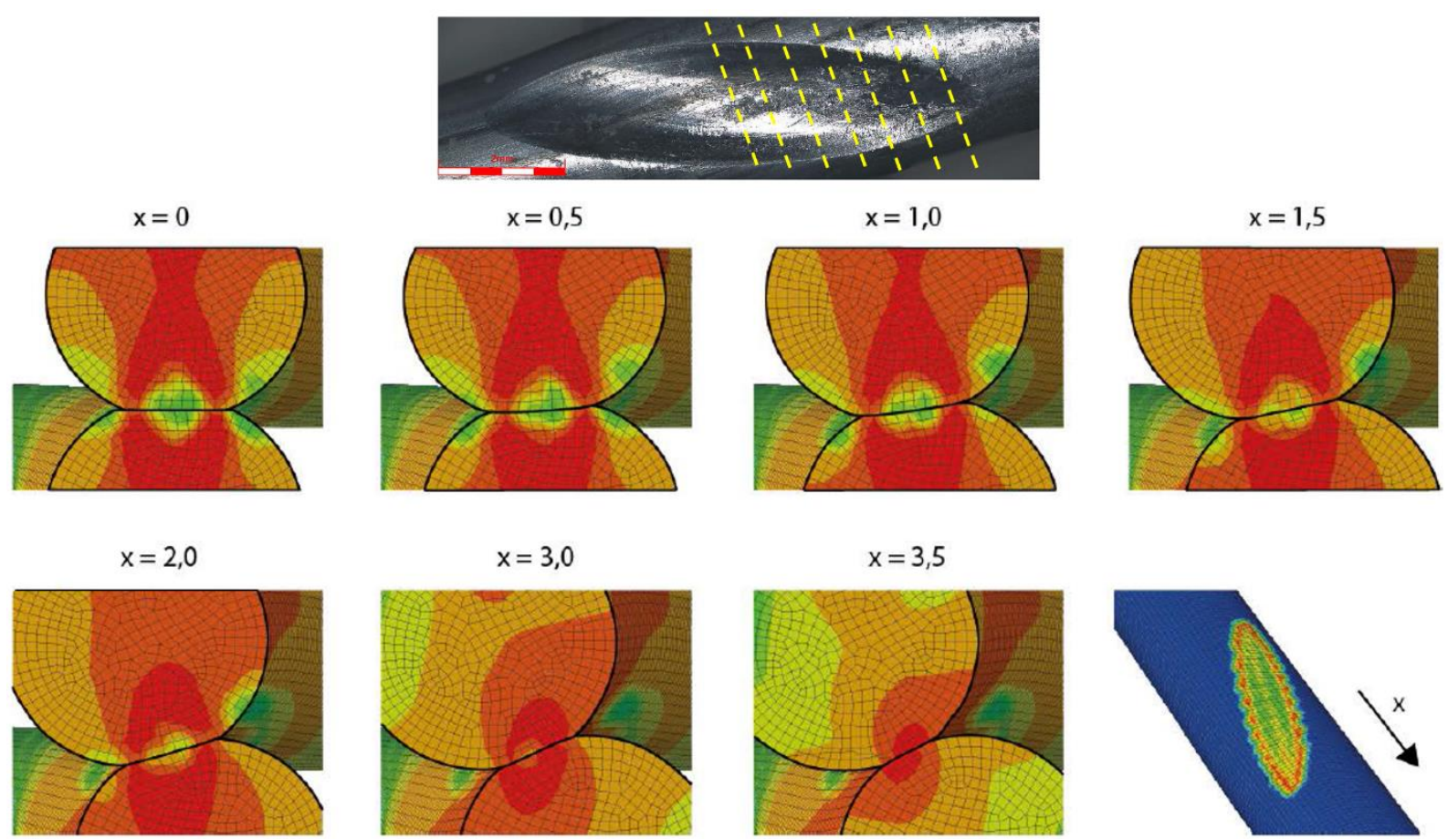

Fig. 4.9 - Cortes transversais dos fios na região de contato, ao longo do eixo x.

As análises desta seção são realizadas somente para o caso de aperto aplicado pelo bloco rígido aos fios do cabo IBIS.

As Figs. 4.10 e 4.11 apresentam a distribuição da pressão de contato, na região de contato e para o fio da camada externa, considerando o modelo global e o submodelo. 


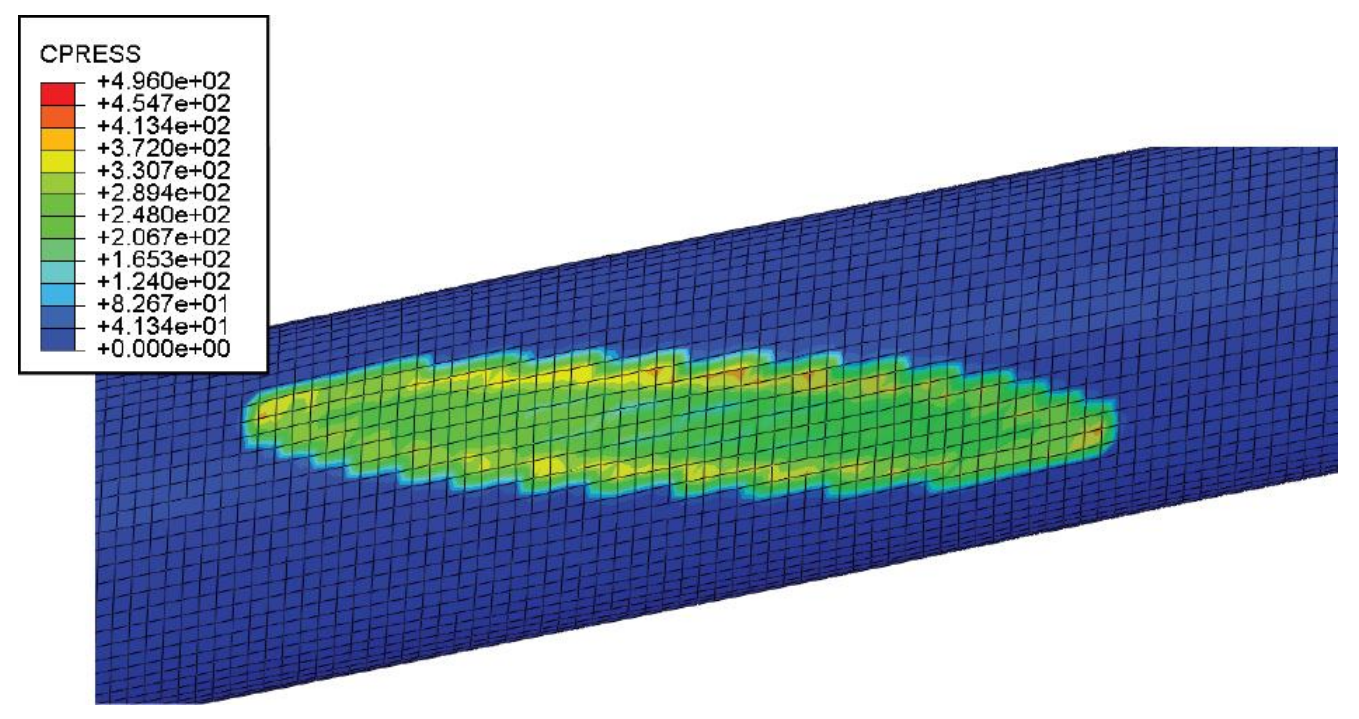

Fig. 4.10 - Distribuição da pressão de contato sobre o fio da camada 1 no modelo global.

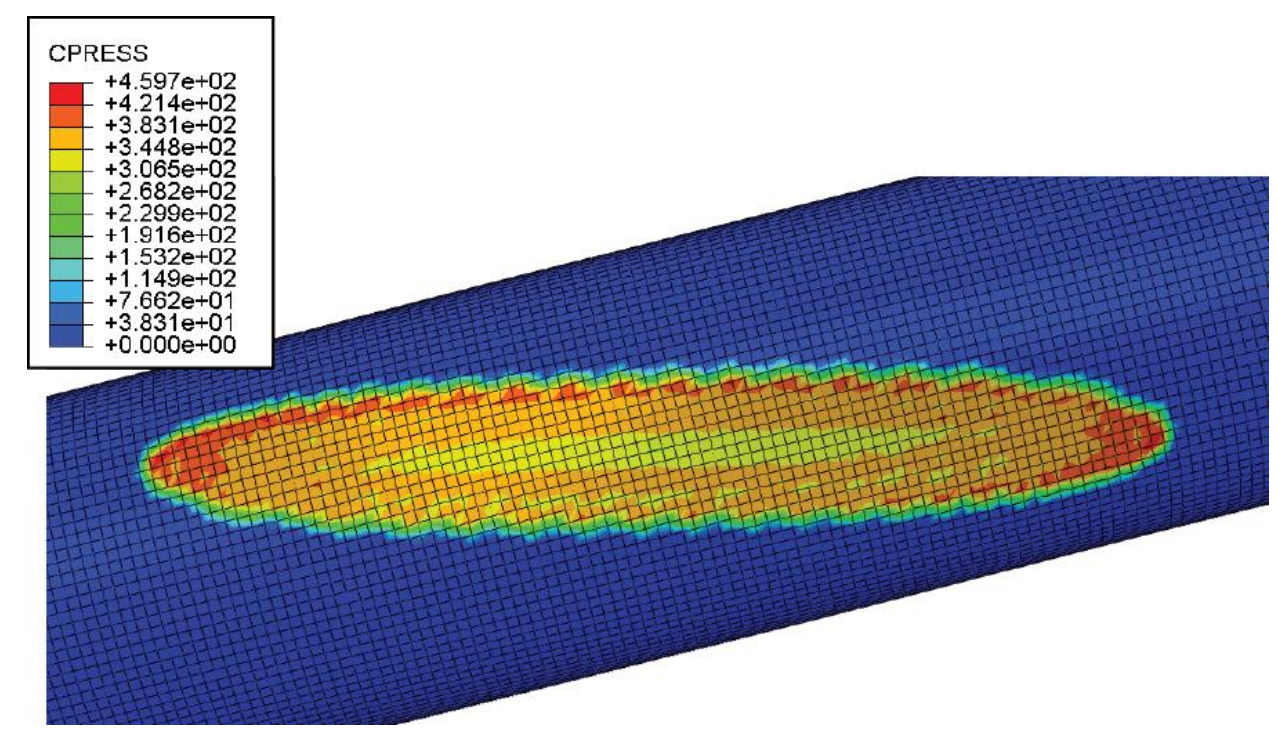

Fig. 4.11 - Distribuição da pressão de contato sobre o fio da camada 1 no submodelo.

A Fig. 4.12 apresenta os caminhos ao longo da marca de contato do fio da camada 1 considerados para a descrição das distribuições da pressão de contato exibidas nas Figs. 4.13 e 4.14 . 


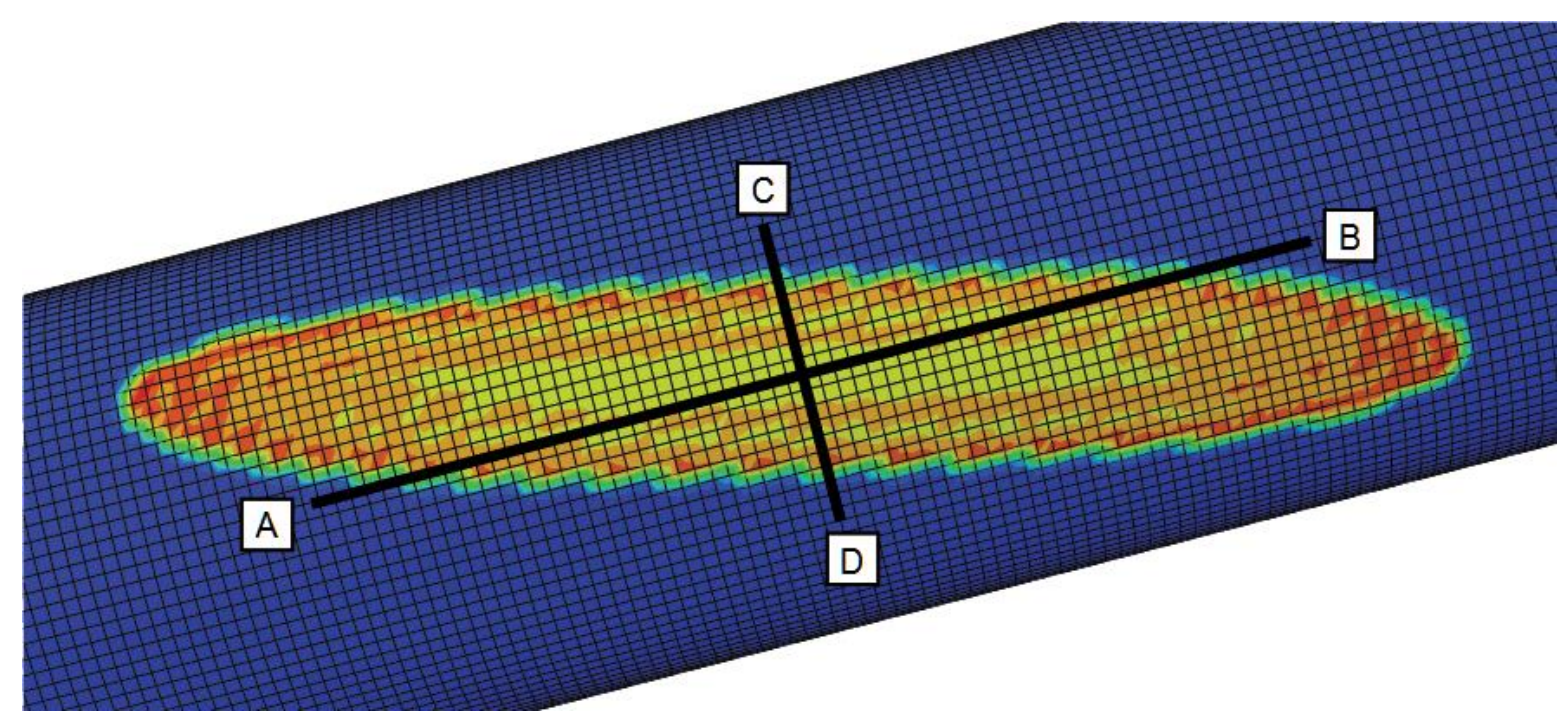

Fig. 4.12 - Caminhos considerados para as descrições das distribuições da pressão de contato nas Figs. 4.12 e 4.13.

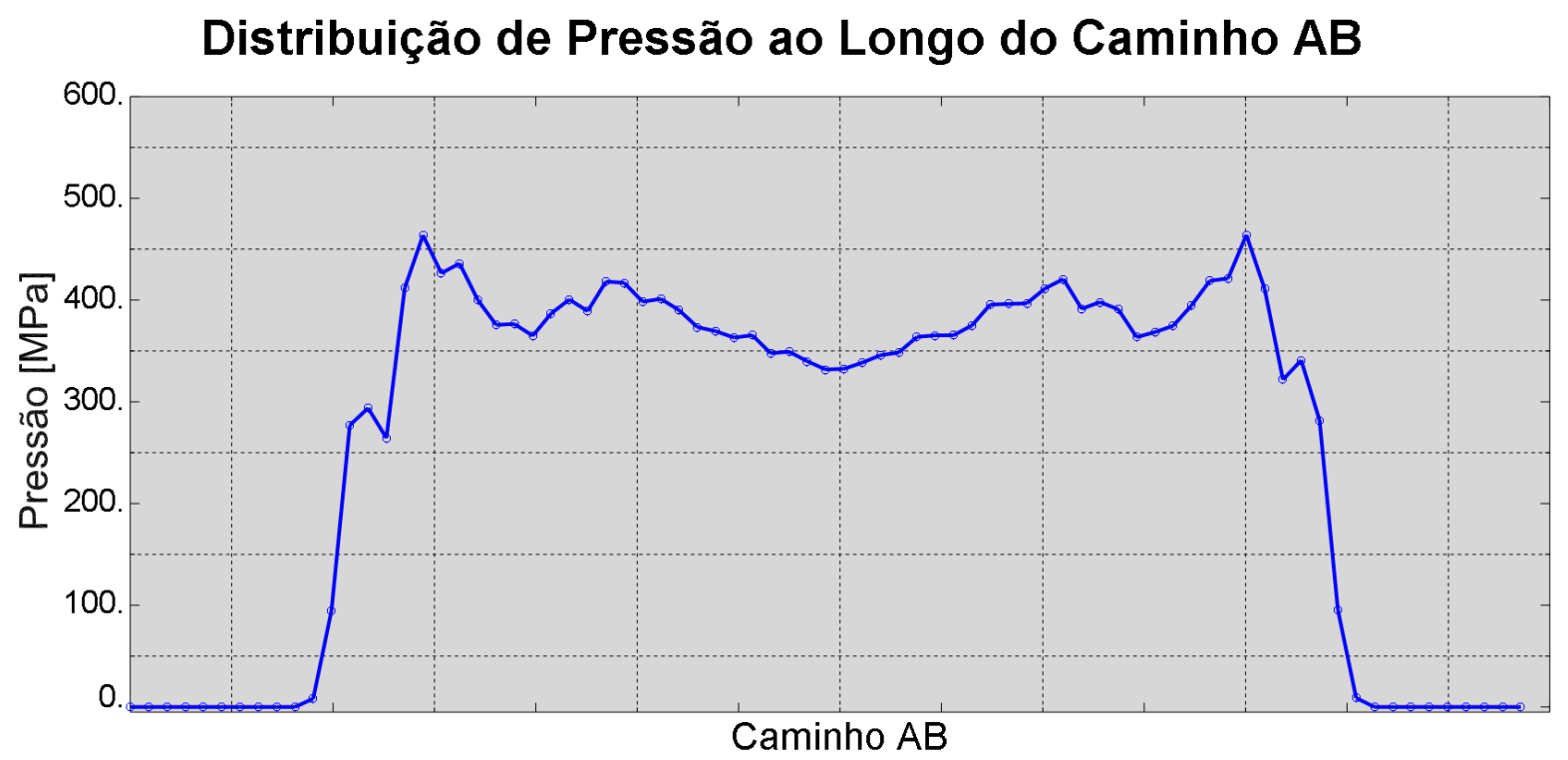

Fig. 4.13 - Distribuição da pressão de contato sobre o fio da camada 1 ao longo do caminho AB da Fig.4.12. 


\section{Distribuição de Pressão ao Longo do Caminho CD}

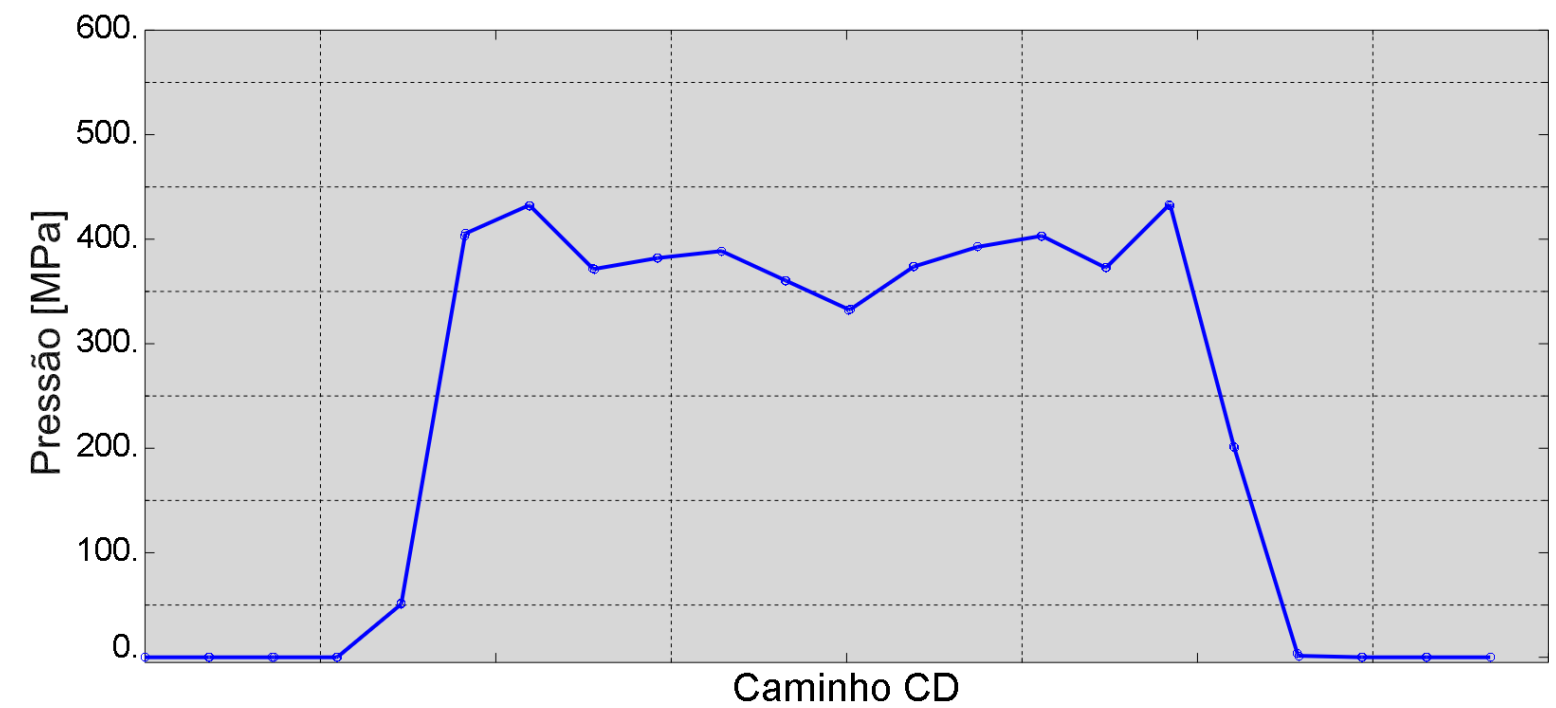

Fig. 4.14 - Distribuição da pressão de contato sobre o fio da camada 1 ao longo do caminho CD da Fig.4.12.

Tais distribuições de pressão exibem deficiência associada ao baixo nível de discretização do domínio. Para ilustrar o nível de refinamento que seria necessário para uma descrição satisfatória do campo de pressões, apresenta-se, a seguir, uma simulação numérica do contato entre dois fios paralelos, descritos no contexto bidimensional. A carga de pressão entre os dois fios considerada no exemplo bidimensional é tal que a região de contato tem a mesma dimensão que a do eixo menor da marca do problema tridimensional. Na Fig.4.15, diferentes discretizações são apresentadas para os fios na configuração não deformada, enquanto a Fig.4.16 apresenta as malhas na configuração deformada. As regiões dos contornos dos fios passível de contato possuem 40, 80 e 160 elementos respectivamente nas Figs. 4.15.A, 4.15.B e 4.15.C. 


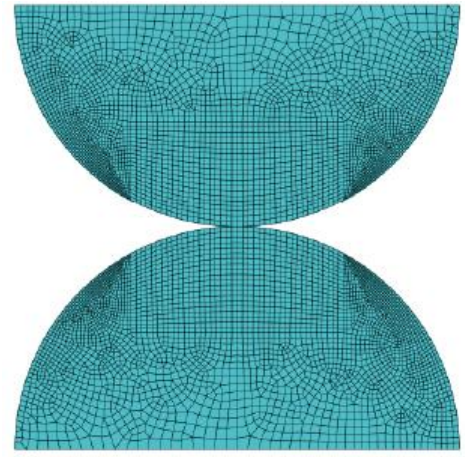

(A)

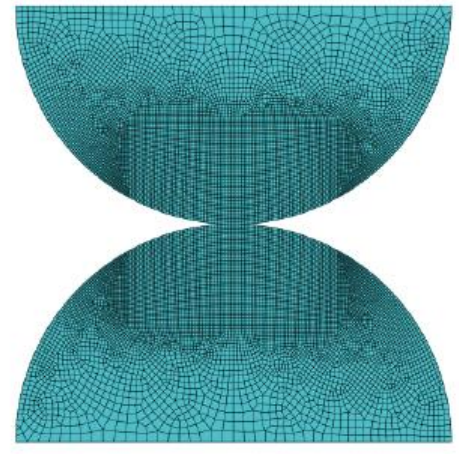

(B)

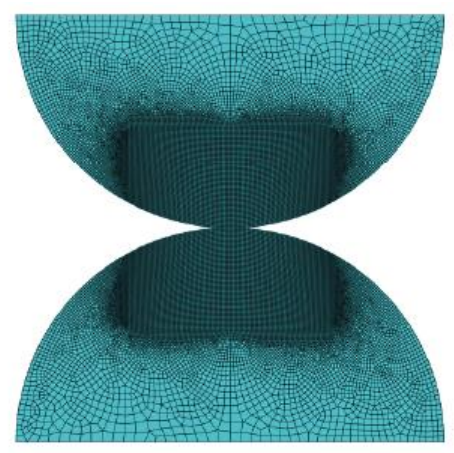

(C)

Fig. 4.15 - Discretizações consideradas para a descrição bidimensional do problema de contato.

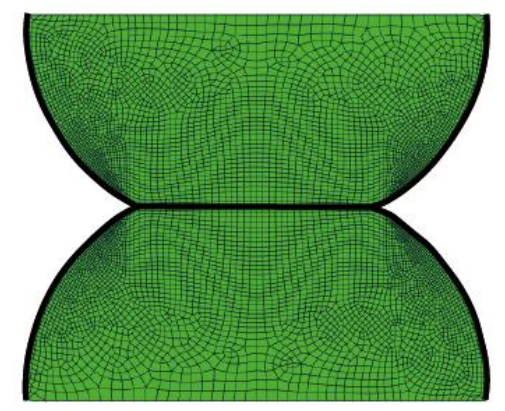

(A)

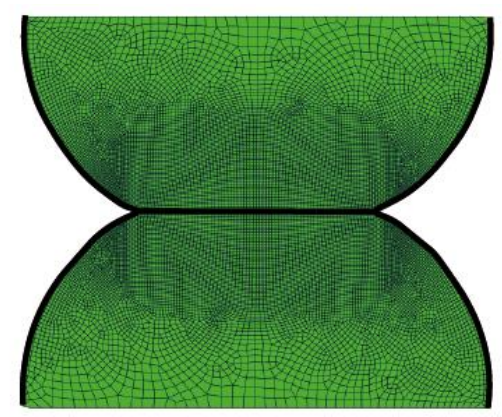

(B)

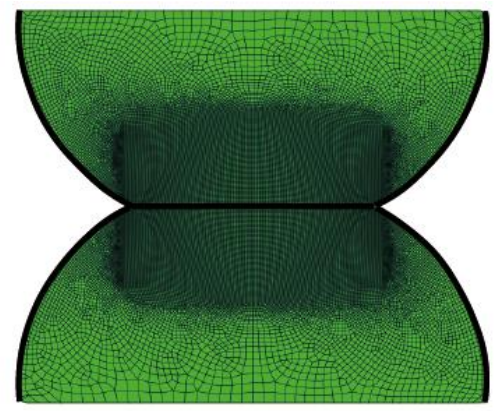

(C)

Fig. 4.16 - Contato entre os fios resultante da aplicação da carga de aperto, exibindo nível elevado de deformações elastoplásticas e região de contato pronunciada.

O gráfico da Fig. 4.17 apresenta a distribuição de pressão para as diferentes discretizações ilustradas na Fig.4.15. 


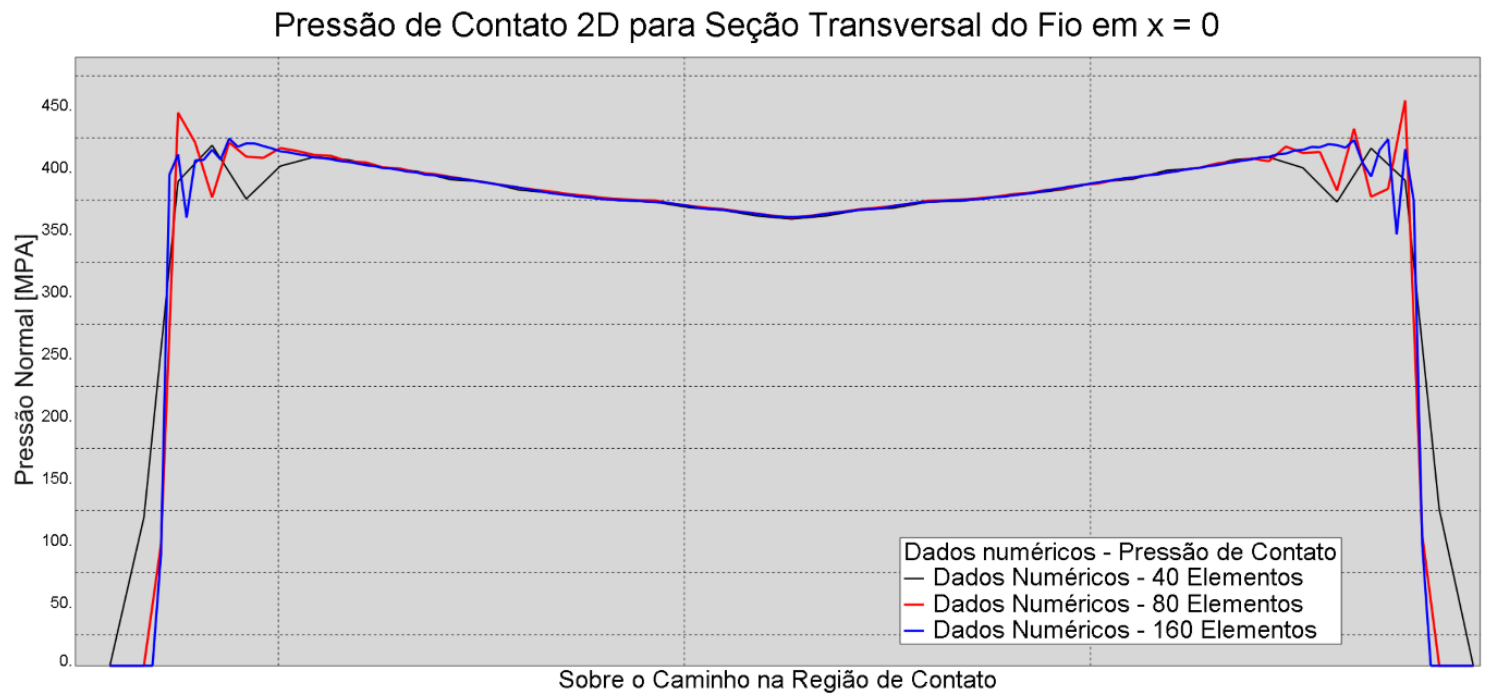

Fig. 4.17 - Distribuição de pressão entre fios descritos no contexto bidimensional.

Na Fig. 4.17, é possível observar uma oscilação nas extremidades da região de contato para todas as discretizações. À medida que o refinamento da região de contato aumenta, as oscilações reduzem obtendo resultados melhores. A comparação destes resultados com aqueles exibidos na Fig. 4.14 permite detectar alguma semelhança no perfil de pressões, mas com qualidade significativamente maior devido ao nível de discretização mais refinado.

A Fig. 4.18 apresenta a distribuição das tensões tangenciais na superfície de contato no fio da camada superior, resultante da carga de aperto.

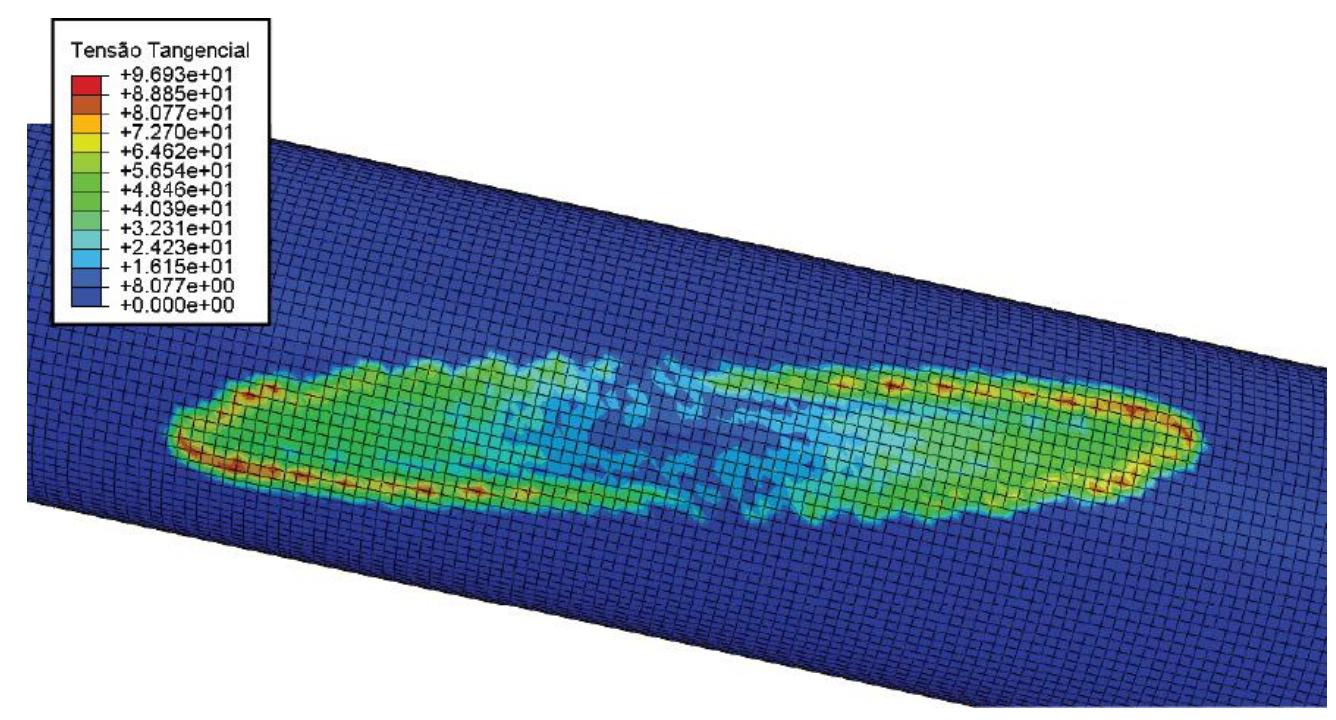

Fig. 4.18 - Distribuição das tensões tangenciais sobre a superfície do fio da camada 1 , devido a carga de aperto. 
Os gráficos das Figs. 4.19 e 4.20 apresentam a distribuição da tensão tangencial ao longo dos caminhos $A B$ e $C D$, respectivamente.

Tensão Tangencial ao Longo de AB

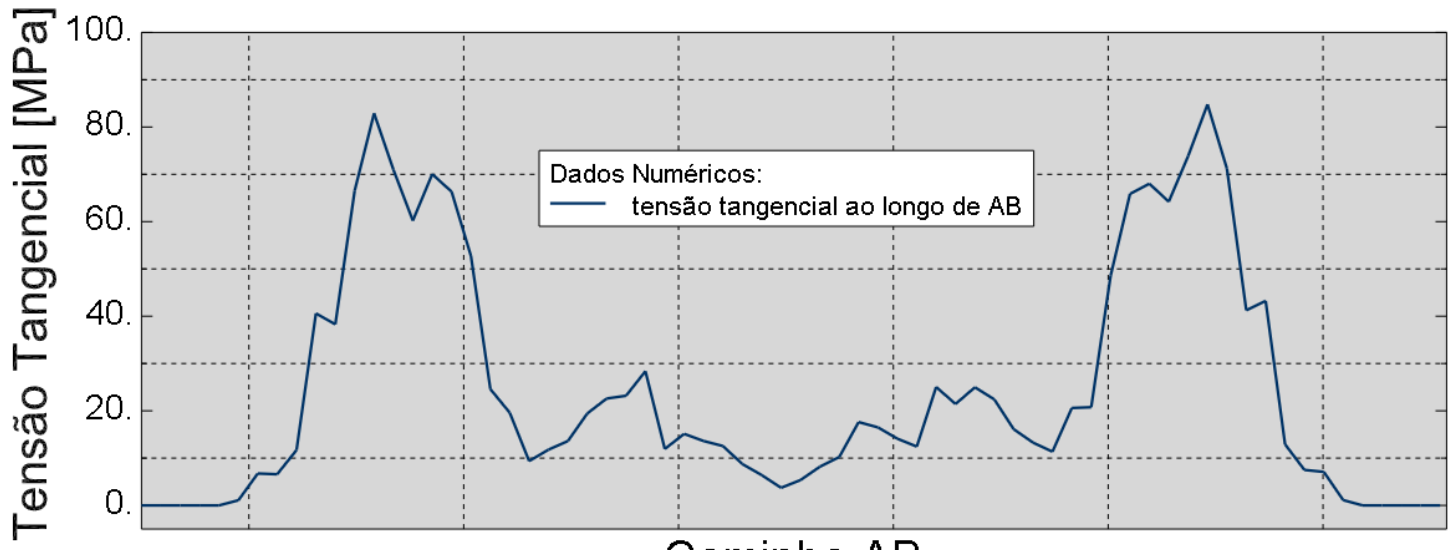

Caminho AB

Fig. 4.19 - Distribuição de tensão tangencial sobre a superfície do fio da camada 1 ao longo do caminho $A B$.

Tensão Tangencial ao Longo de CD

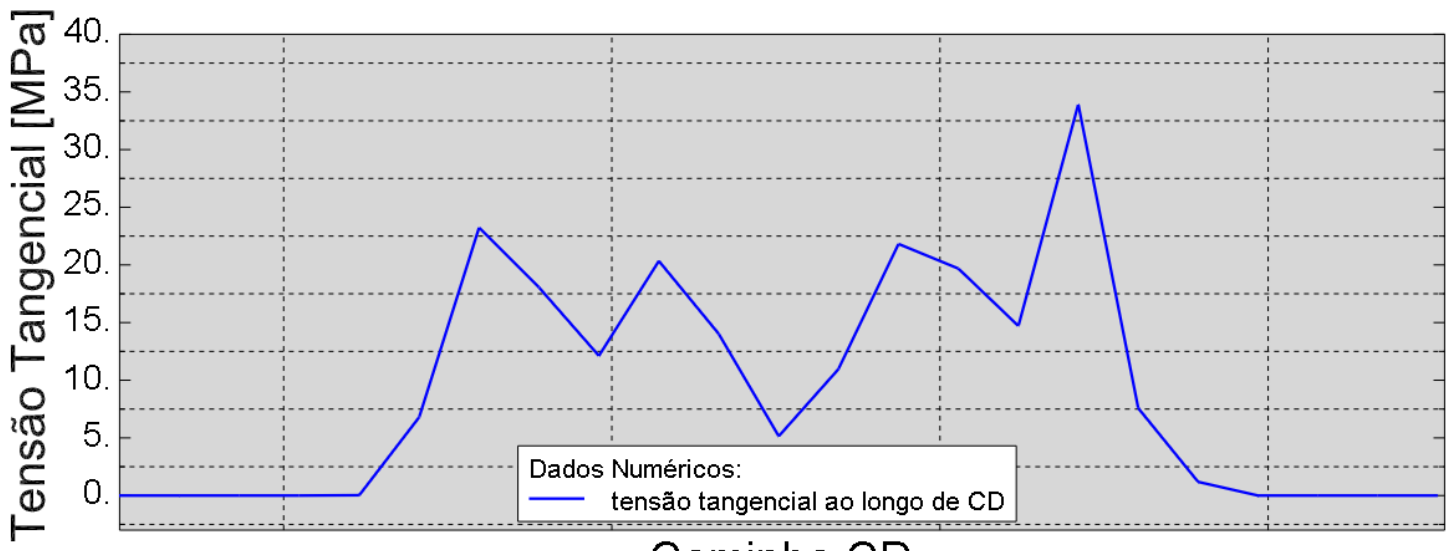

Caminho CD

Fig. 4.20 - Distribuição de tensão tangencial sobre a superfície do fio da camada 1 ao longo do caminho CD.

Observa-se que as tensões tangenciais, devido ao atrito, são maiores nas bordas da região de contato. Entretanto, as oscilações observadas revelam um nível insuficiente de discretização. Observe-se que, em função do equipamento computacional disponível, refinamentos maiores não puderam ser considerados. 


\subsection{SIMULAÇÃO DO CARREGAMENTO CÍCLICO}

Nesta seção, são apresentadas as distribuições de pressão, tensões tangenciais e tensões de Mises na superfície do fio da camada 1, nos instantes de carregamento indicados pelas letras A, B e C da Fig. 4.21.

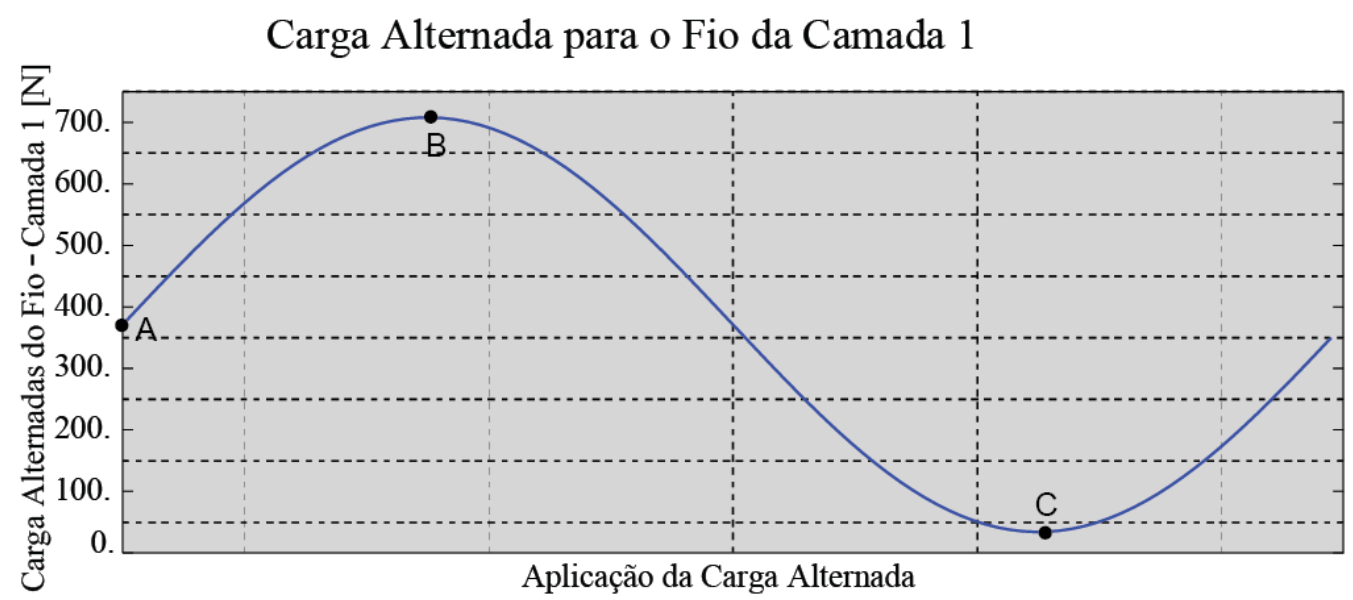

Fig. 4.21 - Carregamento alternado aplicado ao fio da camada 1.

As Figs. 4.22, 4.23 e 4.24 apresentam a distribuição da pressão na região de contato do fio da camada 1.

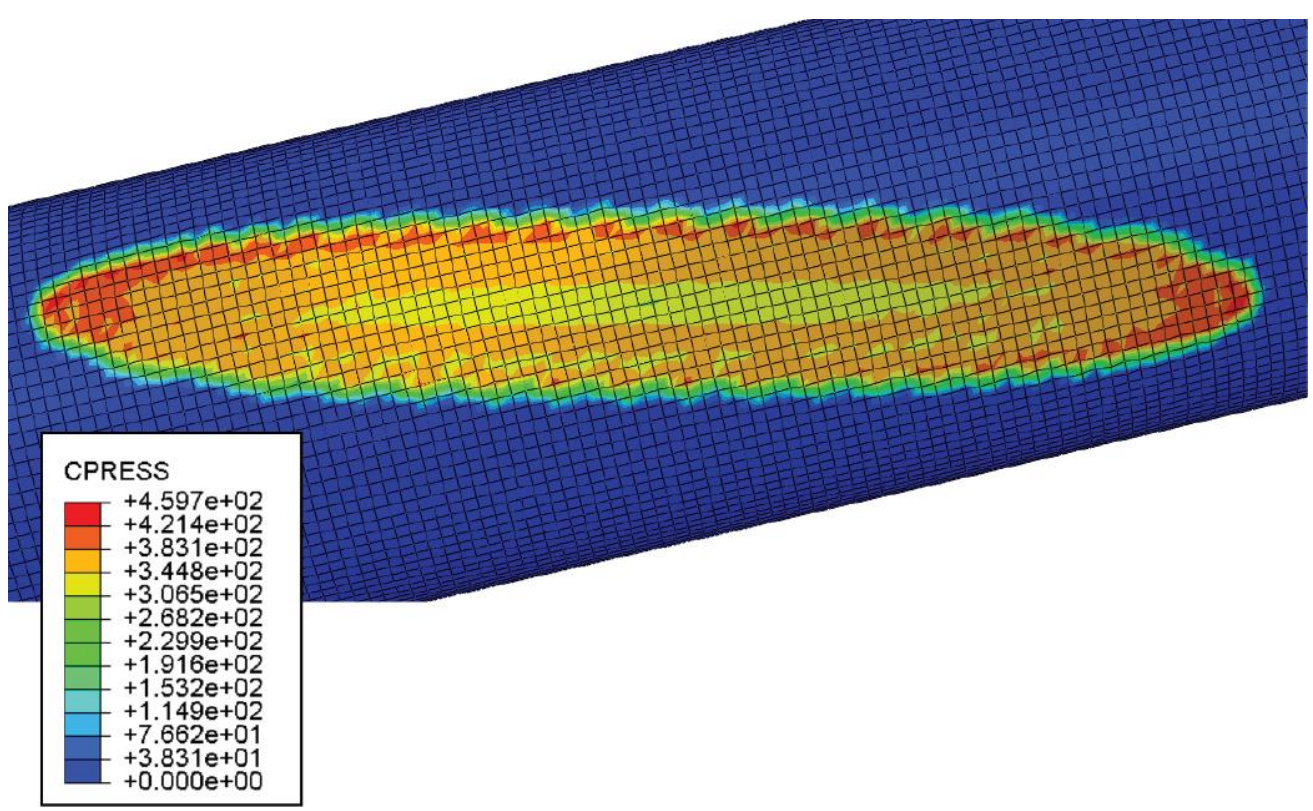

Fig. 4.22 - Pressão de contato sob carregamento indicado pelo ponto A da Fig.4.21. 


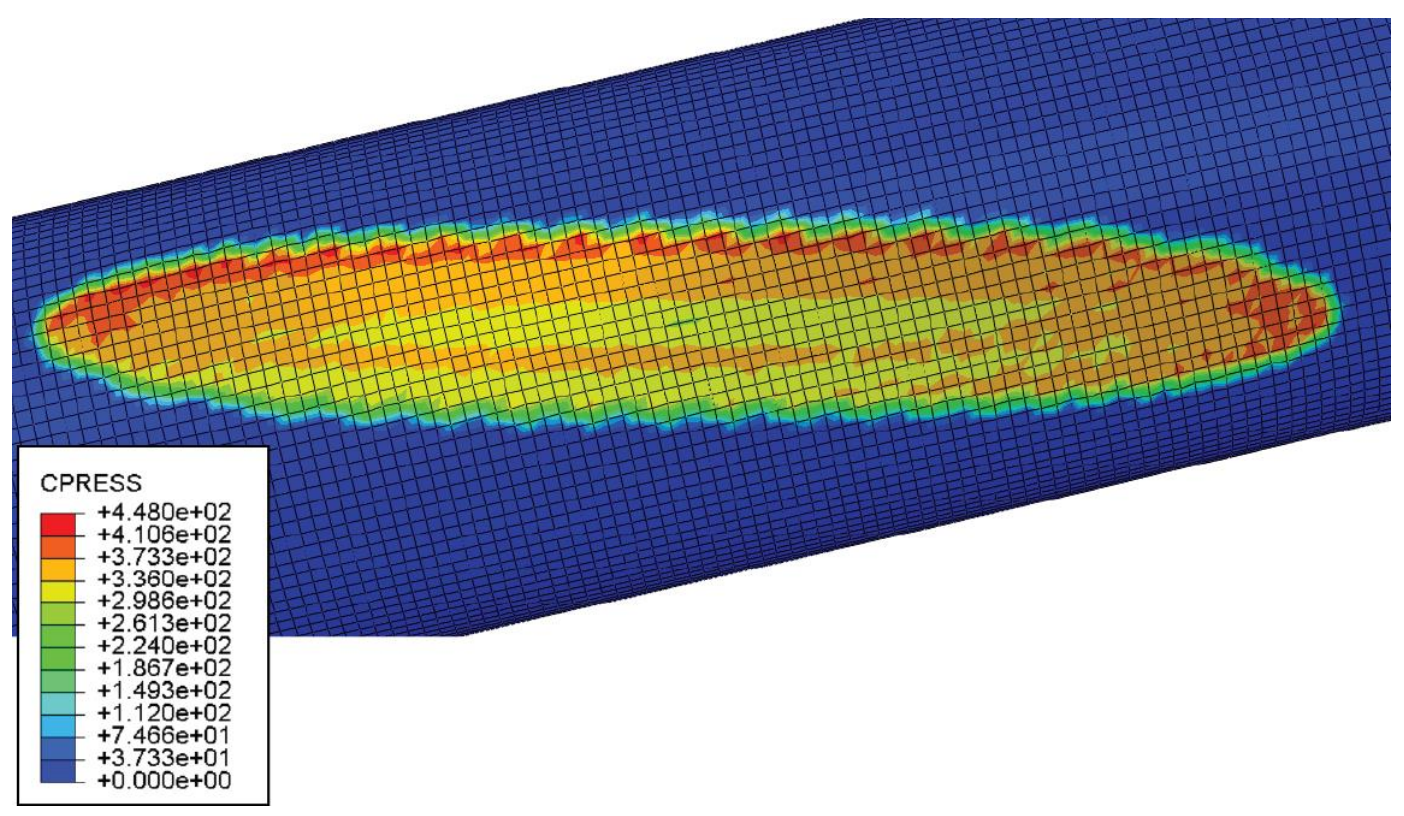

Fig. 4.23 - Pressão de contato sob carregamento indicado pelo ponto B da Fig. 4.21.

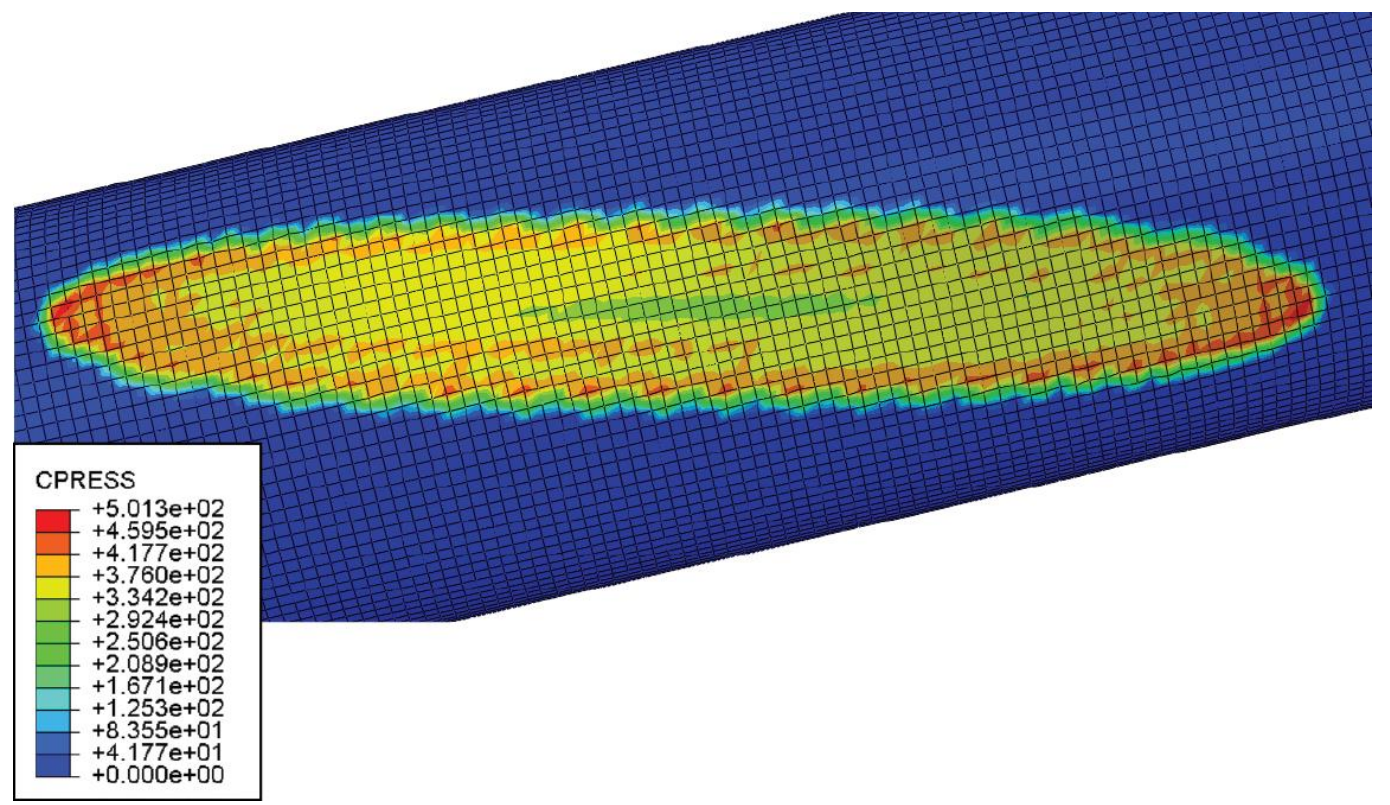

Fig. 4.24 - Pressão de contato sob carregamento indicado pelo ponto C da Fig. 4.21.

A Fig. 4.25 apresenta a distribuição de pressão de contato ao longo da direção longitudinal da marca, nos instantes $\mathrm{A}, \mathrm{B}$ e $\mathrm{C}$ do carregamento alternado. 


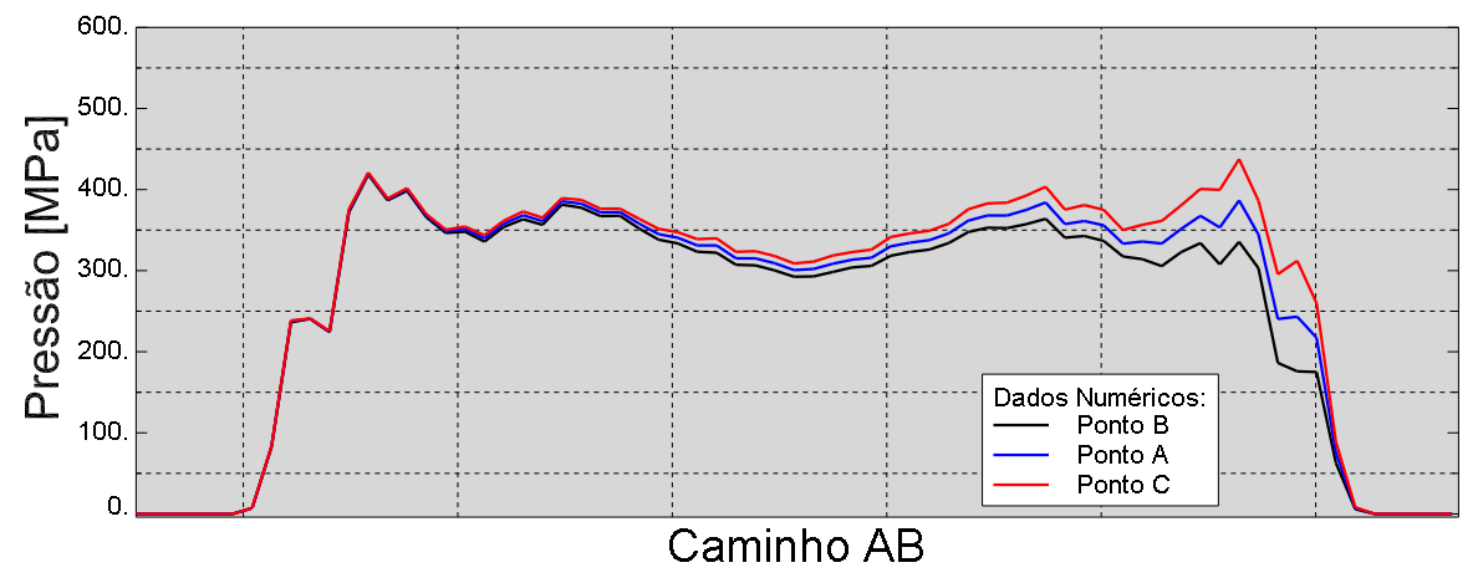

Fig. 4.25 - Distribuição da pressão ao longo da direção longitudinal da marca, para os instantes A, B e C do carregamento cíclico (Fig. 4.21).

É possível observar que a pressão de contato sofre alguma variação na extremidade da região de contato mais afastada do grampo. Tal variação é devido ao efeito de Poisson sofrida pelo fio com a variação do carregamento cíclico aplicado.

A Fig. 4.26 apresenta a distribuição de pressão ao longo da direção circunferencial do fio. A mesma tendência de variação da pressão de contato no lado mais afastado do grampo é observada.

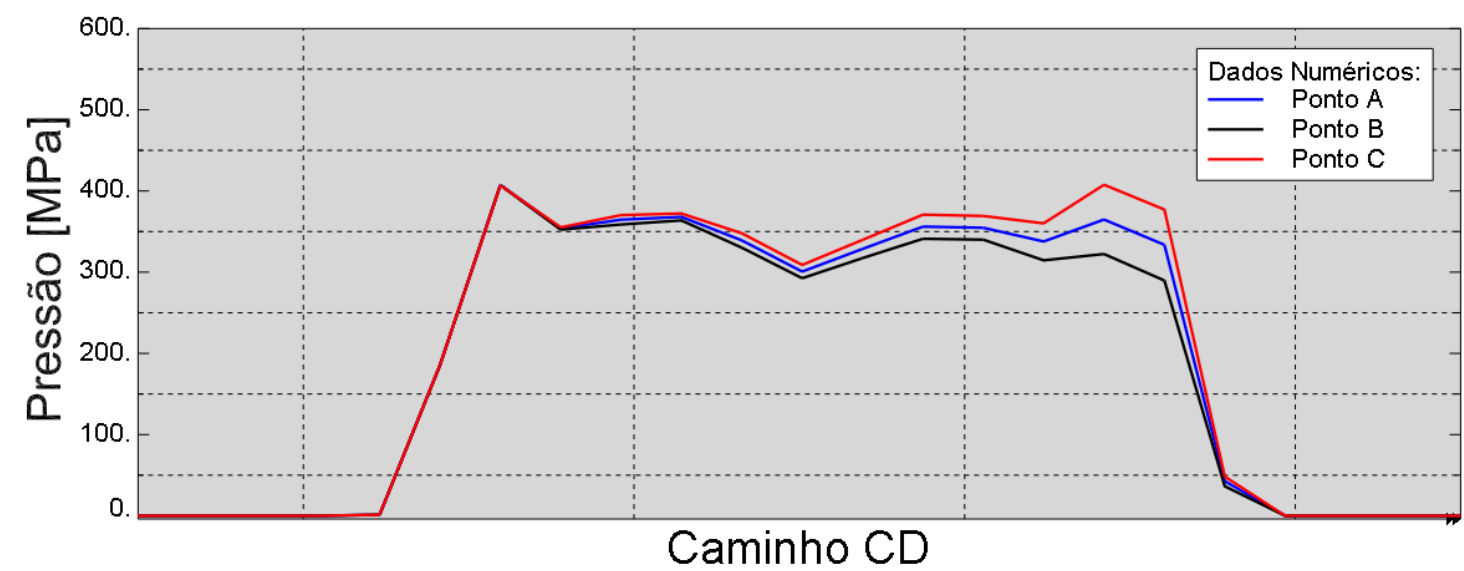

Fig. 4.26 - Distribuição da pressão de contato ao longo da direção circunferencial do fio, para os instantes A, B e C do carregamento cíclico (Fig. 4.21). 
As Figs. 4.27, 4.28 e 4.29 apresentam as distribuições das tensões tangenciais na superfície de contato no fio da camada superior, resultante do carregamento cíclico.

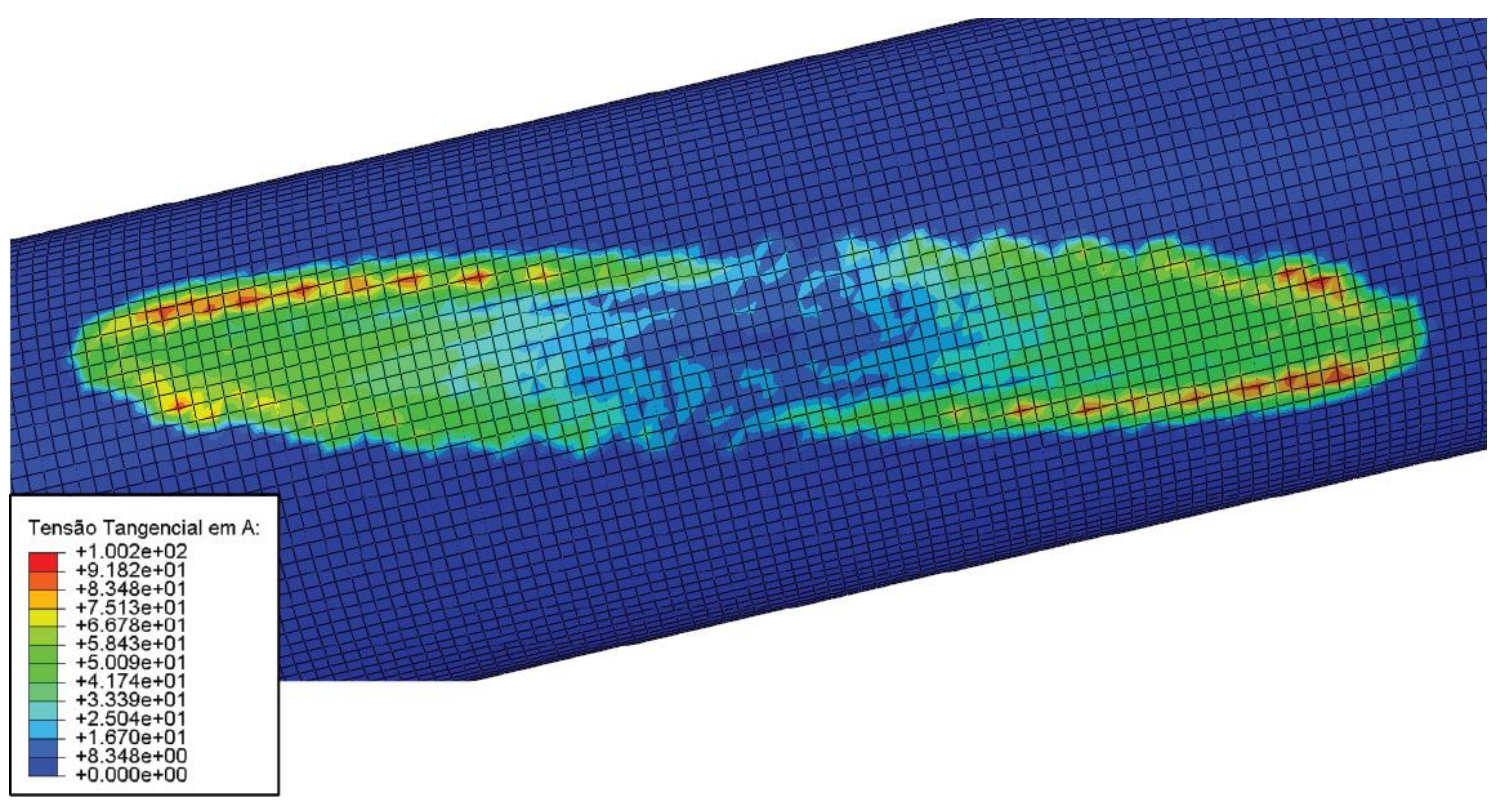

Fig. 4.27 - Distribuição de tensão tangencial sobre a superfície do fio da camada 1 no instante $A$ da história de carregamento.

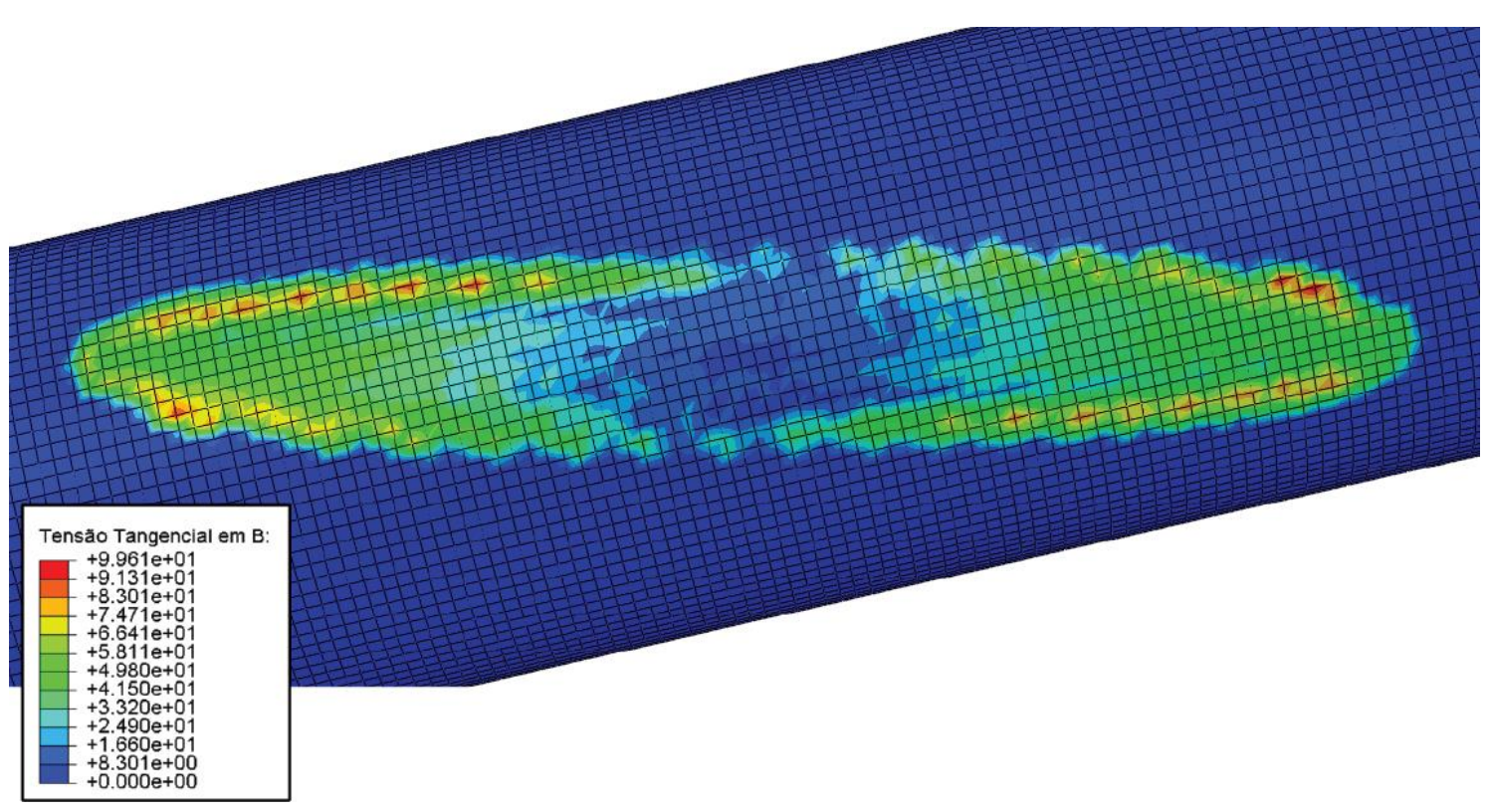

Fig. 4.28 - Distribuição de tensão tangencial sobre a superfície do fio da camada 1 no instante B da história de carregamento. 


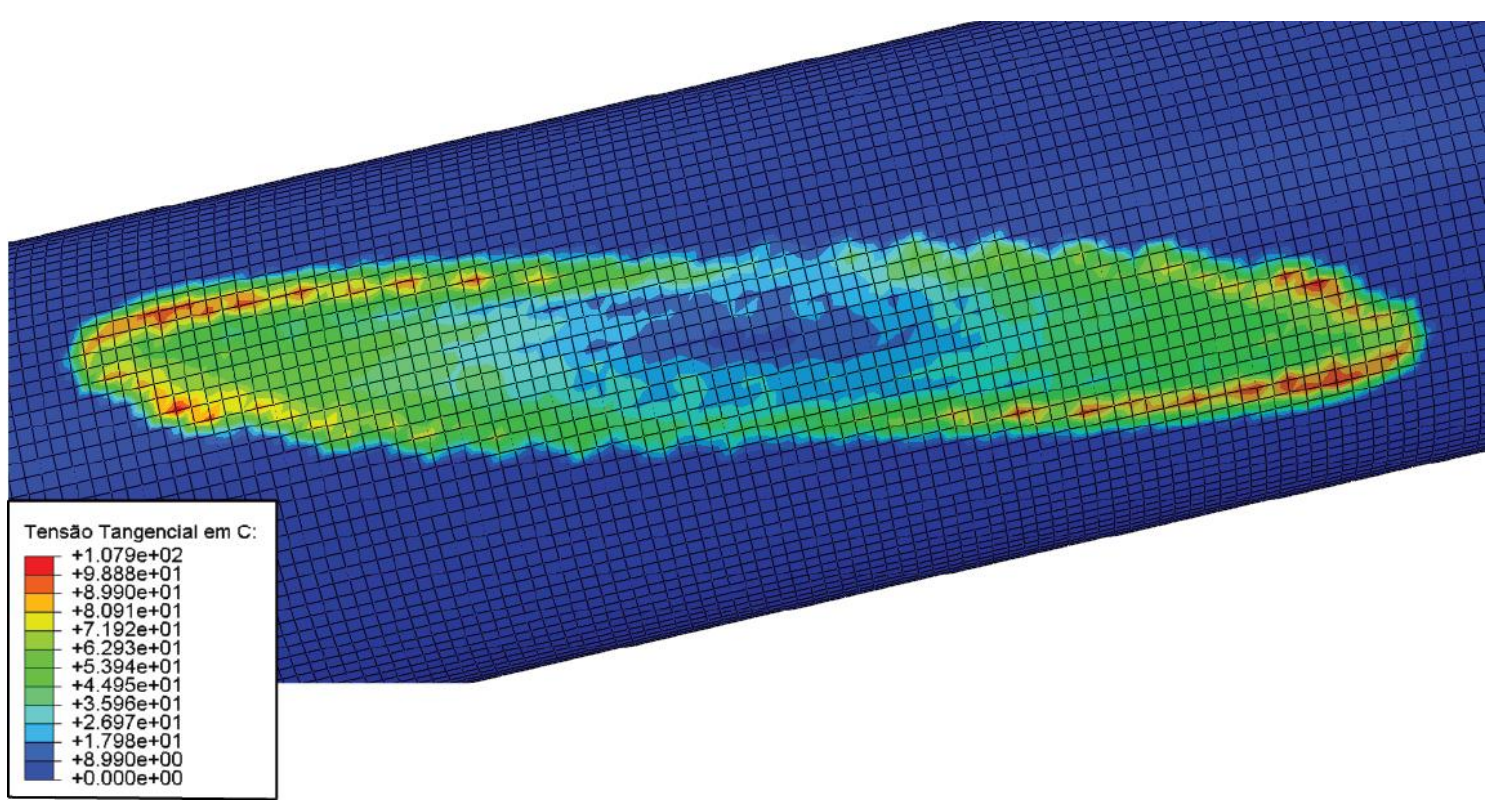

Fig. 4.29 - Distribuição de tensão tangencial sobre a superfície do fio da camada 1 no instante $\mathrm{C}$ da história de carregamento.

Os gráficos das Figs. 4.30 e 4.31 mostram as distribuições das tensões tangenciais ao longo das direções longitudinal e circunferencial do fio.

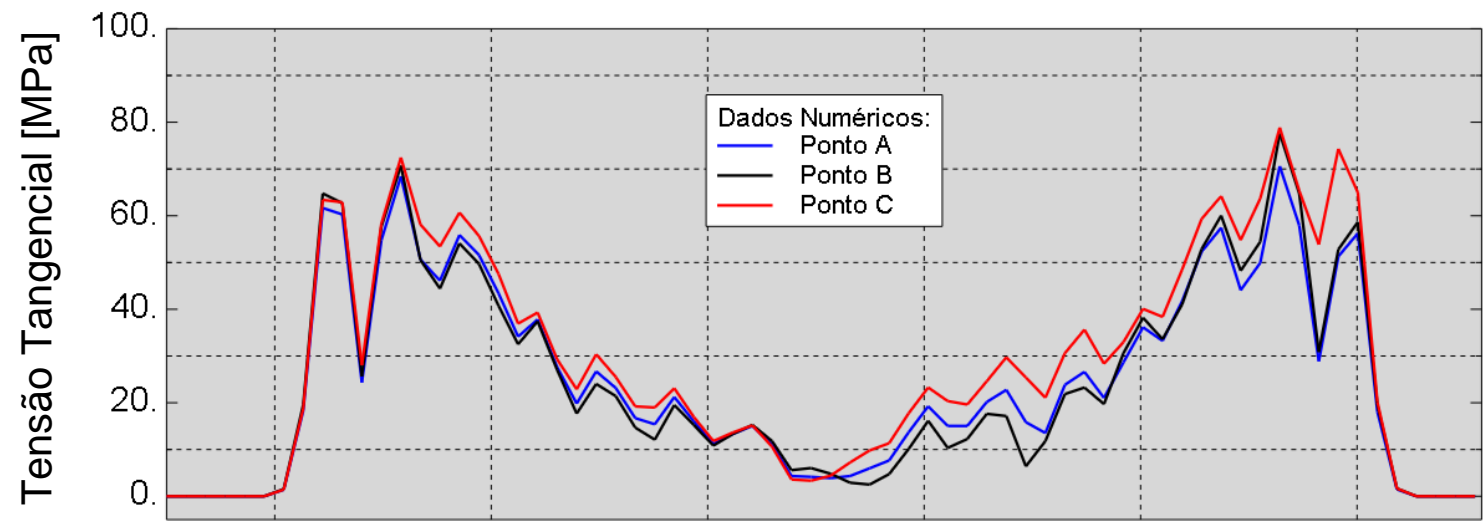

Caminho AB

Fig. 4.30 - Distribuição da tensão tangencial ao longo da direção longitudinal do fio para os instantes A, B e C do gráfico da Fig.4.21. 


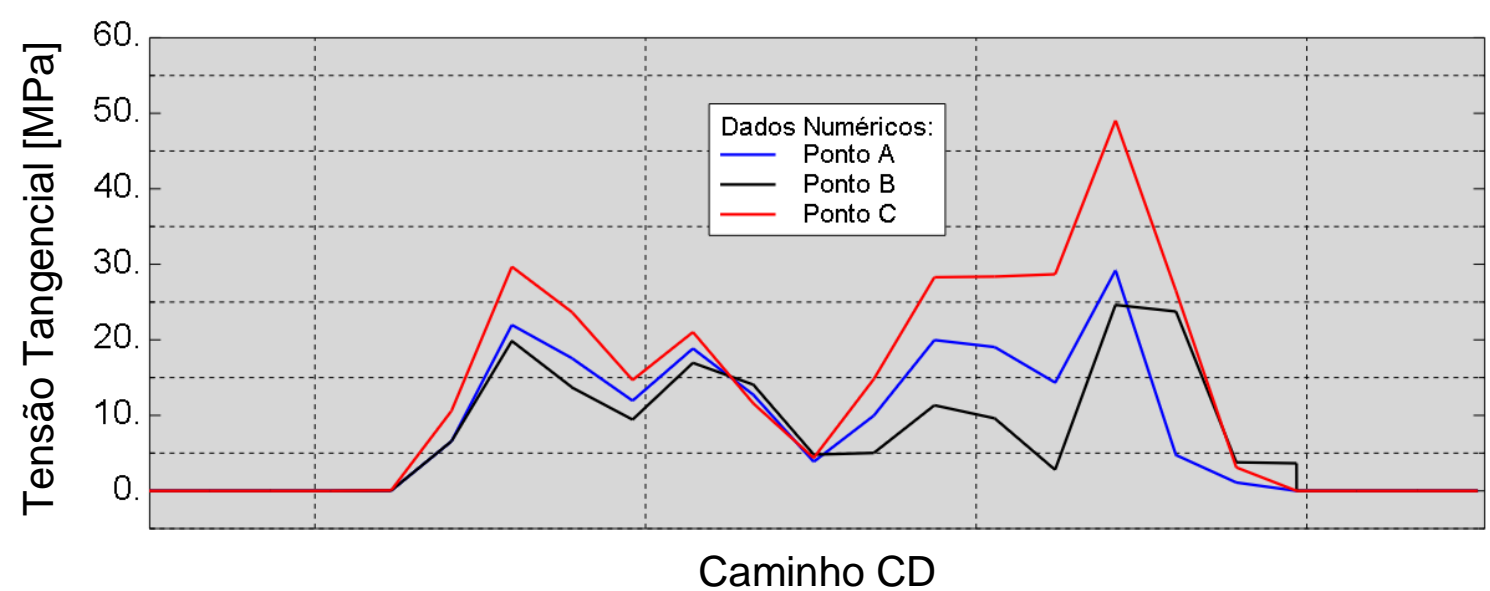

Fig. 4.31 - Distribuição da tensão tangencial ao longo da direção circunferencial do fio para os instantes A, B e C do gráfico da Fig.4.21.

A distribuição das tensões tangenciais para os instantes $A, B$ e $C$ ao longo dos caminhos $\mathrm{AB}$ e CD apresenta comportamento oscilatório espúrio. Tal comportamento pode estar associado ao baixo nível de refinamento da malha ou às deformações espúrias (associadas a modos de energia de deformação nula) decorrentes da estratégia de integração reduzida.

\subsection{MODOS ESPÚRIOS DE DEFORMAÇÃO}

Os diversos resultados apresentados neste capítulo exibem níveis de oscilação que, em princípio, não se esperaria neste problema. Uma das possibilidades de tais oscilações seria a ocorrência dos modos espúrios de deformação devido à integração reduzida adotada para se evitar o travamento numérico das deformações plásticas. Neste sentido, foram adotadas estratégias de controle dos modos espúrios por meio da adição de rigidez artificial disponível no Abaqus. 


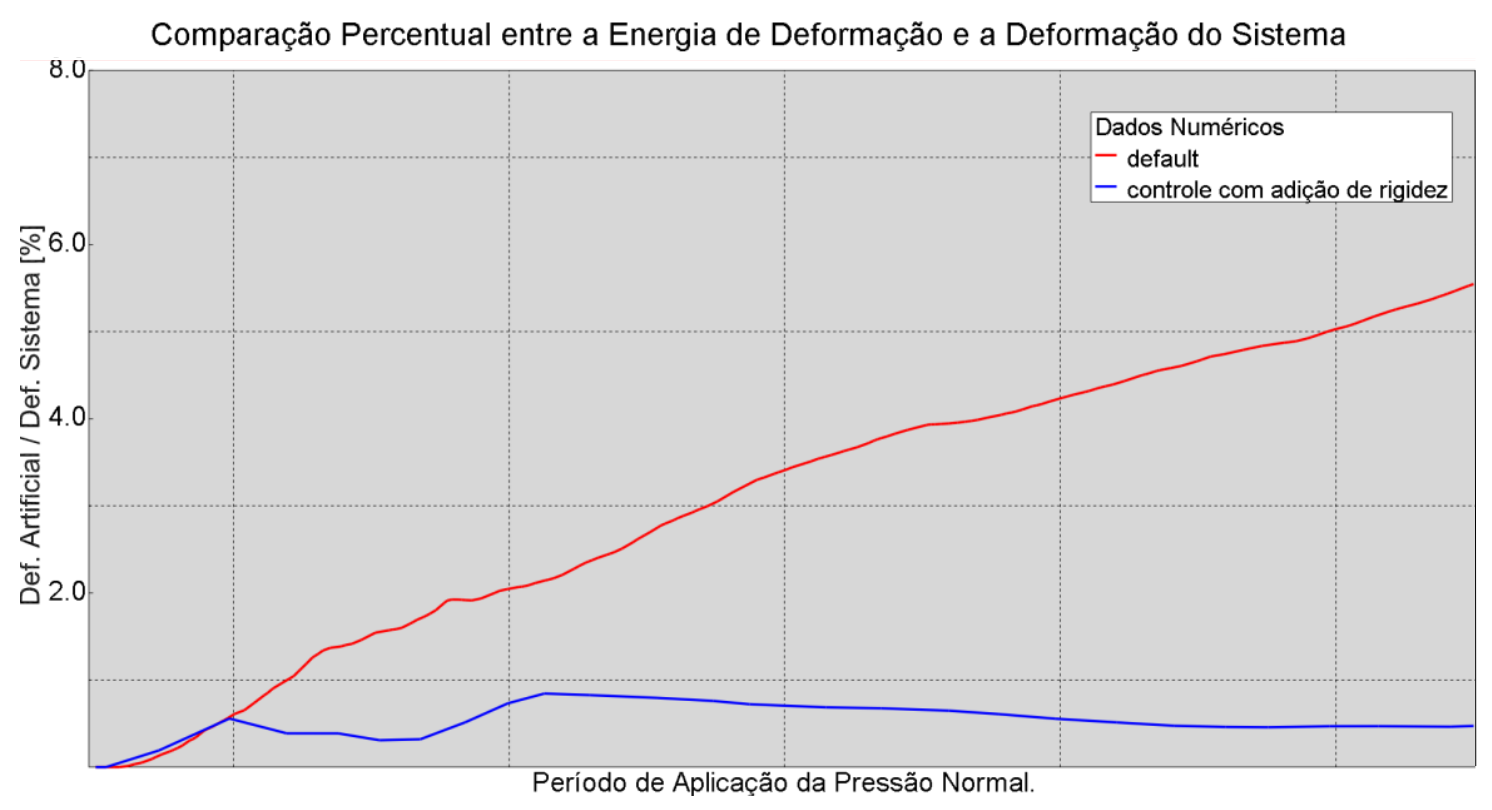

Fig. 4.32 - Energia de deformação associada aos modos espúrios de deformação, sem e com controle via rigidez artificial.

A Fig. 4.32 mostra que, de acordo com o indicador da qualidade deste controle, a estratégia de eliminação dos modos espúrios teria sido bem sucedida. De fato, o gráfico desta figura exibe duas curvas: a primeira, em vermelho, exibe a evolução da razão entre a energia de deformação espúria e a energia de deformação do sistema, à medida que o carregamento é aplicado (e, portanto, o nível de deformação plástica aumenta), sem controle de modos espúrios; por sua vez, a curva azul exibe a mesma medida quando se aplica o controle de modos espúrios. Observa-se que, com o controle, os modos espúrios são responsáveis por menos de $1 \%$ da energia de deformação total do sistema. Este número indicaria um controle bem sucedido das deformações espúrias. 


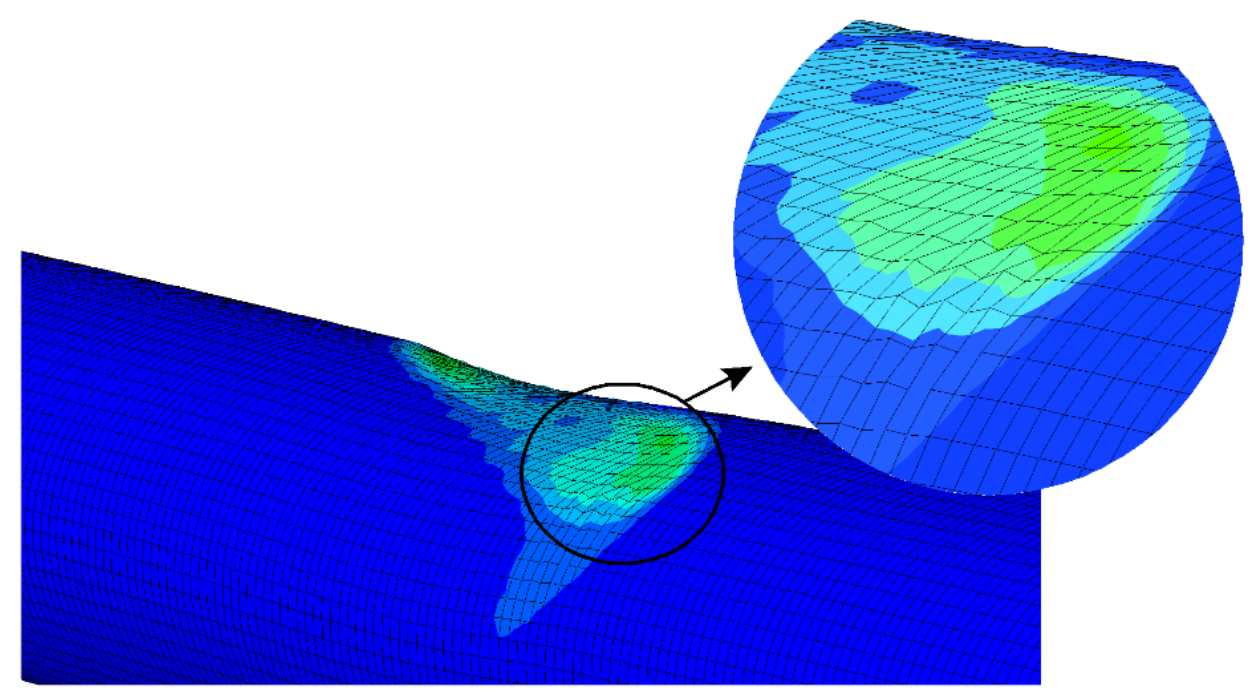

Fig. 4.33 - Topografia da região de contato deformada, onde se observam oscilações espúrias da superfície.

Entretanto, a Fig. 4.33 exibe uma topografia da região de contato típica de simulações com modos espúrios deformação. Esta observação vai de encontro ao indicador de controle dos modos espúrios representado na Fig. 4.32.

Portanto, fazem-se necessárias investigações adicionais para que se possa obter uma representação satisfatória das tensões e das deformações envolvidas nas interações entre fios do sistema cabo-grampo das linhas de transmissão de energia elétrica. 


\section{CONCLUSÃO}

Este trabalho apresentou uma análise das tensões e das deformações em um par de fios de um cabo condutor IBIS na vizinhança de um grampo de suspensão. A análise, conduzida numericamente via método dos elementos finitos, considerou o comportamento elastoplástico dos fios de alumínio no contexto de grandes deformações. As condições de carregamento: pré-carga, aperto do grampo de suspensão e carga cíclica resultante da vibração do cabo foram aquelas consideradas em experimentos de laboratório conduzidas por Fadel (2010).

Os resultados obtidos em termos de deformações permitiram compreender como as marcas podem assumir geometrias côncavas na região de contato entre fios. A geometria da marca de contato obtida por simulação numérica apresentou um erro de cerca de $4 \%$ no seu eixo maior e de cerca de $20 \%$ no seu eixo menor, quando comparada com a marca obtida em laboratório. Estas diferenças podem estar relacionadas com eventuais diferenças entre a curva de encruamento do material e aquela utilizada nas simulações (recuperada da literatura).

Por outro lado, os campos de tensão se mostraram contaminados com oscilações espúrias resultantes da estratégia de integração reduzida, necessária para que o elemento finito hexaédrico fosse capaz de descrever adequadamente as deformações plásticas. As estratégias disponíveis no aplicativo Abaqus para controle de tais modos espúrios não se mostraram eficazes.

A análise mostrou também que uma discretização muito mais refinada da malha, na região de contato, faz-se necessária para se obter uma descrição satisfatória do campo de tensões. Em particular, um refinamento acentuado da malha se faz necessário para se descrever satisfatoriamente as regiões de contato com escorregamento parcial entre os fios, que caracteriza o problema de fretting. O problema se agrava devido a sua natureza tridimensional: estimativas produzidas neste trabalho apontam para a necessidade de um refinamento da malha envolvendo cerca de 6,5 milhões de elementos somente na região de contato. Equipamentos computacionais com cerca de 256 GB de RAM poderiam suportar a demanda computacional para a solução deste problema. Entretanto, uma capacidade de processamento maciçamente paralelo - via GPUs - se faz necessária para que os 
resultados da análise numérica sejam produzidos em tempo razoavelmente aceitável (da ordem de dias).

\subsection{TRABALHOS FUTUROS}

Para trabalhos futuros, sugere-se:

- Implementação de elemento finito baseado na formulação F-bar (de Souza Neto et al., 1996) no aplicativo Abaqus para controle dos problemas de "travamento" e modos espúrios de deformação;

- Realização de ensaios mecânicos para a obtenção da curva de encruamento dos fios de alumínio;

- Realização de simulações numéricas em máquina equipada com GPUs visando a obtenção de soluções em tempo razoavelmente aceitável (da ordem de dias);

- Análise do problema de fadiga por fretting observado em decorrência da interação mecânica entre os fios do cabo condutor ou entre fio e grampo de suspensão. 


\section{REFERÊNCIAS BIBLIOGRÁFICAS}

Azevedo, C.R.F, Cescon e T. (2002). Failure analysis of aluminum cable steel reinforced (ACSR) conductor of the transmission line crossing the Paraná River, Engineering Failure Analysis, 9: 645-664.

Azevedo, C.R.F, Henriques, A.M.D, Pulino Filho, A.R., Ferreira, J.L.A, Araújo e J.A. (2009). Fretting fatigue in overhead conductors: Rig design and failure analysis of a Grosbeak aluminium cablre steel reinforced conductor, Engineering Failure Analysis, 16: 136-151.

Boniardi, M., Cincera, S., D'Errico, F. e Tagliabue, C. (2007). Fretting fatigue phenomena on na all aluminium alloy conductor, Key Engineering Materials, Vols 348-349: 5-8.

Campos, E.R.F.S. e Vilela, T.S.V. (2011). Elaboração de modelo numérico representativo da região de montagem de grampos de suspensão/cabos condutores de energia e levantamento experimental de variáveis por ajuste, Projeto de Graduação - Universidade de Brasília.

Fadel, A.A. (2010). Avaliação do efeito do tracionamento em elevados níveis de EDS sobre a resistência em fadiga do condutor IBIS (CAA 397,5 MCM), tese de doutorado em ciências mecânicas - Universidade de Brasília.

Guérard, S. (2011). Power line conductors, a contribution to the analysis of their dynamic behaviour, Doctoral Thesis, Faculty of Applied Sciences - Université de Liège.

Hills, D.A. e Nowell, D. (1994). Mechanics of fretting fatigue. Solid mechanics and its application, vol. 30. Kluwer Academic Publishers.

Hughes, T.J.R. (2000). The finite element method: linear static and dynamic finite element analysis, Dover Publication.

IEEE (2015). an introduction discussion on aeolian vibration of single conductors, Technical Report.

Kalombo, R.B., Araújo, J.A., Ferreira, J.L.A., da Silva, C.R.M., Alencar, R. e Capra, A.R. (2015). Assessment of the fatigue failure of na all aluminium alloy cable (AAAC) for a 230 $\mathrm{Kv}$ transmission line in the Center-West of Brazil, Engineering Failure Analysis.

Konyukhov, A., Izi, R. (2015). Introduction to computational contact mechanics: a geometrical approach, Wiley Series in Computational Mechanics. 
Kubelwa, Y.D., Papailiou, K.O., Loubser, R. e Moodley, P. (2012). How well does the Poffenberger-Swart formula apply to homogeneous compact overhead line conductors? 18th World Conference on Non-destructive Testing, 16-20.

Lévesque, F., Gourdreau, S., Cloutier, L. e Cardou, A. (2011a). Finite element model of the contact between a vibrating conductor and a suspension clamp, Tribology International, 44:1014-1023.

Lévesque, F., Gourdreau, S. e Cloutier, L. (2011b). Elastic-plastic microcontact model for elliptic contact areas and its application to a treillis point in a overhead electrical conductors.

Preston, B.M. e Ramey, G.E. (1985). Effect os suspension clamp geometry on transmission line fatigue, J. Energy Eng. 1986.112: 168-184.

Rolim, A.L., Moreira, J.L.R., Veloso, L.A.C.M., de Souza e R.M., Araújo, J.A. (2013). Differential displacement and strain analysis of transmission line cables, Soc. Mech. Sci. Eng. 35: 327-336.

de Souza Neto, E.A., Peric, D., Dutko, M. e Owen, D.R.J. (1996). Design of simple low order finite elements for large strain analysis of nearly incompressible solids, Int. J. Solids Structs, 33: 3277-3269.

Talemi, R. H. (2013-2014). Numerical modelling techniques for fretting fatigue crcak initiation and propagation, Faculteit Ingenieurswetenschappen en Architectuur.

Vilela, T. S. V., Fadel, A.A., Ferreira, J.L.A. e Araújo, J.A. (2013). Study of experimental techniques fos fatigue stress measurement in overhead cables for power lines, 22nd International Congresso of Mechanical Engineering (COBEM 2013).

Wang, J.J., Lara-Curzio, E. e King Jr., T.J. (2008). The integrity of ACSR full tension conductor single-stage splice conector at higher operation temperature, Oak Ridge National Laboratory.

Zhou, Z.R., Cardou, A., Fiset, M. e Goudreau, S. (1994). Fretting fatigue in eletrical transmission lines, Wear, 173: 179-188. 
APÊNDICES 


\section{Apêndice A}

Observe a Fig. A.1, a seguir. Nela é apresentado o contato entre um fio pertencente a camada superior de um cabo condutor em contato com fios da camada inferior.

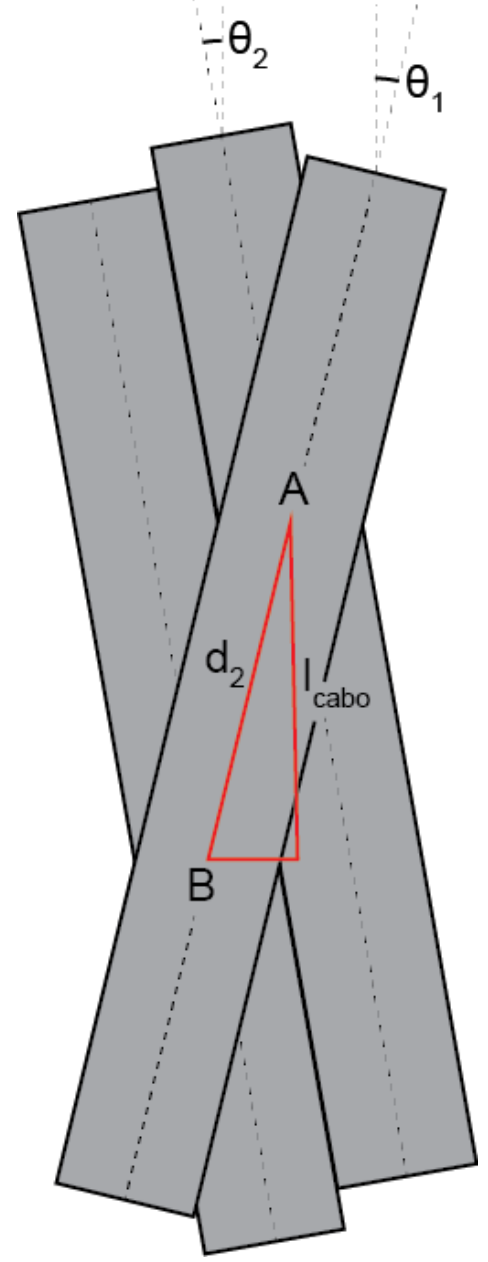

Fig. A.1 - Contato do fio pertencente a camada superior do cabo sobre os pontos A e B dos fios da camada inferior.

Aproximando a região ilustrada pelo triângulo retângulo em vermelho, obtémse as relações geométricas da Fig. A.2. 


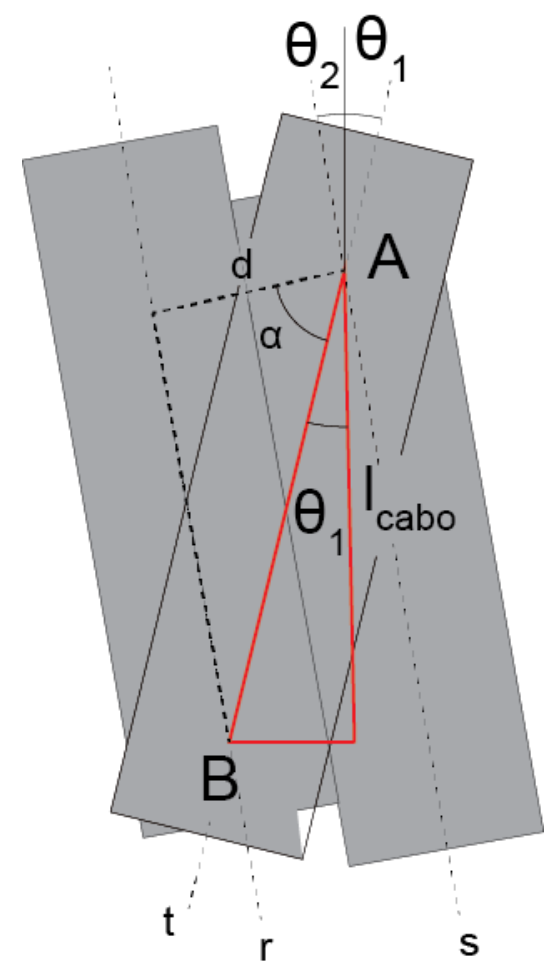

Fig. A.2 - Relações geométricas para os pontos de contato A e B.

Na Fig. A.2, é possível descobrir que o ângulo $\alpha$ vale, em função de $\theta_{1}$ e $\theta_{2}$,

$$
\alpha=90^{\circ}-\left(\theta_{1}+\theta_{2}\right)
$$

onde, $\theta_{1}$ e $\theta_{2}$ são os ângulos de hélice para o fio superior e inferior, respectivamente.

Pode-se tirar da Fig. A.2, as seguintes relações geométricas,

$$
\overline{\mathrm{AB}}=\frac{\mathrm{d}}{\cos \left(90^{\circ}-\left(\theta_{1}+\theta_{2}\right)\right)}
$$

e,

$$
\mathrm{l}_{\text {cabo }}=\overline{\mathrm{AB}} \cos \theta_{1}
$$

sendo, $\mathrm{d}$ o diâmetro dos fios da camada inferior e $\mathrm{l}_{\text {cabo }} \mathrm{o}$ comprimento proporcional do cabo para duas regiões de contato entre os fios. 
Juntando as relações A.2 e A.3, encontra-se o valor de $l_{\text {cabo }}$ em função dos ângulos de hélice e do diâmetro dos fios pertencentes a camada inferior conforme a relação,

$$
\mathrm{l}_{\text {cabo }}=\frac{\mathrm{d} \cos \theta_{1}}{\cos \left(90^{\circ}-\left(\theta_{1}+\theta_{2}\right)\right)}
$$

Para um trecho de cabo, é possível calcular o número de pontos de contato entre fios de camadas diferentes com a relação,

$$
\mathrm{pt}_{\mathrm{c}}=\frac{\text { trecho }}{\mathrm{l}_{\text {cabo }}} \mathrm{nf}_{\mathrm{i}}
$$

onde, trecho é o comprimento do cabo considerado e $\mathrm{nf}_{\mathrm{i}}$ o número de fios na camada i.

Pode-se perceber que existem regiões de contato em ambas as camadas dos fios, devido a isto, a seguinte relação é multiplicada por dois,

$$
\mathrm{n}_{\mathrm{rc}}=\operatorname{trecho}\left(\mathrm{nf}_{1} \frac{\cos \left(90^{\circ}-\left(\theta_{1}+\theta_{2}\right)\right)}{\mathrm{d}_{\mathrm{a}} \cos \left(\theta_{1}\right)}+\mathrm{nf}_{2} \frac{\cos \left(90^{\circ}-\left(\theta_{2}+\theta_{3}\right)\right)}{\mathrm{d}_{\mathrm{s}} \cos \left(\theta_{2}\right)}\right)
$$

A Eq. A.6 anterior calcula o número total de regiões de contato entre fios de cabos com três camadas.

O contato dos fios da camada $3 \mathrm{com}$ a alma foi desconsiderado por causa de sua região de contato ter formato parecido com uma tira retangular. 


\section{Apêndice B}

Como hipótese de compatibilidade geométrica, tem-se:

$$
\delta_{1}=\delta_{2}=\delta_{3}=\delta_{\text {alma }}
$$

onde $\delta_{\mathrm{i}}$ é a deformação dos fios da camada i.

Utilizando a igualdade de deformação dada por (B.1), pode-se calcular as forças nas camadas 2, 3 e da alma do cabo em função da força na camada 1 com as expressões,

$$
\begin{gathered}
\mathrm{F}_{1}=\mathrm{F}_{2} \\
\mathrm{~F}_{3}=\frac{\mathrm{E}_{\mathrm{aço}}}{\mathrm{E}_{\mathrm{Al}}}\left(\frac{\mathrm{d}_{\mathrm{aço}}}{\mathrm{d}_{\mathrm{Al}}}\right)^{2} \mathrm{~F}_{1} \\
\mathrm{~F}_{\text {alma }}=\frac{\mathrm{E}_{\mathrm{aço}}}{\mathrm{E}_{\mathrm{Al}}}\left(\frac{\mathrm{d}_{\mathrm{aço}}}{\mathrm{d}_{\mathrm{Al}}}\right)^{2} \mathrm{~F}_{1}
\end{gathered}
$$

onde $\mathrm{F}_{1}, \mathrm{~F}_{1}, \mathrm{~F}_{1}$ e $\mathrm{F}_{1}$ são as forças nas camadas 1, 2, 3 e na alma do cabo, $\mathrm{E}_{\mathrm{aço}}$ e $\mathrm{E}_{\mathrm{Al}}$ são os módulos de elasticidade dos fios de aço e de alumínio e $\mathrm{d}_{\mathrm{aço}}$ e $\mathrm{d}_{\mathrm{Al}}$ são os diâmetros dos fios de aço e alumínio.

Por equilíbrio, o somatório das forças em cada camada é dado por

$$
\mathrm{n}_{1} \mathrm{~F}_{1}+\mathrm{n}_{2} \mathrm{~F}_{2}+\mathrm{n}_{3} \mathrm{~F}_{3}+\mathrm{F}_{\mathrm{alma}}=\mathrm{F}_{\mathrm{EDS}}
$$

e sendo, $\mathrm{n}_{\mathrm{i}}$ o número de fios da camada $\mathrm{i}, \mathrm{F}_{\mathrm{i}}$ a força aplicada ao fio da camada $\mathrm{i}$ e $\mathrm{F}_{\text {EDS }}$ a força de tração do cabo. 
Substituindo as Eqs. (B.2), (B.3) e (B.4) na Eq. (B.5), tem-se que a força no fio da primeira camada é dada por

$$
\mathrm{F}_{1}=\frac{\mathrm{F}_{\mathrm{EDS}}}{\mathrm{n}_{\mathrm{Al}}+\mathrm{n}_{\mathrm{aço}} \frac{\mathrm{E}_{\mathrm{aço}}}{\mathrm{E}_{\mathrm{Al}}}\left(\frac{\mathrm{d}_{\mathrm{aço}}}{\mathrm{d}_{\mathrm{Al}}}\right)^{2}}
$$

e

$$
\mathrm{F}_{1}=\mathrm{F}_{2}
$$




\section{Apêndice C}

A simulação de contato desta seção é realizada para a obtenção da marca de contato entre os dois fios levando em consideração as medições realizadas com o microscópio Confocal.

\section{Código em python:}

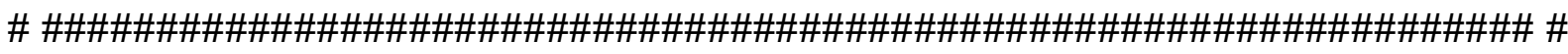

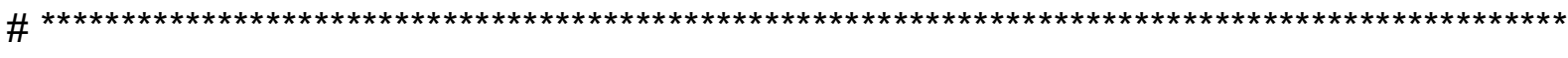

\# UNIVERSIDADE DE BRASILIA - UNB

\# Faculdade de Tecnologia - FT

\# Departamento de Engenharia Mecanica - ENM

\#

\# Simulacao de Dois Fios Rotacionados do Cabo IBIS \#

\#

\# Descricao: Carga de aperto sobre os fios pertecentes a ultima camada e sua

\# retirada para comparacao com o observado experimentalmente

\#

\#

\#

\# Criado por: Eduardo Luis Souza de Athayde Nunes Filho \#

\# Versão de: 25/07/2016

\#

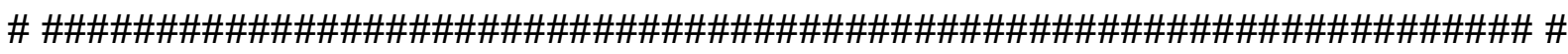

from abaqus import *

from abaqusConstants import *

import regionToolset

session.viewports['Viewport: 1'].setValues(displayedObject=None) 


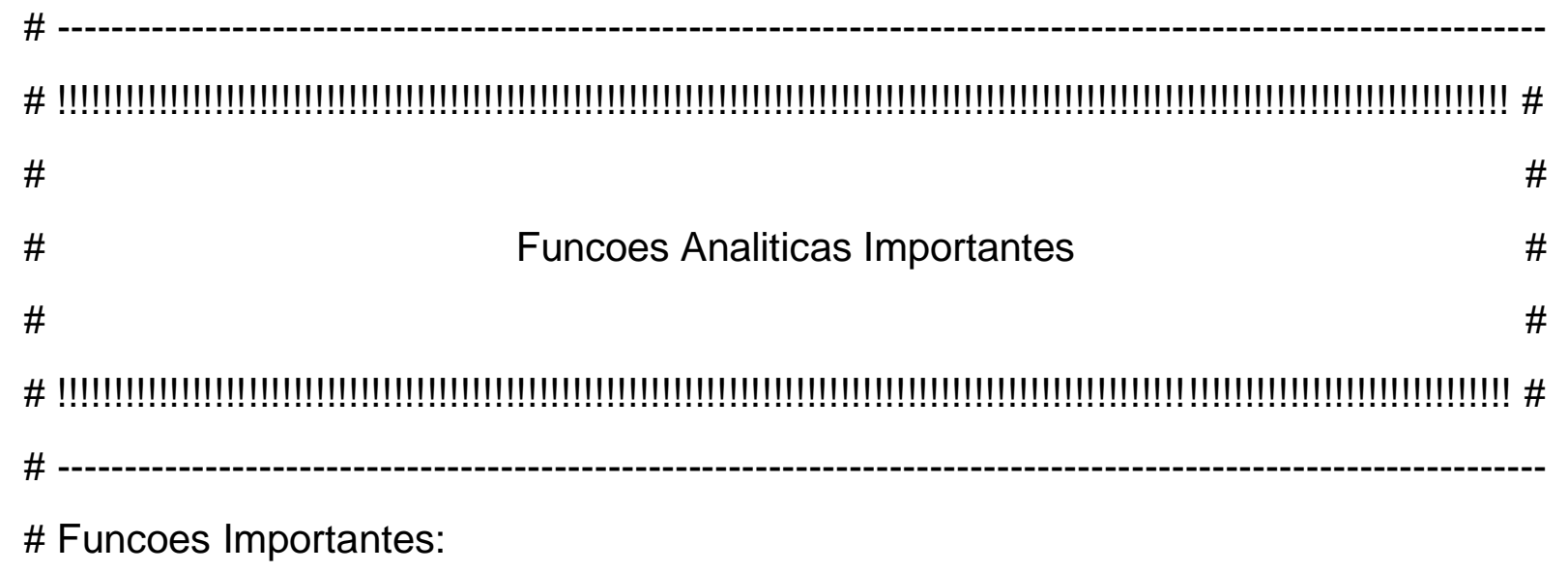

\# Graus para Radianos:

def graus2rad(angulo_graus): $\quad$ \# Converte angulos em graus para $\mathrm{rad}=\left(\right.$ angulo_graus $\left.{ }^{*} \mathrm{pi}\right) / 180 \quad$ \# radianos return rad \# Sentido de Enrolamento do Primeiro Fio:

def sent_enrol(x):

if $x==1$ : $\operatorname{sgn}=1 ; \quad$ \# Define o Sinal para o Sentido de if $x==-1$ : $\quad$ \# enrolamento do fio pertencente $\operatorname{sgn}=-1 ; \quad$ \# a primeira camada

return sgn $\#$

\# Criacao do Modelo de Analise Global:

mdb.models.changeKey(fromName='Model-1', toName = 'Modelo_2Fios_Global') Fios_Global =mdb.models['Modelo_2Fios_Global'] 


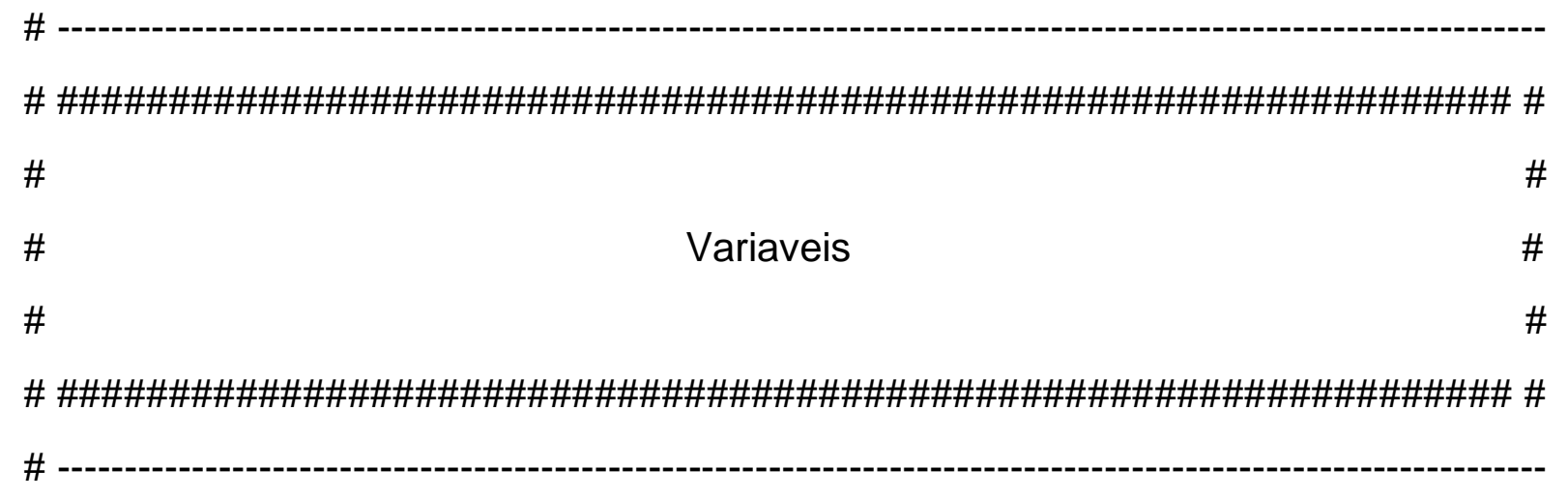

\# Variaveis de Entrada:

\# Angulo de Rotacao entre os Fios:

theta1 = 13.9; \# Angulo de Rotacao Relativo a Primeira Camada [graus]

theta2 $=10.1 ; \quad$ \# Angulo de Rotacao Relativo a Segunda Camada [graus]

sentido $=-1 ; \quad$ \# Sentido de Enrolamento do Fio da Primeira Camada

\# (sinal = 1 -> sentido-horario)

\# (sinal $=-1$-> sentido-antihorario)

\# Dados Referentes aos Fios Externos Analisados

dal $=3.139 ; \quad$ \# Diametro do Fio de Aluminio [mm]

$\mathrm{cal}=30.0 ; \quad$ \# Comprimento do Fio de Aluminio [mm]

\# Dados Referentes ao Conjunto de Fios que Formam o Cilindro Rigido:

dst $=2.441 ; \quad$ \# Diametro do Fio de Aco [mm]

cst $=40.0 ; \quad$ \# Comprimento do Cilindro de Aco [mm]

\# Dados Referentes ao Bloco Rigido:

$\mathrm{cbl}=15.0 ; \quad$ \# Comprimento do Bloco $[\mathrm{mm}]$

$\mathrm{lbl}=5.0 ; \quad$ \# Lado Secao Transversal (Quadrado) do Bloco [mm]

$\mathrm{rfbl}=1.0 \quad$ \# Raio Filete da Quina no Bloco Rigido [mm] 
\# Dados do Material Utilizado na Analise:

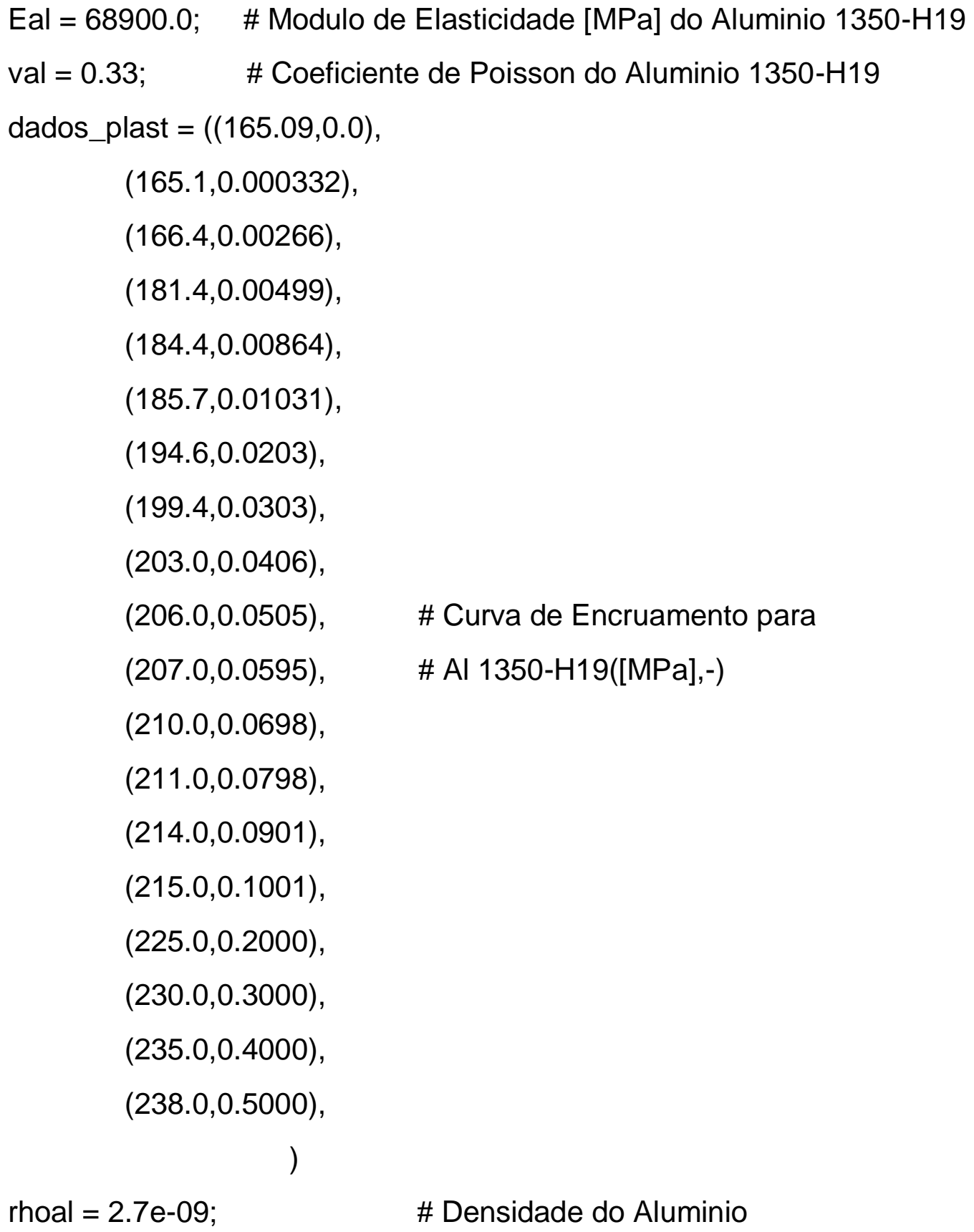

\# Informacoes do Contato entre os Fios:

coef_atrito $=0.6 ; \quad$ \# Coeficiente de atrito entre os fios de aluminio \# \# Relacoes Obtidas das Variaveis de Entrada: 


$$
\begin{array}{ll}
\text { Ral }=\text { dal/2.0; } & \text { \# Raio do Fio de Aluminio } \\
\text { Rst }=\text { dst/2.0; } & \text { \# Raio do Fio de Aco } \\
\text { Rcil }=3.0^{*} \text { Rst; } & \text { \# Raio do Cilindro Rigido } \\
\text { sinal }=\text { sent_enrol(sentido) } & \text { \# Sinal para Definir Enrolamento do Fio }
\end{array}
$$$$
\text { \# }
$$

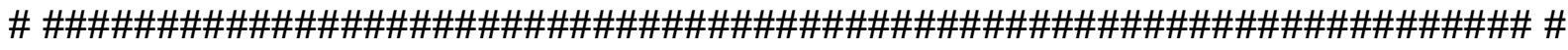$$
\#
$$$$
\text { \# } \quad \text { Partes \# }
$$$$
\#
$$

\# \#\#\#\#\#\#\#\#\#\#\#\#\#\#\#\#\#\#\#\#\#\#\#\#\#\#\#\#\#\#\#\#\#\#\#\#\#\#\#\#\#\#\#\#\#\#\#\#\#\#\#\#\#\# \# \#

\# Importando os modulos de desenho e criacao de pecas para simulacao numerica:

import sketch

import part

\# Fio de Aluminio da Camada 1 (camada mais externa do cabo IBIS):

Fios_Global_Sketch $=$ Fios_Global. $\mid$

$$
\begin{gathered}
\text { ConstrainedSketch }(\text { name }=\text { 'Fios Global Sketch', I } \\
\text { sheetSize }=\text { dal })
\end{gathered}
$$

Fios_Global_Sketch.CircleByCenterPerimeter $($ center $=(0.0,0.0)$, ।

$$
\text { point1 }=(0.0, \text { Ral }))
$$

fio_aluminio_1 = Fios_Global.Part(name = 'Fio de Aluminio - Camada 1', I

$$
\begin{aligned}
& \text { dimensionality = THREE_D, } 1 \\
& \text { type = DEFORMABLE_BODY) }
\end{aligned}
$$

parte1 $=$ Fios_Global.parts['Fio de Aluminio - Camada 1']

parte1.BaseSolidExtrude $($ sketch $=$ Fios_Global_Sketch, depth $=$ cal $)$

\# Plano em Relacao aos Eixos xz e yz: 
parte1.DatumPlaneByPrincipalPlane (principalPlane $=$ YZPLANE, offset $=0.0$ ) parte1. DatumPlaneByPrincipalPlane (principalPlane $=X Z P L A N E$, offset $=0.0$ ) \# print parte1.datums[plano_selec.id]

\# Removendo extremidade do fio:

planos $=$ parte1. datums $[3]$

arestas $=$ parte 1. edges. findAt $((\operatorname{Ral}, 0.0,0.0)$,

$\mathrm{t}=$ parte1.MakeSketchTransform(sketchPlane $=$ planos, sketchUpEdge $=$ arestas, sketchPlaneSide $=S I D E 1$, sketchOrientation $=\mathrm{RIGHT}$, origin $=(0.0,0.0, \mathrm{cal} / 2.0))$ $\mathrm{s}=$ mdb.models['Modelo_2Fios_Global'].ConstrainedSketch(name='_profile__', sheetSize $=176.27$, gridSpacing $=4.4$, transform $=\mathrm{t}$ )

s.Line $($ point1 $=(\mathrm{cal} / 2.0, \mathrm{Ral})$, point2 $=(\mathrm{cal} / 2.0,-\mathrm{Ral}))$ parte_inferior $1=\mathrm{cal} / 2.0$-tan $(\operatorname{graus} 2 \operatorname{rad}(\text { theta1 }))^{*}$ dal s.Line $\left(\right.$ point $1=\left(\right.$ parte_inferior $1,-$ Ral ${ }^{*}$ sinal $)$, point2 $=\left(\right.$ cal $/ 2.0,-$ Ral ${ }^{*}$ sinal $\left.)\right)$ s.Line $\left(\right.$ point $1=\left(\right.$ parte_inferior $1,-$ Ral ${ }^{*}$ sinal $)$, point2 $=\left(\mathrm{cal} / 2.0\right.$, Ral ${ }^{*}$ sinal $\left.)\right)$

s.Line $($ point1 $=(-\mathrm{cal} / 2.0, \mathrm{Ral})$, point2 $=(-\mathrm{cal} / 2.0,-\mathrm{Ral}))$ parte_inferior2 $=-\mathrm{cal} / 2.0+\tan (\operatorname{graus} 2 \mathrm{rad}(\text { theta1 }))^{*}$ dal s.Line $\left(\right.$ point1 $=\left(-\mathrm{cal} / 2.0\right.$, Ral $^{*}$ sinal $)$, point2 $=\left(\right.$ parte_inferior2,Ral ${ }^{*}$ sinal $\left.)\right)$ s.Line $\left(\right.$ point $1=\left(-\right.$ cal $/ 2.0,-$ Ral ${ }^{*}$ sinal $)$, point2 $=\left(\right.$ parte_inferior2,Ral ${ }^{*}$ sinal $\left.)\right)$

parte1.CutExtrude(sketchPlane=planos, 1

$$
\begin{aligned}
& \text { sketchUpEdge=arestas, । } \\
& \text { sketchPlaneSide=SIDE1, । } \\
& \text { sketchOrientation=RIGHT, । } \\
& \text { sketch=s, । } \\
& \text { flipExtrudeDirection=OFF) }
\end{aligned}
$$

planos $=$ parte 1. datums $[3]$

$$
\text { arestas }=\text { parte1.edges } . \text { findAt }((\operatorname{Ral}, 0.0,0.0),)
$$


$\mathrm{t}=$ parte1.MakeSketchTransform(sketchPlane $=$ planos, sketchUpEdge $=$ arestas, sketchPlaneSide $=S I D E 1$, sketchOrientation $=\mathrm{RIGHT}$, origin $=(0.0,0.0, \mathrm{cal} / 2.0))$ $\mathrm{s}=$ mdb.models['Modelo_2Fios_Global'].ConstrainedSketch(name='_profile__, sheetSize $=176.27$, gridSpacing $=4.4$, transform=t)

s.Line $($ point1 $=(\mathrm{cal} / 2.0, \mathrm{Ral})$, point2 $=(\mathrm{cal} / 2.0,-$ Ral $))$

parte_inferior $1=\mathrm{cal} / 2.0-\tan (\operatorname{graus} 2 \operatorname{rad}(\text { theta1 }))^{*}$ dal

s.Line $\left(\right.$ point1 $=\left(\right.$ parte_inferior1, - Ral ${ }^{*}$ sinal $)$, point2 $=\left(\right.$ cal $/ 2.0,-$ Ral ${ }^{*}$ sinal $\left.)\right)$

s.Line $\left(\right.$ point $1=\left(\right.$ parte_inferior $1,-$ Ral ${ }^{*}$ sinal $)$, point2 $=\left(\right.$ cal $/ 2.0$, Ral ${ }^{*}$ sinal $\left.)\right)$

s.Line $($ point1 $=(-\mathrm{cal} / 2.0, \mathrm{Ral})$, point2 $=(-\mathrm{cal} / 2.0,-\mathrm{Ral}))$

parte_inferior2 $=-\mathrm{cal} / 2.0+\tan (\operatorname{graus} 2 \mathrm{rad}(\operatorname{theta} 1))^{*} \mathrm{dal}$

s.Line $\left(\right.$ point1 $=\left(-\right.$ cal $/ 2.0$, Ral $^{*}$ sinal $)$, point2 $=\left(\right.$ parte_inferior2, Ral $^{*}$ sinal $\left.)\right)$

s.Line $\left(\right.$ point $1=\left(-\right.$ cal $/ 2.0,-$ Ral ${ }^{*}$ sinal $)$, point2 $=\left(\right.$ parte_inferior2,Ral ${ }^{*}$ sinal $\left.)\right)$

parte1.CutExtrude(sketchPlane=planos, I

$$
\begin{aligned}
& \text { sketchUpEdge=arestas, । } \\
& \text { sketchPlaneSide=SIDE1, । } \\
& \text { sketchOrientation=RIGHT, । } \\
& \text { sketch=s, । } \\
& \text { flipExtrudeDirection=ON) }
\end{aligned}
$$

\# Fio de Aluminio da Camada 2(abaixo da camada mais externa do cabo IBIS):

Fios_Global_Sketch = Fios_Global.ConstrainedSketch(name='Fios Global Sketch', ।

$$
\text { sheetSize }=\text { dal) }
$$

Fios_Global_Sketch.CircleByCenterPerimeter $(\operatorname{center}=(0.0,0.0), ।$

$$
\text { point 1 }=(0.0, \mathrm{Ral}))
$$

fio_aluminio_2 = Fios_Global.Part(name='Fio de Aluminio - Camada 2', ।

$$
\begin{aligned}
& \text { dimensionality=THREE_D, } 1 \\
& \text { type=DEFORMABLE_BODY) }
\end{aligned}
$$

parte2 = Fios_Global.parts['Fio de Aluminio - Camada 2'] 
parte2.BaseSolidExtrude(sketch=Fios_Global_Sketch, depth = cal)

\# Plano em Relacao aos Eixos xz e yz:

plano_selec $=$ parte2.DatumPlaneByPrincipalPlane $($ principalPlane $=$ YZPLANE, I offset $=0.0$ )

parte2.DatumPlaneByPrincipalPlane(principalPlane $=X Z P L A N E$, offset=0.0)

\# print parte2.datums[plano_selec.id]

\# Removendo extremidade do fio:

planos $=$ parte2.datums[3]

arestas $=$ parte2.edges. findAt((Ral,0.0,0.0), $)$

$\mathrm{t}=$ parte2.MakeSketchTransform(sketchPlane=planos, sketchUpEdge=arestas, sketchPlaneSide $=S I D E 1$, sketchOrientation $=\mathrm{RIGHT}$, origin $=(0.0,0.0$, cal/2.0) $\mathrm{s}=$ mdb.models['Modelo_2Fios_Global'].ConstrainedSketch(name='_profile__', sheetSize=176.27, gridSpacing=4.4, transform=t)

s.Line $($ point1 $=(\mathrm{cal} / 2.0, \mathrm{Ral})$, point2 $=(\mathrm{cal} / 2.0,-\mathrm{Ral}))$

parte_inferior $1=\mathrm{cal} / 2.0$-tan $(\operatorname{graus} 2 \mathrm{rad}(\text { theta2 }))^{\star}$ dal

s.Line (point1 = (parte_inferior1,Ral ${ }^{*}$ sinal), point2 $=\left(\mathrm{cal} / 2.0, \mathrm{Ral}^{*}\right.$ sinal $\left.)\right)$

s.Line $\left(\right.$ point1 $=\left(\right.$ parte_inferior 1, Ral $^{*}$ sinal $)$, point2 $=\left(\right.$ cal $/ 2.0,-$ Ral $^{*}$ sinal $\left.)\right)$

s.Line $($ point1 $=(-\mathrm{cal} / 2.0, \mathrm{Ral})$, point2 $=(-\mathrm{cal} / 2.0,-\mathrm{Ral}))$

parte_inferior2 $=-\mathrm{cal} / 2.0+\tan (\operatorname{graus} 2 \mathrm{rad}(\text { theta2 }))^{*} \mathrm{dal}$

s.Line $\left(\right.$ point1 = $\left(-\right.$ cal $/ 2.0,-$ Ral ${ }^{*}$ sinal $)$, point2 $=\left(\right.$ parte_inferior2,-Ral ${ }^{*}$ sinal $\left.)\right)$

s.Line $\left(\right.$ point1 $=\left(-\right.$ cal $/ 2.0$, Ral $^{*}$ sinal $)$, point2 $=\left(\right.$ parte_inferior2, - Ral ${ }^{*}$ sinal $\left.)\right)$

parte2.CutExtrude(sketchPlane=planos, I

sketchUpEdge=arestas, I

sketchPlaneSide=SIDE1, I

sketchOrientation=RIGHT, । 
sketch=s, I

flipExtrudeDirection=OFF)

planos $=$ parte2.datums[3]

arestas $=$ parte2.edges.. indAt $((\operatorname{Ral}, 0.0,0.0)$,

$\mathrm{t}=$ parte2.MakeSketchTransform(sketchPlane=planos, sketchUpEdge=arestas, sketchPlaneSide $=S I D E 1$, sketchOrientation $=\mathrm{RIGHT}$, origin $=(0.0,0.0, \mathrm{cal} / 2.0))$ $\mathrm{S}=$ mdb.models['Modelo_2Fios_Global'].ConstrainedSketch(name='_profile__', sheetSize $=176.27$, gridSpacing $=4.4$, transform $=$ t)

s.Line $($ point1 $=(\mathrm{cal} / 2.0, \mathrm{Ral})$, point2 $=(\mathrm{cal} / 2.0,-\mathrm{Ral}))$

parte_inferior1 $=\mathrm{cal} / 2.0-\tan (\operatorname{graus} 2 \mathrm{rad}(\operatorname{theta} 2))^{\star} \mathrm{dal}$

s.Line $\left(\right.$ point1 $=\left(\right.$ parte_inferior 1, Ral $^{*}$ sinal $)$, point2 $=\left(\mathrm{cal} / 2.0, \mathrm{Ral}^{*}\right.$ sinal $\left.)\right)$

s.Line $\left(\right.$ point $1=\left(\right.$ parte_inferior 1, Ral $^{*}$ sinal $)$, point2 $=\left(\right.$ cal $/ 2.0,-$ Ral $^{*}$ sinal $\left.)\right)$

s.Line $($ point1 = $(-$ cal/2.0,Ral $)$, point2 $=(-$ cal $/ 2.0,-$ Ral $))$

parte_inferior2 $=-\mathrm{cal} / 2.0+\tan (\operatorname{graus} 2 \mathrm{rad}(\text { theta2 }))^{*} \mathrm{dal}$

s.Line $\left(\right.$ point1 $=\left(-\right.$ cal $/ 2.0,-$ Ral ${ }^{*}$ sinal $)$, point2 $=\left(\right.$ parte_inferior2,-Ral ${ }^{*}$ sinal $\left.)\right)$

s.Line $\left(\right.$ point1 $=\left(-\right.$ cal $/ 2.0$, Ral $^{*}$ sinal $)$, point2 $=\left(\right.$ parte_inferior2, - Ral ${ }^{*}$ sinal $\left.)\right)$

parte2.CutExtrude(sketchPlane=planos, I

$$
\begin{aligned}
& \text { sketchUpEdge=arestas, । } \\
& \text { sketchPlaneSide=SIDE1, । } \\
& \text { sketchOrientation=RIGHT, । } \\
& \text { sketch=s, । } \\
& \text { flipExtrudeDirection=ON) }
\end{aligned}
$$

\# Bloco Representando a Telha do Grampo de Suspensao:

bloco $=$ mdb.models['Modelo_2Fios_Global']. ।

ConstrainedSketch(name='Bloco', sheetSize = lbl) bloco.rectangle(point1=(-|b|/2.0, -|b|/2.0), । 
point2=(lbl/2.0, lbl/2.0) $)$

Fios_Global.Part(name='Bloco', ।

dimensionality=THREE_D, I

type=DISCRETE_RIGID_SURFACE)

parte3 = Fios_Global.parts['Bloco']

parte3.BaseSolidExtrude $($ sketch=bloco, depth $=\mathrm{cbl})$

\# Transformando Solido em Casca:

cells_bloco $=$ parte3.cells.findAt $((0.0,0.0, \mathrm{cbl} / 2.0)$,

parte3.RemoveCells $($ cellList $=($ cells_bloco, $))$

\# Utilizar o Comando Round nas Extremidades do Bloco:

aresta_para_round $1=$ parte3.edges.findAt $((0.0,-\mid \mathrm{lbl} / 2.0,0.0)$, $)$

aresta_para_round2 $=$ parte3.edges.findAt $((0.0,-\mid \mathrm{lbl} / 2.0, \mathrm{cbl})$,

parte3. Round $($ radius $=$ rfbl, $\backslash$

$$
\begin{array}{r}
\text { edgeList }=(\text { aresta_para_round1, I } \\
\text { aresta_para_round2, ) })
\end{array}
$$

\# Cilindro Representando a Camada 3 e a Alma de Aco:

cilindro = mdb.models['Modelo_2Fios_Global']. ।

ConstrainedSketch(name='Cilindro de Aco', । sheetSize $=3.0^{*} \mathrm{dst}$ )

cilindro. CircleByCenterPerimeter $($ center $=(0.0,0.0), ।$

$$
\text { point1 }=(0.0, \text { Rcil }))
$$

Fios_Global.Part(name='Cilindro de Aco', ।

$$
\begin{aligned}
& \text { dimensionality=THREE_D, I } \\
& \text { type=DISCRETE_RIGID_SURFACE) }
\end{aligned}
$$

parte4 = Fios_Global.parts['Cilindro de Aco'] 
parte4.BaseSolidExtrude(sketch=cilindro,depth $=$ cst $)$

\# Transformando Solido em Casca:

cells_cilindro $=$ parte4.cells. findAt $((0.0,0.0$, cst $)$,

parte4.RemoveCells $($ cellList $=($ cells_cilindro, $))$

\#

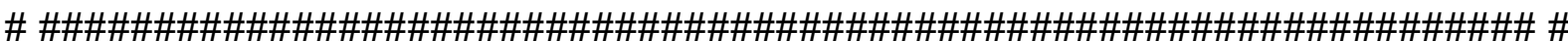

\#

Material

\#

\#

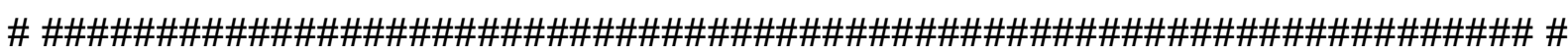
\#

\# Importanto o modulo responsavel pela definicao do material da simulacao:

import material

\# Aluminio $1350 \mathrm{H} 19$ :

Fios_Global.Material(name='Aluminio 1350-H19')

Fios_Global.materials['Aluminio 1350-H19'].Elastic(table $=(($ Eal, val), $))$

Fios_Global.materials['Aluminio 1350-H19'].Plastic(table $=$ dados_plast)

Fios_Global.materials['Aluminio 1350-H19'].Density $($ table $=(($ rhoal, $), ~))$

\#

\# Criando a Secao e Selecionando as Partes:

import section

\# Criar a secao para o material da simulacao

secaoaluminio=Fios_Global. $\mid$

HomogeneousSolidSection(name='Secao do Aluminio', । 
\# Selecionar a secao dos fios

\# Fio de aluminio camada 1

fiocamada1_regiao=(fio_aluminio_1.cells, $)$

fio_aluminio_1.SectionAssignment(region=fiocamada1_regiao, ।

sectionName='Secao do Aluminio')

\# Fio de aluminio camada 2

fiocamada2_regiao=(fio_aluminio_2.cells, $)$

fio_aluminio_2.SectionAssignment(region=fiocamada2_regiao, ।

sectionName='Secao do Aluminio')

\# -

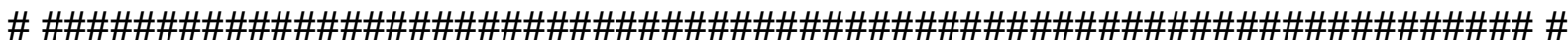

\#

\#

Montagem

\#

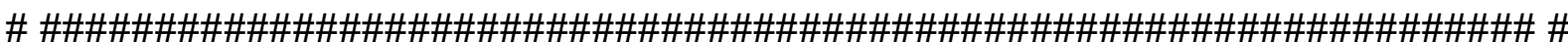
\#

\# Importando o modulo de montagem da simulacao numerica:

import assembly

\#

\# Plano de Referencia

Modelo_assembly =Fios_Global.rootAssembly

Modelo_assembly.DatumCsysByDefault(CARTESIAN)

\# 
\# Inserir partes da montagem

fio_aluminio_1Instance $=$ Modelo_assembly. ।

$$
\begin{gathered}
\text { Instance(name='Fio de Aluminio - Camada 1-1', । } \\
\text { part=parte1, । } \\
\text { dependent=ON) }
\end{gathered}
$$

fio_aluminio_2Instance $=$ Modelo_assembly. I

$$
\begin{gathered}
\text { Instance(name='Fio de Aluminio - Camada 2-1', । } \\
\text { part=parte2, । } \\
\text { dependent=ON) }
\end{gathered}
$$

blocolnstance $=$ Modelo_assembly.Instance $($ name $=$ 'Bloco-1', I

part=parte3, I

dependent=ON)

cilindrolnstance $=$ Modelo_assembly.Instance $($ name $=$ 'Cilindro de Aco-1', I

$$
\begin{aligned}
& \text { part=parte4, I } \\
& \text { dependent=ON) }
\end{aligned}
$$

\#

\# Montagem das Partes Considerando o Posicionamento:

\# Translacao em z:

Modelo_assembly.translate(instanceList=('Fio de Aluminio - Camada 1-1', ), I

$$
\text { vector }=(0.0,0.0,-\mathrm{cal} / 2.0))
$$

Modelo_assembly.translate(instanceList=('Fio de Aluminio - Camada 2-1', ), I

$$
\text { vector }=(0.0,0.0,-\mathrm{cal} / 2.0))
$$

Modelo_assembly.translate(instanceList=('Bloco-1', ), ।

$$
\text { vector }=(0.0,0.0,-\mathrm{cbl} / 2.0))
$$

Modelo_assembly.translate(instanceList=('Cilindro de Aco-1', ), I 


$$
\text { vector }=(0.0,0.0,-\mathrm{cst} / 2.0))
$$

\# Translacao em y:

Modelo_assembly.translate(instanceList=('Fio de Aluminio - Camada 1-1', ), I

$$
\text { vector }=(0.0, \text { Ral, 0.0) })
$$

Modelo_assembly.translate(instanceList=('Fio de Aluminio - Camada 2-1', ), I

$$
\text { vector }=(0.0,- \text { Ral, 0.0) })
$$

Modelo_assembly.translate(instanceList=('Bloco-1', ), ।

$$
\text { vector }=(0.0, \mathrm{lbl} / 2.0+\text { dal, } 0.0))
$$

Modelo_assembly.translate(instanceList=('Cilindro de Aco-1', ), I

$$
\text { vector }=(0.0,- \text { dal }- \text { Rcil, } 0.0))
$$

\# Rotacao:

Modelo_assembly.rotate $\left(\right.$ angle $=$ theta ${ }^{*}{ }^{*}$ sinal, I

$$
\begin{aligned}
& \text { axisDirection }=(0.0, \text { dal, } 0.0), \backslash \\
& \text { axisPoint=(0.0, - Ral, 0.0), । } \\
& \text { instanceList=('Fio de Aluminio - Camada 1-1', )) }
\end{aligned}
$$

Modelo_assembly.rotate(angle=-theta2* ${ }^{*}$ inal, ।

$$
\begin{aligned}
& \text { axisDirection }=(0.0, \text { dal, } 0.0), \backslash \\
& \text { axisPoint=(0.0, - Ral, 0.0), । } \\
& \text { instanceList=('Fio de Aluminio - Camada 2-1', )) }
\end{aligned}
$$

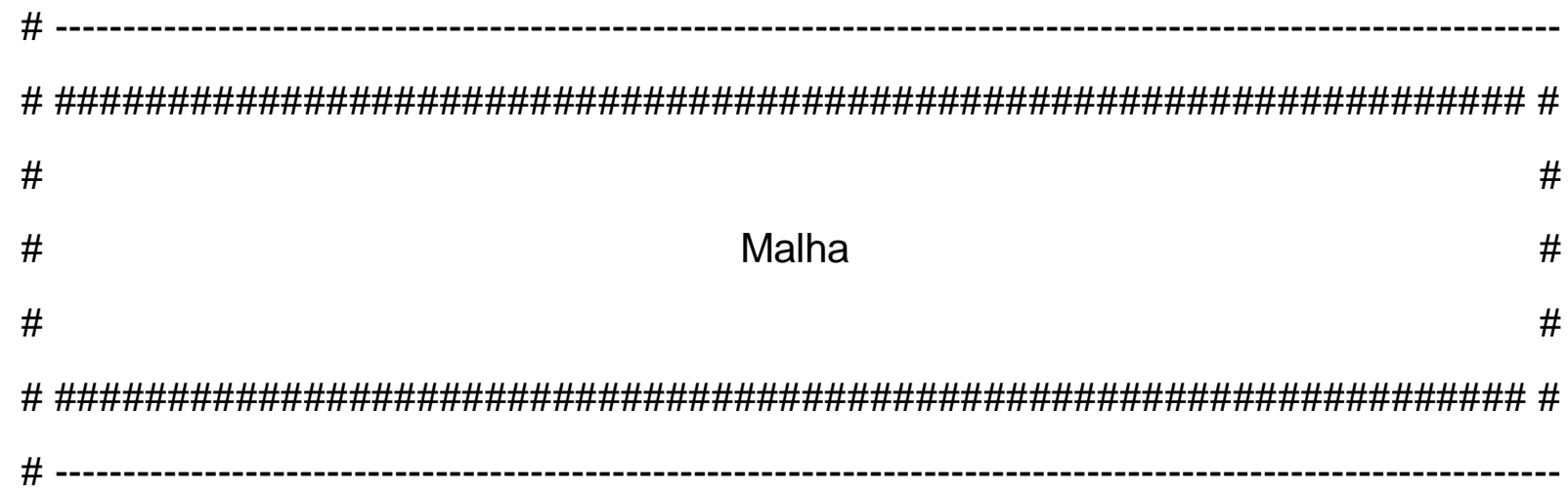


\# Importando o modulo de criacao da malha de elementos finitos:

import mesh

\#

\# Fio de aluminio da camada 1

fio_aluminio_1_Cells = parte1.cells

parte1.setMeshControls(algorithm=ADVANCING_FRONT, I

regions=fio_aluminio_1_Cells, 1

technique=SWEEP)

\# Elemento do Fio Camada 1:

elemType1 $=$ mesh. ElemType $($ elemCode $=$ C3D8R, 1

elemLibrary=STANDARD, 1

hourglassStiffness $=0.5,1$

kinematicSplit=AVERAGE STRAIN, ।

secondOrderAccuracy=OFF, 1

hourglassControl=STIFFNESS, I

distortionControl=DEFAULT)

parte1.setElementType(elemTypes=(elemType1,), ।

regions $=($ parte 1. cells, $))$

\#

\# Fio de aluminio da camada 2

fio_aluminio_2_Cells = parte2.cells

parte2.setMeshControls(algorithm=ADVANCING_FRONT, I 
regions=fio_aluminio_2_Cells, I

technique=SWEEP)

\# Elemento do Fio Camada 2:

elemType2 $=$ mesh. ElemType $($ elemCode $=$ C3D8R, $।$

elemLibrary=STANDARD, I

hourglassStiffness $=0.5$, ।

kinematicSplit=AVERAGE_STRAIN, I

secondOrderAccuracy=OFF, I

hourglassControl=STIFFNESS, I

distortionControl=DEFAULT)

parte2.setElementType(elemTypes=(elemType2,), ।

regions $=($ parte2.cells, $))$

\#

\# Gerando a Malha:

parte1.seedPart(size $=0.13$, deviationFactor $=0.04$, minSizeFactor $=0.1$ )

parte2. seedPart(size=0.13, deviationFactor=0.04, minSizeFactor $=0.1$ )

parte3.seedPart(size=0.5, deviationFactor=0.1, minSizeFactor=0.1)

parte4. seedPart(size $=0.5$, deviationFactor $=0.1$, $\operatorname{minSizeFactor}=0.1$ )

parte1.generateMesh()

parte2.generateMesh()

parte3.generateMesh()

parte4.generateMesh() 


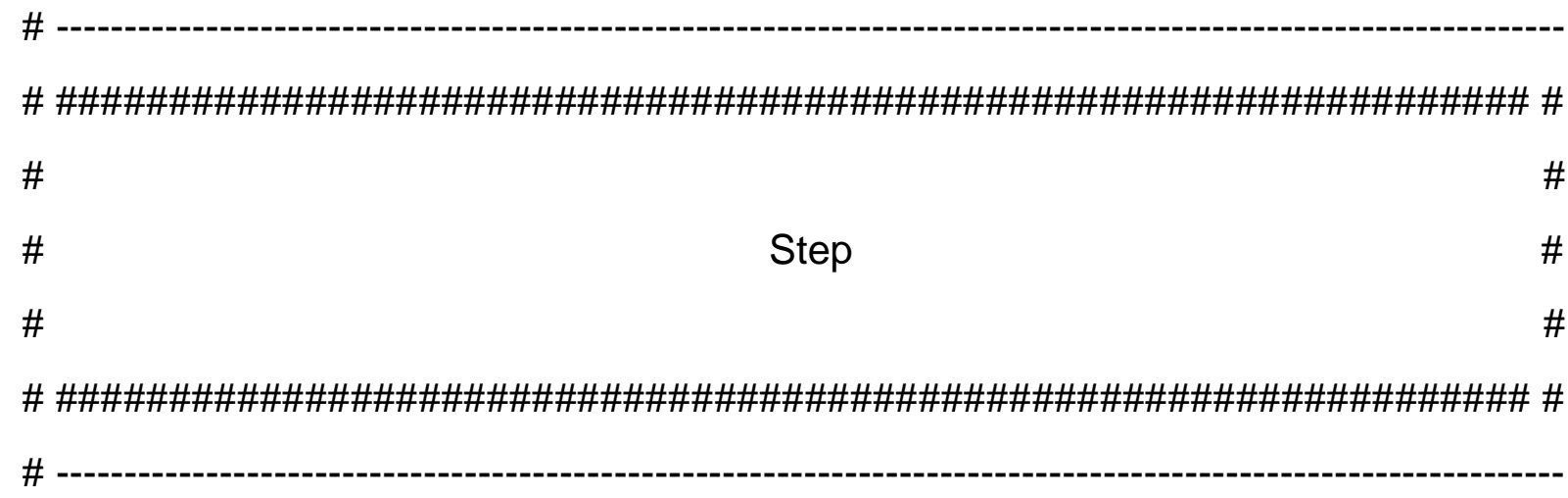

\# Importando o modulo para criacao do metodo de obtencao de solucao por \# elementos finitos:

import step

\# step - 'Tracao dos Fios'

Fios_Global.I

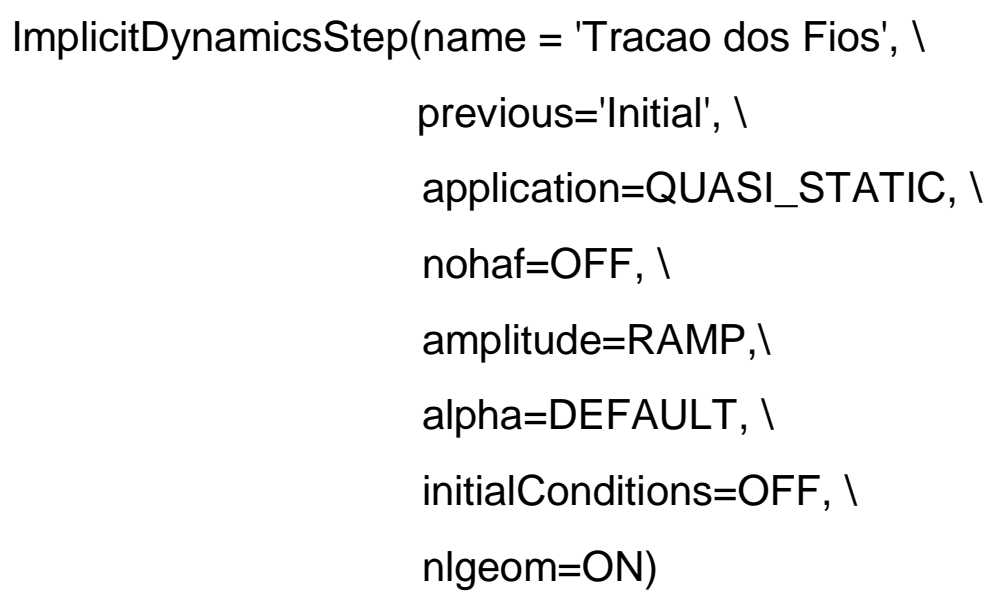

\# step - 'Pressao Realizada pelo Grampo'

Fios_Global.I

ImplicitDynamicsStep(alpha=DEFAULT, ।

amplitude=RAMP, ।

application=QUASI_STATIC, ।

initialConditions=OFF, 1 


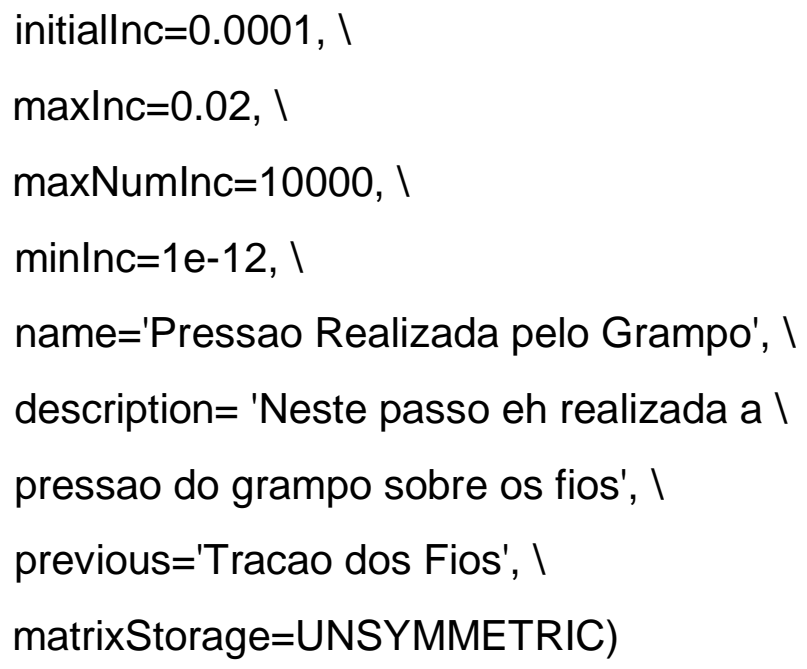

\# step - 'Retirada da Carga Normal'

Fios_Global.I

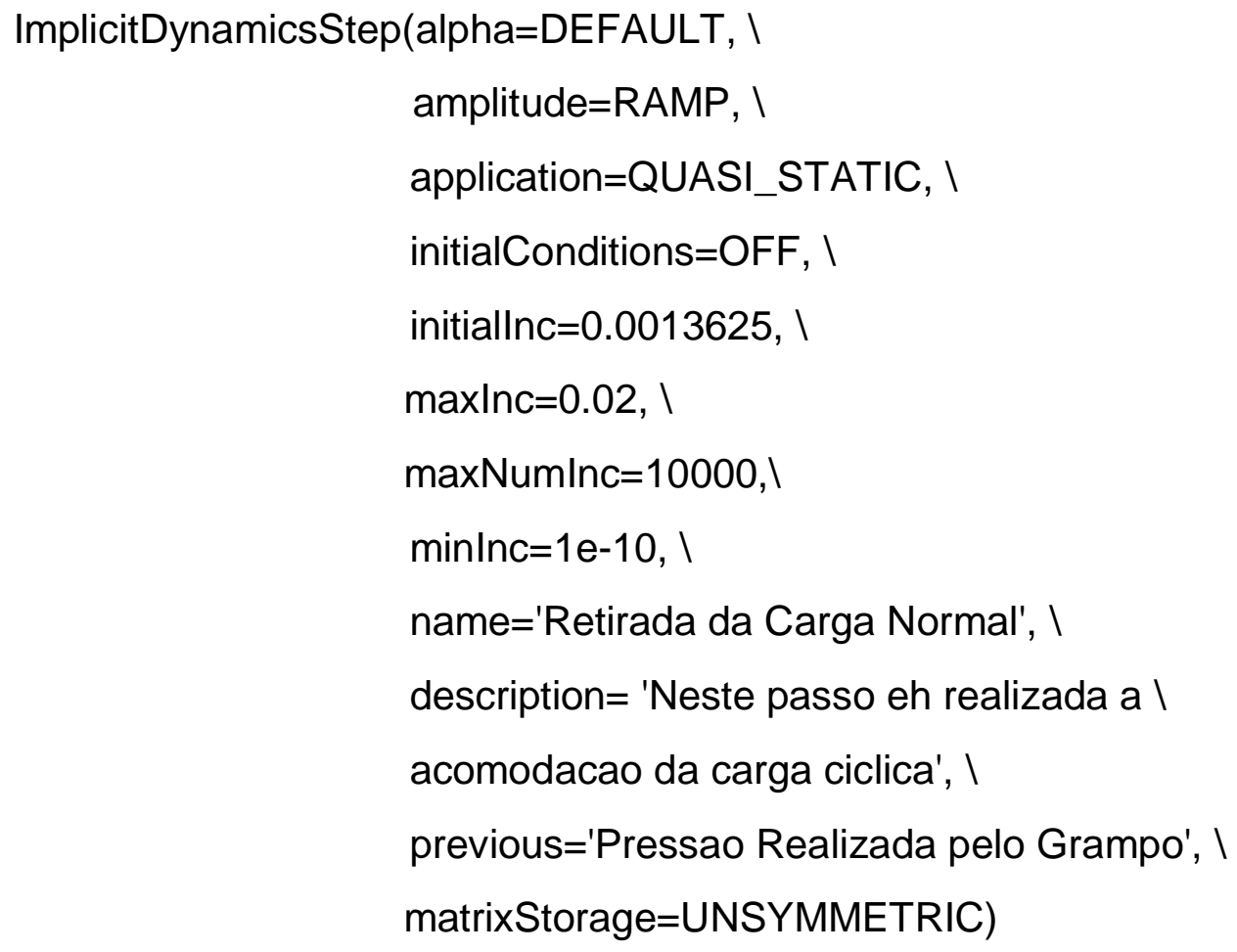

\# step - 'Retirada da Carga de Tracao'

Fios_Global.I

ImplicitDynamicsStep(alpha=DEFAULT, । amplitude=RAMP, $\backslash$ 

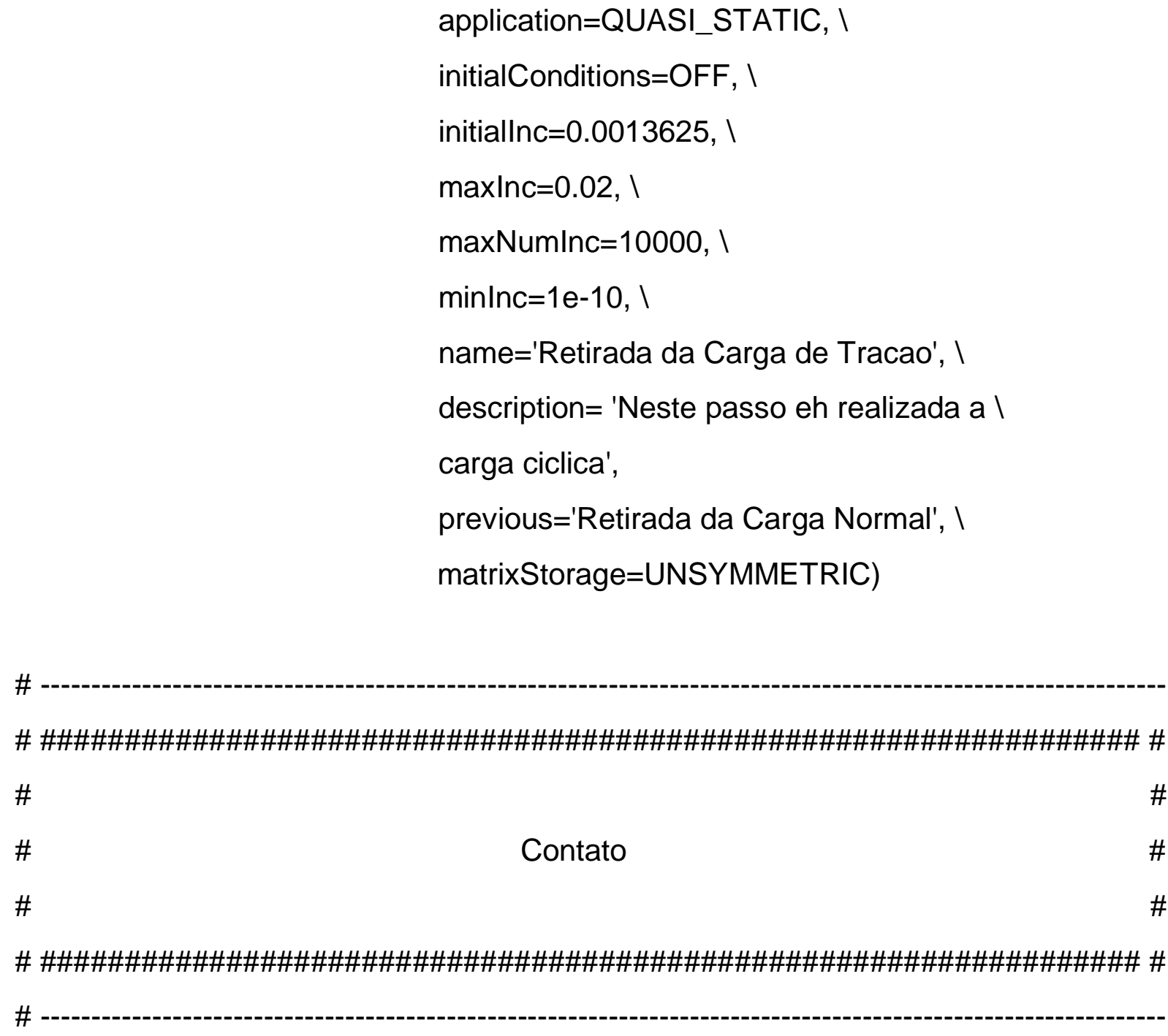

\# Propriedade de Contato entre os Fios de Aluminio

contato_atrito=Fios_Global.ContactProperty('Propriedades de Contato')

Fios_Global.interactionProperties['Propriedades de Contato']. I

TangentialBehavior(dependencies $=0,1$

$$
\begin{aligned}
& \text { directionality=ISOTROPIC, \} } \\
{\text { formulation=PENALTY, । }} \\
{\text { pressureDependency=OFF, । }} \\
{\text { shearStressLimit=None, \} } \\
{\text { slipRateDependency=OFF, । }} \\
{\text { table=((coef_atrito, ), ), । }} \\
{\text { temperatureDependency=OFF, । }}
\end{array}
\end{aligned}
$$




$$
\begin{aligned}
& \text { maximumElasticSlip=FRACTION, I } \\
& \text { fraction=0.005, । } \\
& \text { elasticSlipStiffness=None) }
\end{aligned}
$$

Fios_Global.interactionProperties['Propriedades de Contato']. I

$$
\begin{aligned}
& \text { NormalBehavior } \\
& \qquad \begin{array}{l}
\text { allowSeparation=ON, } \\
\text { constraintEnforcementMethod=DEFAULT, } \\
\text { pressureOverclosure=HARD) }
\end{array}
\end{aligned}
$$

\#

\# Propriedade de Contato com os Corpos Rigidos:

contato $=$ Fios_Global.ContactProperty('Propriedades de Contato Corpos Rigidos')

Fios_Global.interactionProperties['Propriedades de Contato Corpos Rigidos']. I TangentialBehavior(formulation = FRICTIONLESS)

Fios_Global.interactionProperties['Propriedades de Contato Corpos Rigidos']. I NormalBehavior(allowSeparation=ON, constraintEnforcementMethod=DEFAULT, pressureOverclosure=HARD)

\# -

\# Criando as Interacoes de Contato:

\# Entre o Bloco e o Fio de Aluminio da Camada 1:

$$
\mathrm{xbl}=0.0
$$$$
\mathrm{ybl}=\text { dal+rfbl-rfbl }{ }^{*} \sin (\operatorname{graus} 2 \operatorname{rad}(45)) \text {; }
$$$$
\mathrm{zbl}=-(\mathrm{cbl} / 2.0)+\left(\mathrm{rfbl}-\mathrm{rfb}{ }^{*} \cos (\operatorname{graus} 2 \mathrm{rad}(45))\right)
$$

face_bloco_ponto1=(xbl,ybl,zbl)

face_bloco_ponto2 $=(0.0, \mathrm{dal}, 0.0)$

face_bloco_ponto3=(xbl,ybl,-zbl)

face_bloco=blocolnstance.faces.findAt((face_bloco_ponto1,), I 
(face_bloco_ponto2,), I

(face_bloco_ponto3,))

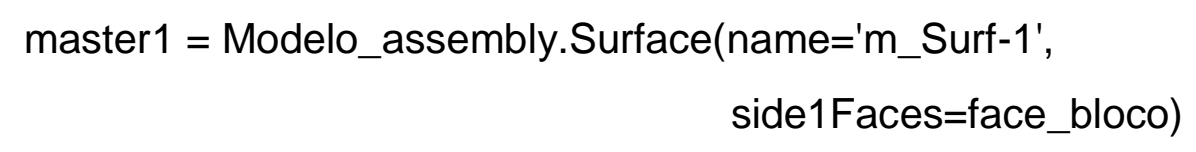

Fios_Global. ।

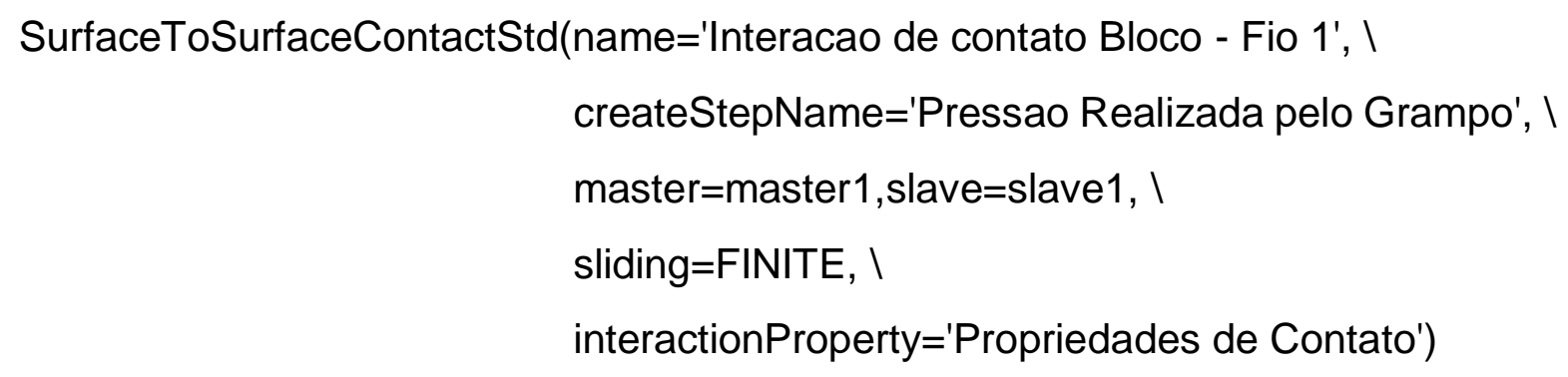

\# Entre o Fio de Aluminio da Camada 1 e da Camada 2:

master2 = Modelo_assembly.Surface(name='m_Surf-2', I side1Faces=face_sup_fio_aluminio_1)

face_sup_fio_aluminio_2_ponto1 $=(0.0,0.0,0.0)$

face_sup_fio_aluminio_2=fio_aluminio_2Instance. I faces.findAt((face_sup_fio_aluminio_2_ponto1,)) 
slave2 = Modelo_assembly.Surface(name='s_Surf-2', ।

side1Faces=face_sup_fio_aluminio_2)

Fios_Global. I

SurfaceToSurfaceContactStd(name='Interacao de contato Fio 1 - Fio 2', I createStepName='Pressao Realizada pelo Grampo', । master $=$ master2, slave=slave2, । sliding=FINITE, I interactionProperty='Propriedades de Contato')

\# Entre o Fio de Aluminio da Camada 2 e o Cilindro de Aco:

slave3 = Modelo_assembly.Surface(name='s_Surf-3', । side1Faces=face_sup_fio_aluminio_2)

face_sup_cilindro_ponto $1=(0 .,-$ dal, 0 . $)$

face_sup_cilindro=cilindrolnstance. $I$ faces.findAt((face_sup_cilindro_ponto1,))

master3 = Modelo_assembly.Surface(name='m_Surf-3', । side1Faces=face_sup_cilindro)

Fios_Global. I

SurfaceToSurfaceContactStd(name='Interacao de contato Fio 2 - Cilindro', I createStepName='Pressao Realizada pelo Grampo', । master $=$ master 3 ,slave=slave3, । sliding=FINITE, I interactionProperty='Propriedades de Contato')

\#

\# Restricoes e Pontos de Referencia: 
\# Pontos de Referencia:

$$
\begin{aligned}
& \text { XRP_1 }=(\sin (\operatorname{graus} 2 \operatorname{rad}(\text { theta1 })) / 2.0)^{*}\left(\text { cal-dal }{ }^{*} \tan (\operatorname{graus} 2 \operatorname{rad}(\text { theta1 }))\right) \\
& x R P \_2=(\sin (\operatorname{graus} 2 \operatorname{rad}(\text { theta2 })) / 2.0)^{*}(\text { cal-dal*tan }(\operatorname{graus} 2 \operatorname{rad}(\text { theta2 }))) \\
& x R P \_3=x R P \_2 \\
& x R P \_4=-x R P \_1 \\
& x R P \_5=(d a l+\mid b l)^{*} 1.843 \text {; } \\
& x R P \_6=-x R P \_5 \text {; } \\
& \text { RP1 = Modelo_assembly.ReferencePoint }\left(\text { point }=\left(x R P \_1{ }^{*} \text { sinal,Ral, }(\text { cal } / 2.0)^{*} 1.125\right)\right) \\
& \text { RP2 = Modelo_assembly.ReferencePoint(point=(-xRP_2*sinal,-Ral,(cal/2.0)*1.125)) } \\
& \text { RP3 = Modelo_assembly.ReferencePoint (point=(xRP_3*sinal,-Ral,-(cal/2.0)*1.125) }) \\
& \text { RP4 = Modelo_assembly.ReferencePoint(point }=\left(x R P \_4{ }^{*}\right. \text { sinal,Ral,-(cal/2.0*1.125)) } \\
& \text { RP5 = Modelo_assembly.ReferencePoint }(\text { point=(0.0,xRP_5,0.0)) } \\
& \text { RP6 = Modelo_assembly. ReferencePoint }\left(\text { point }=\left(0.0, x R P \_6,0.0\right)\right)
\end{aligned}
$$

\# Restricoes:

\# Fio de Aluminio Camada 1 - Lado Esquerdo:

refPoints1=(Modelo_assembly.referencePoints[16], )

Modelo_assembly.Set(referencePoints=refPoints1, name='Set-1')

yp1 = ((cal/2.0)-Ral*tan(graus2rad(theta1)) ${ }^{\star} \cos (\operatorname{graus} 2 \mathrm{rad}($ theta1 $))$

face_lateral_esq_fio1_1=(xRP_1*sinal,Ral,yp1)

face_lateral_esq_fio1 = fio_aluminio_1lnstance.faces. I findAt((face_lateral_esq_fio1_1,))

Modelo_assembly.Surface(name='master_RP_1',side1Faces=face_lateral_esq_fio1) 
Fios_Global.Coupling(controlPoint=Modelo_assembly.sets['Set-1'], ।

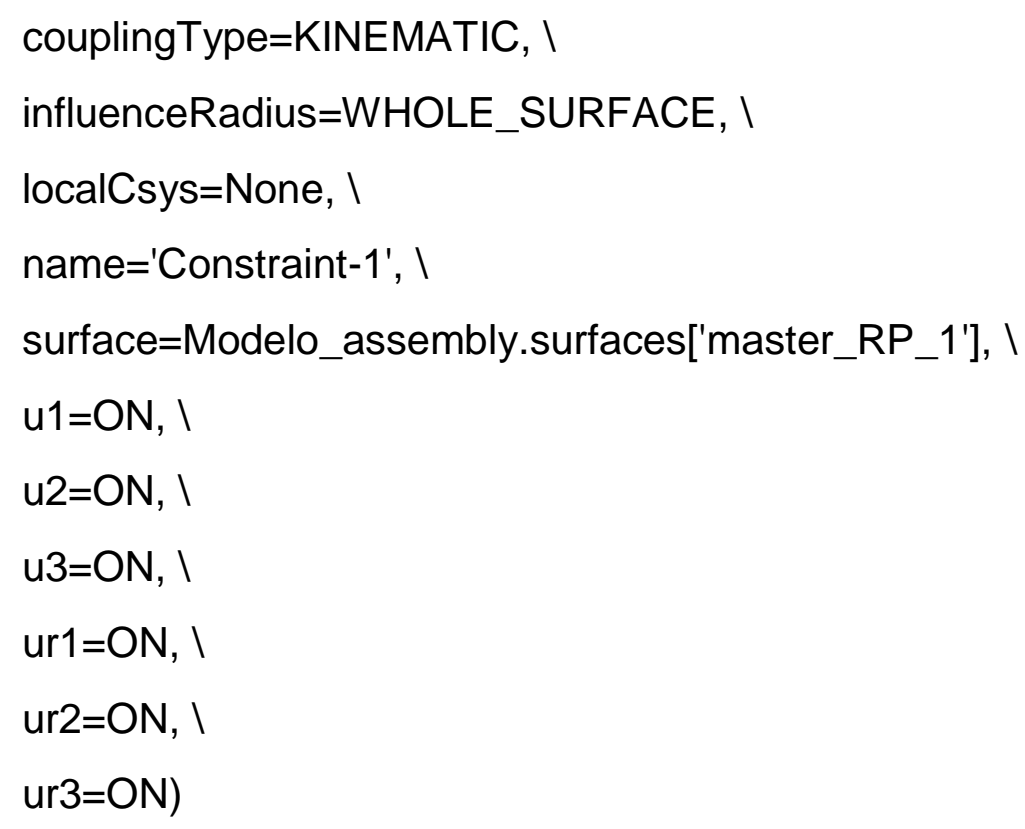

\# Fio de Aluminio Camada 2 - Lado Esquerdo:

refPoints2=(Modelo_assembly.referencePoints[17], )

Modelo_assembly.Set(referencePoints=refPoints2, name='Set-2')

yp2 $=\left(\left(\text { cal/2.0) }- \text { Ral }{ }^{\star} \tan (\operatorname{graus} 2 \operatorname{rad}(\text { theta2 }))\right)^{*} \cos (\right.$ graus2rad (theta2) $)$

face_lateral_esq_fio2_1=(-xRP_2*sinal,-Ral,yp2)

face_lateral_esq_fio2 = fio_aluminio_2Instance.faces. 1

findAt((face_lateral_esq_fio2_1, ))

Modelo_assembly.Surface(name='master_RP_2',side1Faces=face_lateral_esq_fio2) 
Fios_Global.Coupling(controlPoint=Modelo_assembly.sets['Set-2'], ।

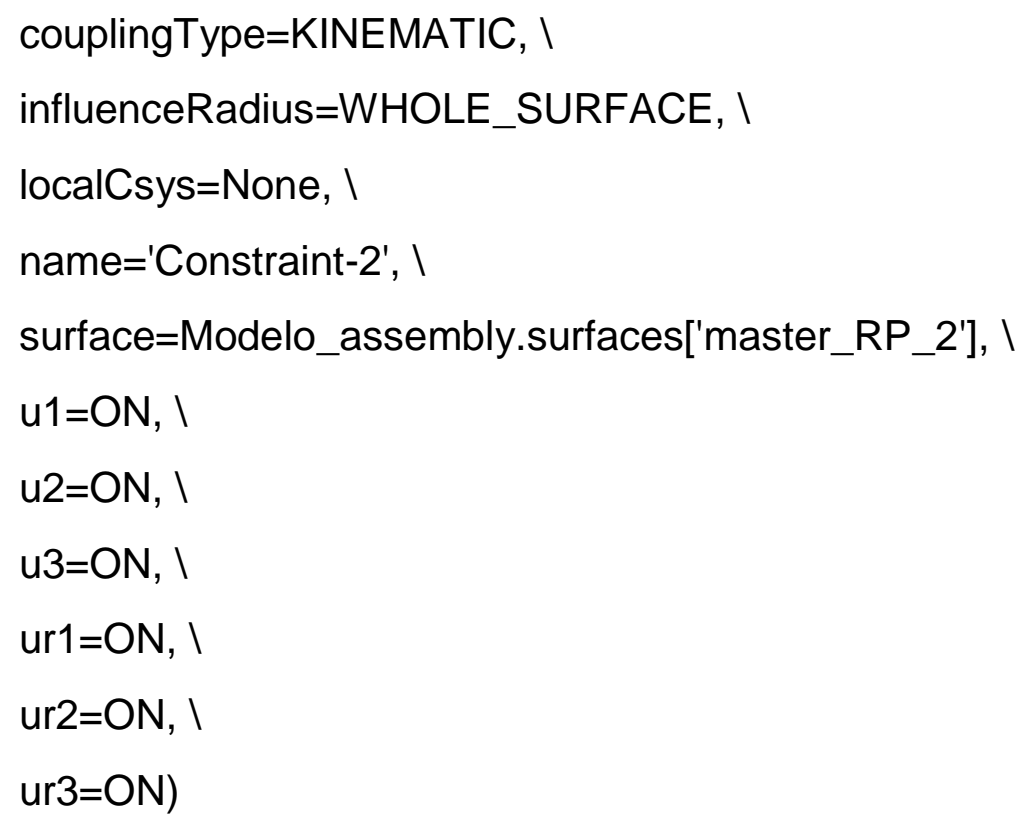

\# Fio de Aluminio Camada 2 - Lado Direito:

refPoints3=(Modelo_assembly.referencePoints[18], )

Modelo_assembly.Set(referencePoints=refPoints3, name='Set-3')

face_lateral_dir_fio2_1=(xRP_3*sinal,-Ral,-yp2)

face_lateral_dir_fio2 = fio_aluminio_2Instance.faces. I findAt((face_lateral_dir_fio2_1,))

Modelo_assembly.Surface(name='master_RP_3',side1Faces=face_lateral_dir_fio2)

Fios_Global.Coupling(controlPoint=Modelo_assembly.sets['Set-3'], । couplingType=KINEMATIC, । influenceRadius=WHOLE_SURFACE, 1 


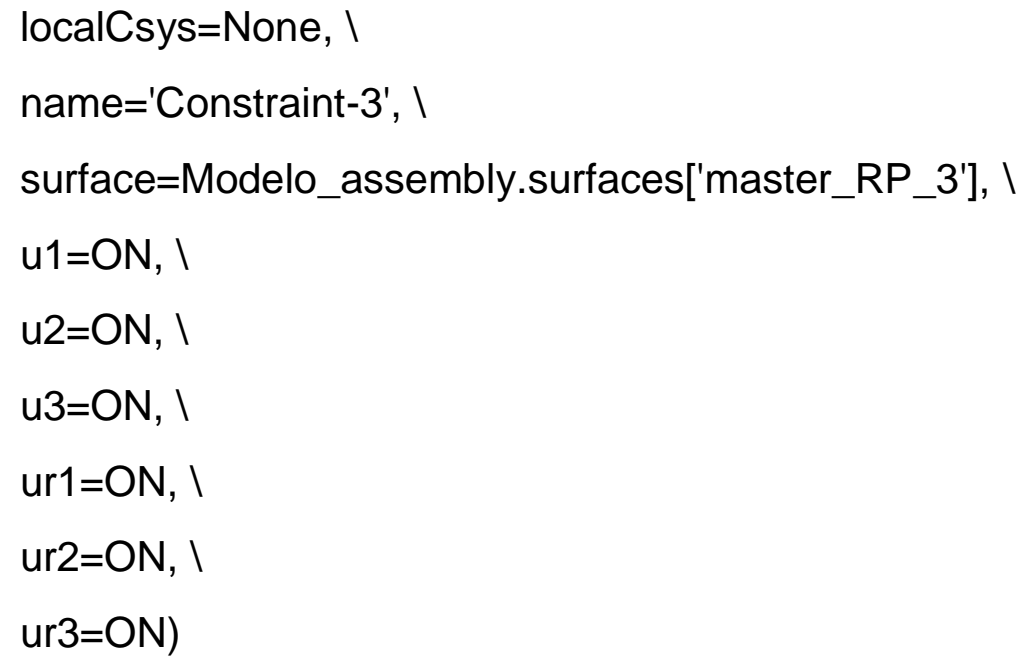

\# Fio de Aluminio Camada 1 - Lado Direito:

refPoints4=(Modelo_assembly.referencePoints[19], )

Modelo_assembly.Set(referencePoints=refPoints4, name='Set-4')

face_lateral_dir_fio1_1=(xRP_4*sinal,Ral,-yp1)

face_lateral_dir_fio1=fio_aluminio_1Instance.faces. I

findAt((face_lateral_dir_fio1_1,))

Modelo_assembly.Surface(name='master_RP_4',side1Faces=face_lateral_dir_fio1)

Fios_Global.Coupling(controlPoint=Modelo_assembly.sets['Set-4'], ।

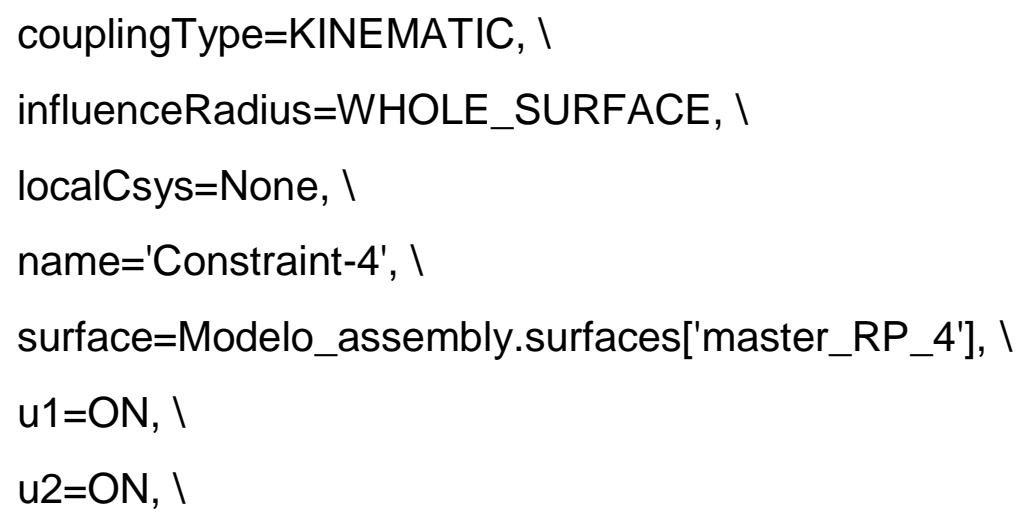




$$
\begin{aligned}
& u 3=O N, 1 \\
& u r 1=O N, 1 \\
& u r 2=O N, 1 \\
& u r 3=O N \text { ) }
\end{aligned}
$$

\# Bloco:

refPoints5=(Modelo_assembly.referencePoints[20], )

Modelo_assembly.Set(referencePoints=refPoints5, name='Set-5')

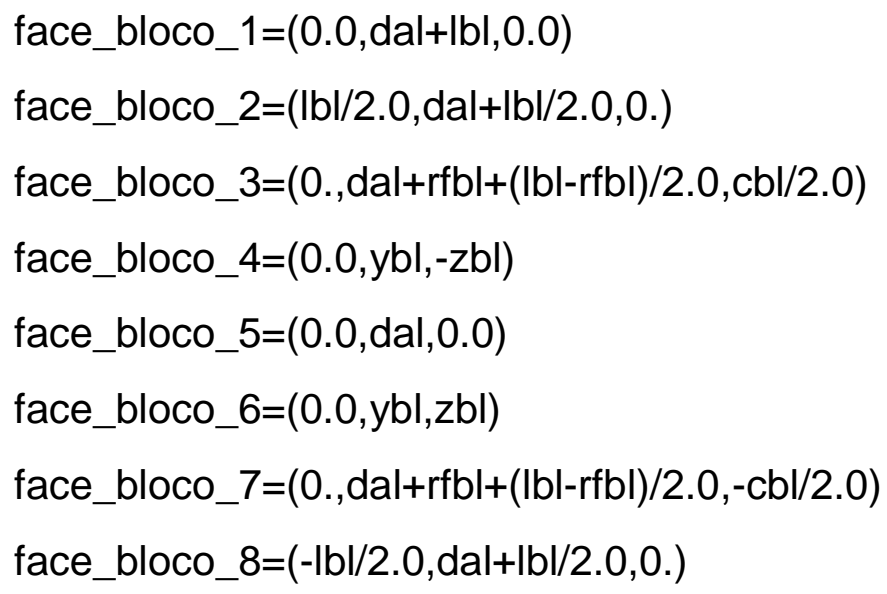

Modelo_assembly.Set(name='b_Set-RP5',faces=(face_bloco, ) )

Fios_Global.RigidBody(bodyRegion=Modelo_assembly.sets['b_Set-RP5'], I name='Constraint-5', । 
refPointRegion=Modelo_assembly.sets['Set-5'])

\# Cilindro:

refPoints6=(Modelo_assembly.referencePoints[21], )

Modelo_assembly.Set(referencePoints=refPoints6, name='Set-6')

ycilr $=$ dal + Rcil

face_cilindro_1 $=(0.0,-$ ycilr, cst $/ 2.0)$

face_cilindro_2 $=(0.0,-$ dal, 0.0$)$

face_cilindro_3=(0.0,-ycilr,-cst/2.0)

face_cilindro=cilindroInstance.faces.findAt((face_cilindro_1,), I

(face_cilindro_2,), ।

(face_cilindro_3,))

Modelo_assembly.Set(name='b_Set-RP6',faces=(face_cilindro, ))

Fios_Global.RigidBody(bodyRegion=Modelo_assembly.sets['b_Set-RP6'], ।

name='Constraint-6', ।

refPointRegion=Modelo_assembly.sets['Set-6'])

$\#$

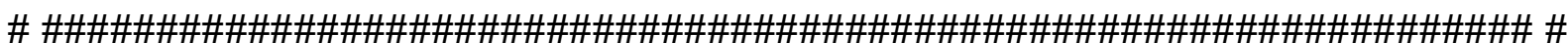

\# Condicoes de Contorno \#

\#

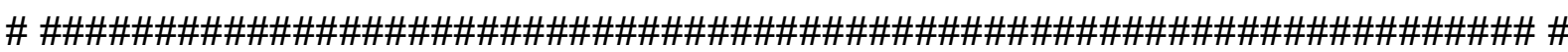
$\#$

\# Amplitudes:

Fios_Global.SmoothStepAmplitude(name='Amp-1', I 


$$
\begin{gathered}
\text { timeSpan=STEP }, \backslash \\
\text { data }=((0.0,1.0), \backslash \\
(0.5,0.0)))
\end{gathered}
$$

\#

\# Engaste - Cilindro de Aco:

Fios_Global.EncastreBC(createStepName='Initial', । localCsys=None,name='Engaste do fio de aco', । region=Modelo_assembly.sets['Set-6'])

\# -

\# Bloco:

Fios_Global.DisplacementBC(amplitude=UNSET, ।

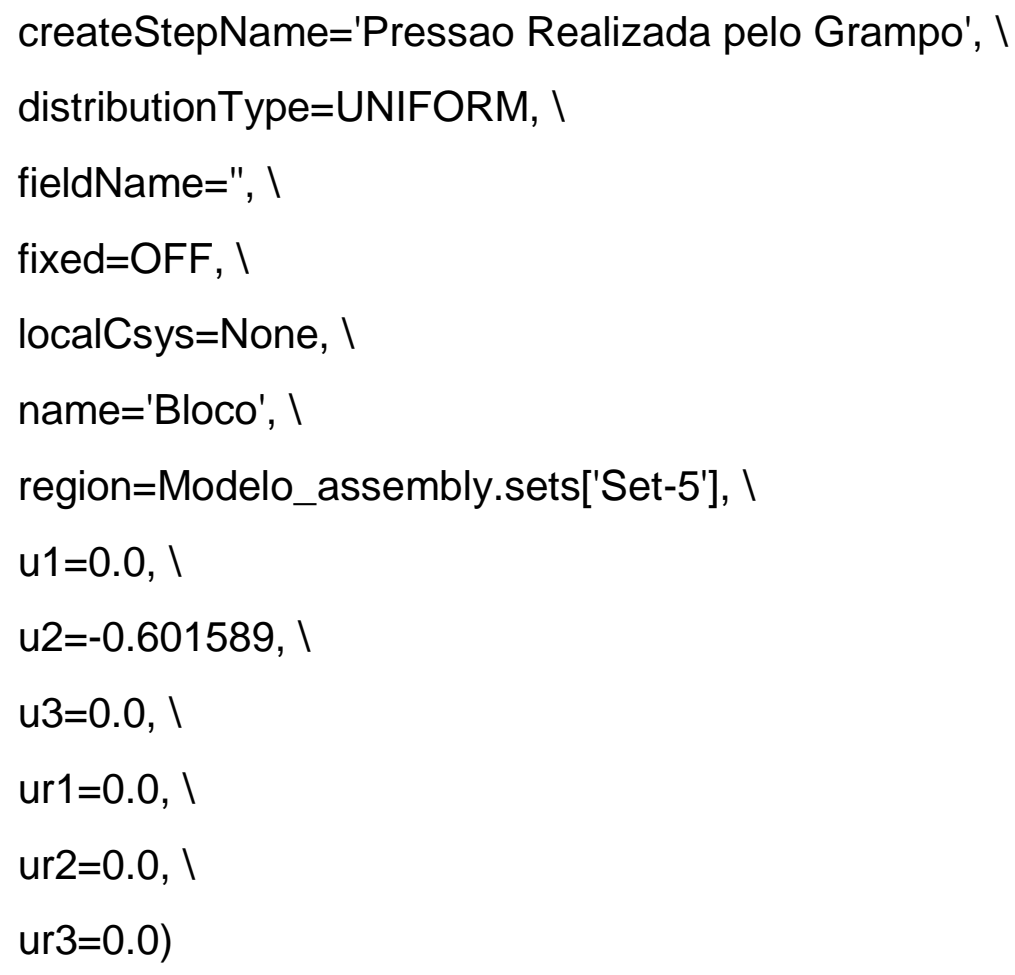

Fios_Global.boundaryConditions['Bloco']. I

setValuesInStep(stepName='Retirada da Carga Normal', ।

amplitude='Amp-1') 
Fios_Global.boundaryConditions['Bloco']. I

setValuesInStep(stepName='Retirada da Carga de Tracao', । $\mathrm{u} 2=0.0,1$

amplitude=FREED)

\#

\# Fio de Aluminio da Camada 1

Fios_Global.DisplacementBC(amplitude=UNSET, I

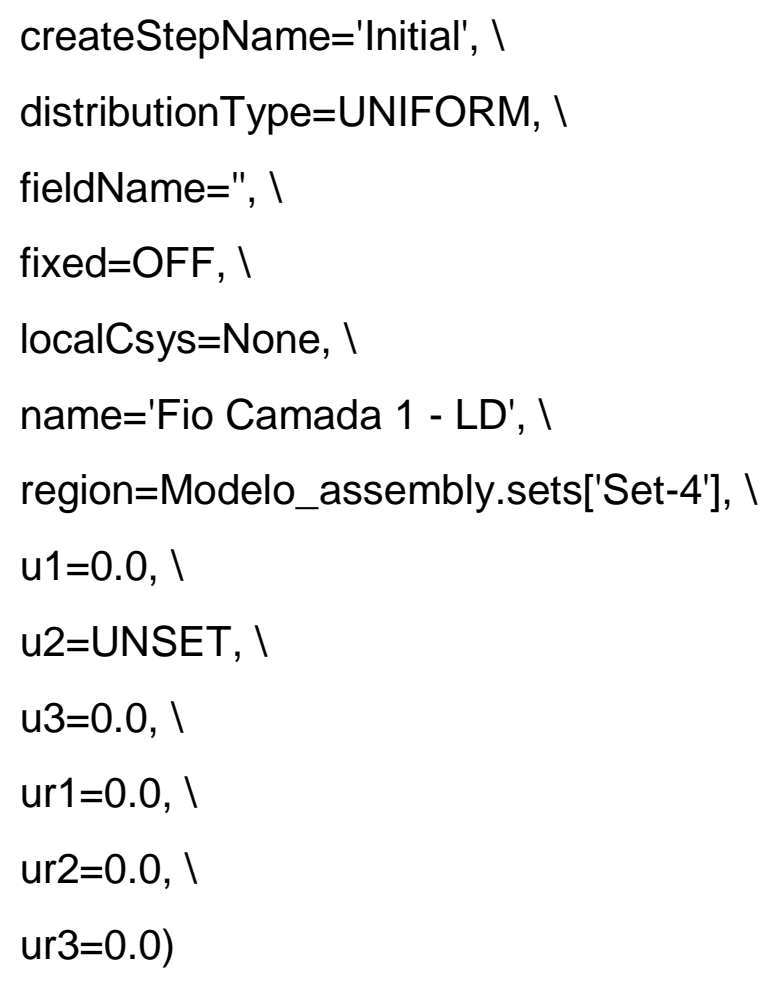

Fios_Global.DisplacementBC(amplitude=UNSET, ।

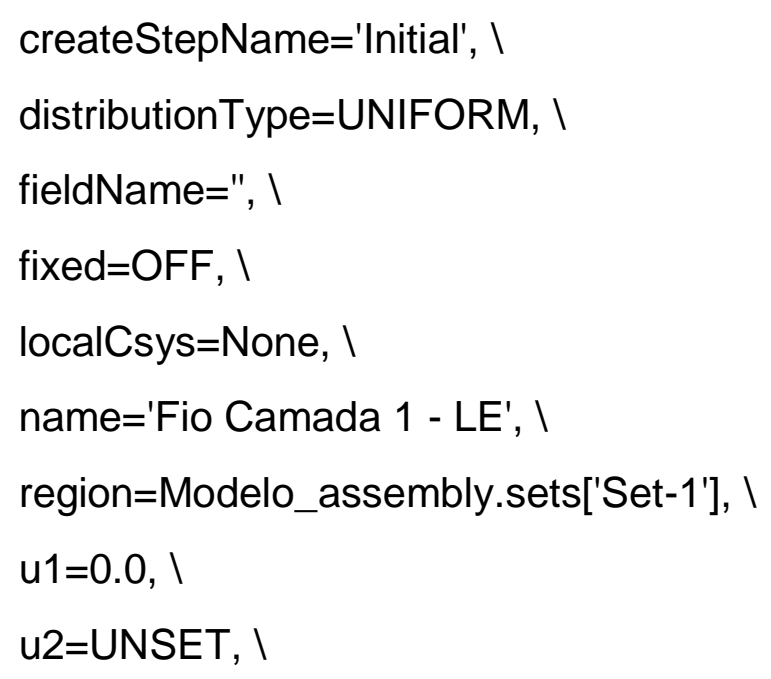




$$
\begin{aligned}
& \text { u3=UNSET, । } \\
& \text { ur1=0.0, । } \\
& \text { ur2=0.0, । } \\
& \text { ur3=0.0) }
\end{aligned}
$$

\#

\# Fio de Aluminio da Camada 2

Fios_Global.DisplacementBC(amplitude=UNSET, I

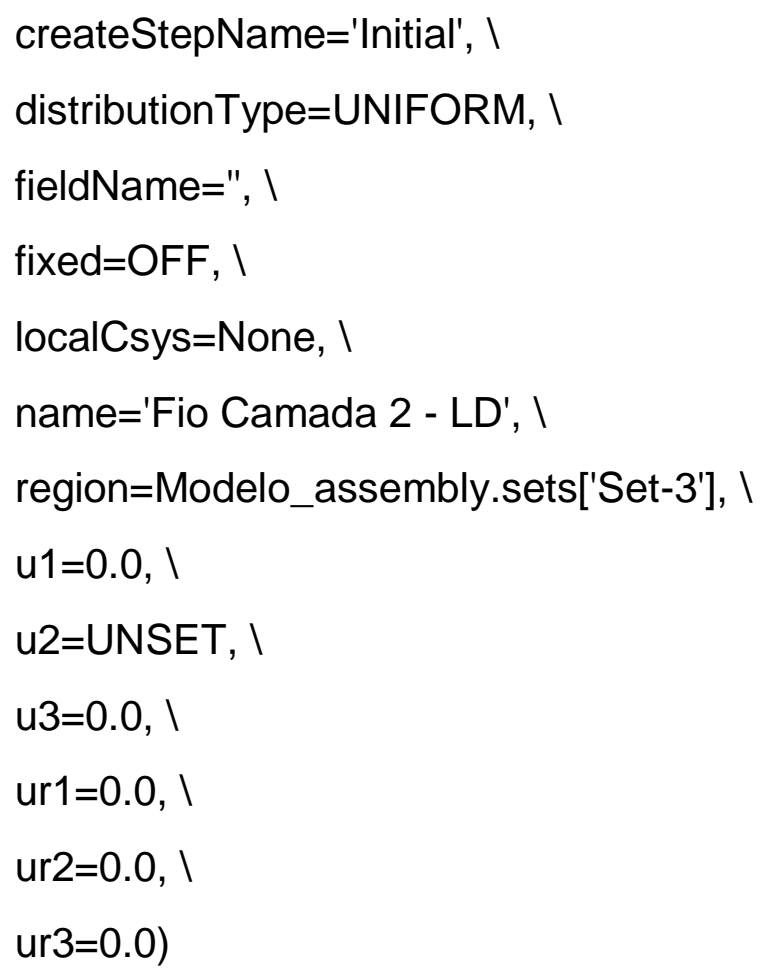

Fios_Global.DisplacementBC(amplitude=UNSET, I

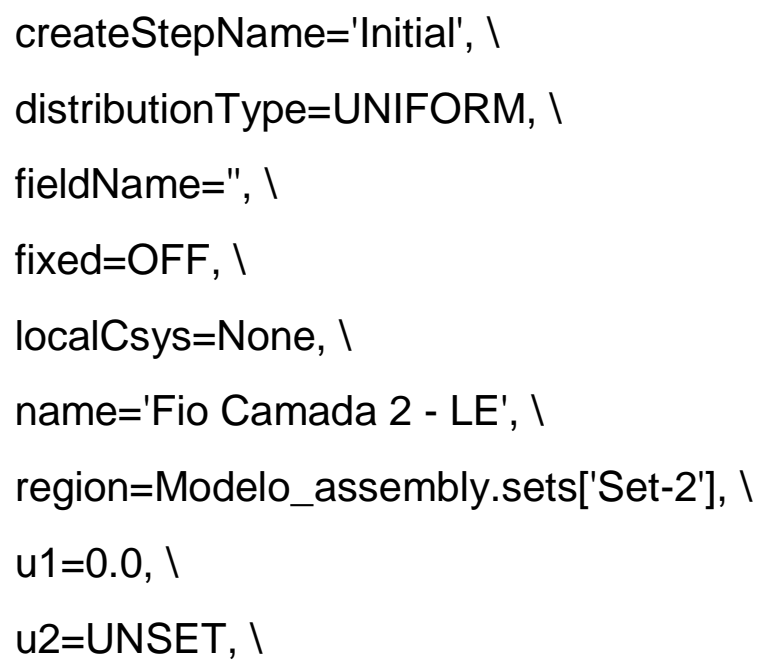




$$
\begin{aligned}
& \text { u3=UNSET, । } \\
& \text { ur1 }=0.0,1 \\
& \text { ur2 }=0.0, \backslash \\
& \text { ur3 }=0.0)
\end{aligned}
$$

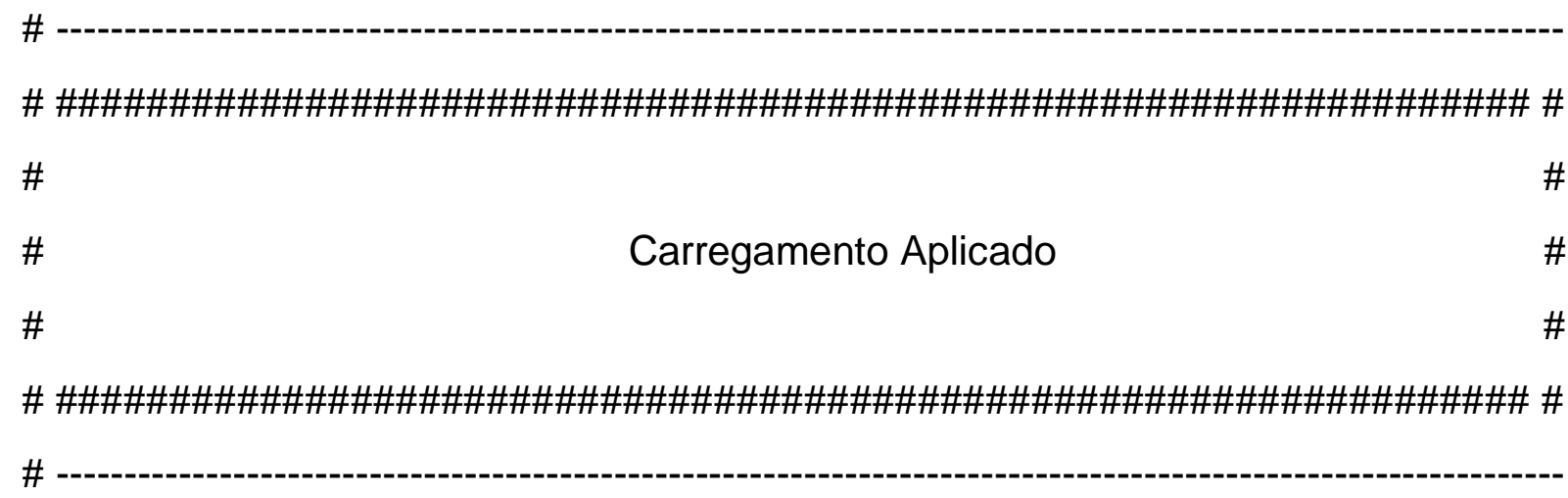

\# Fio de Aluminio Camada 1:

Fios_Global.ConcentratedForce(name='Forca Fio Aluminio 1 - Esq', I

$$
\begin{aligned}
& \text { createStepName='Tracao dos Fios', । } \\
& \text { region=Modelo_assembly.sets['Set-1'], । } \\
& \text { localCsys=None, I } \\
& \text { cf3=371.651, । } \\
& \text { distributionType=UNIFORM) }
\end{aligned}
$$

Fios_Global.loads['Forca Fio Aluminio 1 - Esq']. I

$$
\begin{aligned}
& \text { setValuesInStep(amplitude='Amp-1', । } \\
& \text { stepName='Retirada da Carga de Tracao') }
\end{aligned}
$$

\# -

\# Fio de Aluminio Camada 2:

Fios_Global.ConcentratedForce(name='Forca Fio Aluminio 2 - Esq', I createStepName='Tracao dos Fios', I region=Modelo_assembly.sets['Set-2'], । 


$$
\begin{aligned}
& \text { localCsys=None, } \backslash \\
& \text { cf3=371.651, } \backslash \\
& \text { distributionType=UNIFORM) }
\end{aligned}
$$

Fios_Global.loads['Forca Fio Aluminio 2 - Esq']. I setValuesInStep(amplitude='Amp-1', ।

$$
\text { stepName='Retirada da Carga de Tracao') }
$$

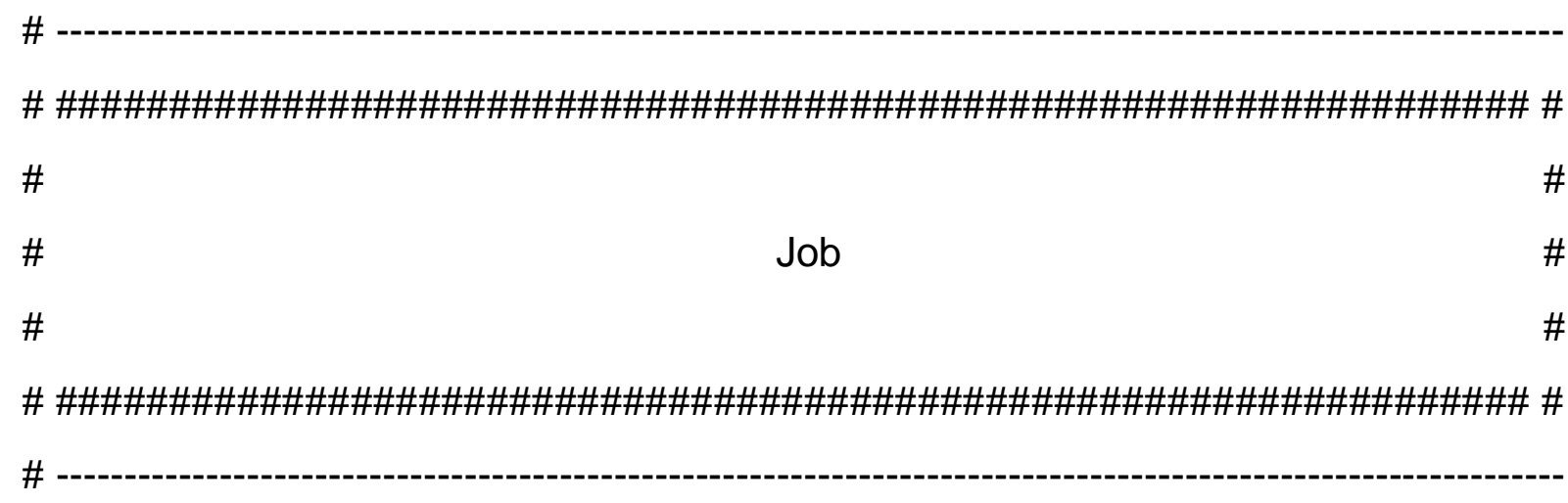

\# Importando o Modulo para Obter Resultados Numericos:

import job

\# Criando o Arquivo para Simulacao

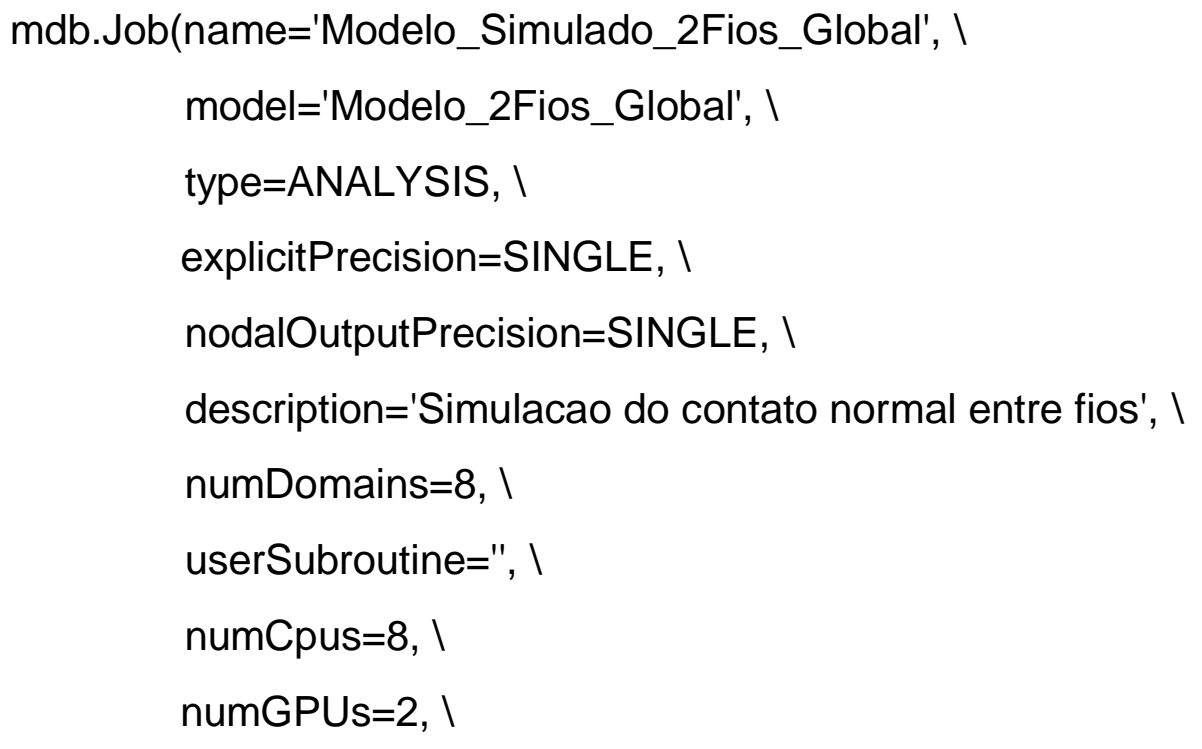


memory $=90, ।$

memoryUnits=PERCENTAGE, ।

scratch=", ।

echoPrint=OFF, I

modelPrint=OFF, I

contactPrint=OFF, ।

historyPrint=OFF) 